\title{
Forecast Uncertainties in Macroeconometric Modelling: An Application to the UK Economy*
}

\author{
Anthony Garratt \\ Department of Applied Economics, University of Cambridge \\ Kevin Lee \\ Department of Economics, University of Leicester \\ M. Hashem Pesaran \\ Trinity College, Cambridge \\ Yongcheol Shin \\ Department of Economics, University of Edinburgh
}

May 10, 2000

\begin{abstract}
This paper argues that probability forecasts convey information on the uncertainties that surround macro-economic forecasts in a manner which is straightforward and which is preferable to other alternatives, including the use of confidence intervals. Probability forecasts relating to UK output growth and inflation, obtained using a small macro-econometric model, are presented. We discuss in detail the probability that inflation will fall within the Bank of England's target range and that recession will be avoided, both as separate single events and jointly. The probability forecasts are also used to provide insights on the interrelatedness of output growth and inflation outcomes at different horizons.
\end{abstract}

Keywords: Probability Forecasting, Long Run Structural VARs, Macroeconometric Modelling, Probability Forecasts of Inflation, Interest Rates and Output Growth JEL Classifications: C32, C53, E17

${ }^{*}$ We are grateful to Manuel Arellano, Michael Binder, David Hendry, Ron Smith and Ken Wallis for helpful comments. Financial support from the ESRC (grant no. L116251016) and from the Isaac Newton Trust of Trinity College Cambridge is also gratefully acknowledged. 


\section{Introduction}

With few exceptions, macroeconomic forecasts are presented in the form of point forecasts and their uncertainty is characterized (if at all) by forecast confidence intervals. Focusing on point forecasts is justified when the underlying decision problems faced by agents and the government are linear in constraints and quadratic in the loss function; the so-called LQ problem. But for most decision problems, reliance on point forecasts will not be sufficient and event probability forecasts will be needed (see, for example, Granger and Pesaran, 1999, 2000). It is also important that statements about economic policy are made in probabilistic terms, since the public's perception of the credibility of the policy has important implications for its success or failure, irrespective of whether the underlying decision problem is of the LQ type or not. A prominent example, discussed in Peel and Nobay (1998) is the choice of an optimal monetary policy in an economy where the government loss function is asymmetric around the inflation target. In this context, a stochastic approach to the credibility of the monetary policy will be required, and policy announcements should be made with reference to probabilistic statements, such as "the probability that inflation will fall in the range $\left(\pi_{L}, \pi_{U}\right)$ is at least $\alpha$ per cent". Policy targets expressed in terms of a fixed range only partially account for the uncertainty that surrounds policy making. ${ }^{1}$

One of the main advantages of the use of probability forecasts as a means of conveying the uncertainties surrounding forecasts is their straightforward use in decision theoretic contexts. In general, where the loss function underlying the decision problem is non-quadratic and/or one or more of the constraints facing the decision maker are non-linear, the solution to the decision problem invariably involves a comparison of the probability of an event (for example the occurrence of an adverse future event) to the cost-benefit ratio of taking a decision. ${ }^{2}$ In a macroeconomic context, the motivation for the current monetary policy arrangements in the UK is that it provides for transparency in policy-making and an economic environment in which firms and individuals are better able to make investment and consumption decisions. The range of possible decisions that a firm can make regarding an investment plan, for example, represents the firm's action space. The 'states of nature' in this case are defined by all of the possible future out-turns for the macro-economy. For example, the investment decision might rely on output growth over the next period, or the average output growth over some longer period, remaining positive; or interest might focus on the future path of inflation and output growth considered together. In making a decision, the firm should define a loss function which evaluates the profits or losses associated with each point in the action space and given any 'state of nature'. Except for LQ decision problems, decisions rules by individual households and firms will generally require probability forecasts with respect to different threshold values reflecting their specific cost-benefit ratios. For this purpose, we need to provide estimates of the totality of the probability distribution function of the events of interest, rather than particular forecast intervals which are likely to be relevant only to the decision problem of a few.

The need for probability forecasts is acknowledged by a variety of researchers and in-

\footnotetext{
${ }^{1}$ For example, see the discussion on the design of inflation targets in Yates (1995).

${ }^{2} \mathrm{~A}$ simple two-state, two-action decision problem is discussed in some detail in Granger and Pesaran (1999).
} 
stitutions. The Bank of England, for example, routinely publishes a range of outcomes for its inflation and output growth forecasts (see Britton, Fisher and Whitley, 1998, or Wallis, 1999). In the statistics literature, Dawid (1984) has been advocating the use of probability forecasting in a sequential approach to the statistical analysis of data; the so-called "prequential approach". ${ }^{3}$ In the econometric modelling literature, Fair $(1980,1993)$ was one of the first to compute probability forecasts using a macroeconometric model of the US economy. The National Institute use their model to produce probability statements alongside their central forecasts (their methods are described in Blake, 1996, and Poulizac et al., 1996), and in the financial sector, J.P. Morgan presents 'Event Risk Indicators' in its analysis of foreign exchange markets. ${ }^{4}$ However, it remains rare for forecasters to provide probability forecasts in a systematic manner. One explanation may be due to the difficulty in measuring the uncertainties associated with forecasts in the large-scale macroeconometric models typically employed. Another explanation relates to the various types of uncertainty that are involved in forecasting. For example, probability forecasts typically provided in the literature deal with future uncertainty only, assuming that the parameters of the underlying model are known with certainty. This is true of the probability forecasts published by the National Institute, for example. To allow for parameter uncertainty, one also needs to compute confidence intervals around the probability forecasts. Similar considerations also apply to the uncertainty that surrounds the choice of the model.

In this paper, we discuss the use of event probability forecasts in the characterization of the various sources of uncertainty that surround forecasts from a macroeconomic model. The event can be defined with respect to the values of a single variable or a set of variables, measured at a particular point in time, over a sequence of time periods, or over different time intervals in the future. We consider alternative ways of characterizing the uncertainty surrounding forecasts from a macroeconomic model and argue that probability forecasts convey information about this uncertainty in a straightforward way and one which is superior to many alternatives, including the use of confidence intervals. Having described formally a framework for the analysis of probability forecasts in a general model, we provide probability estimates of a number of macroeconomic events using a revised and updated version of the small cointegrating macroeconometric model of the UK developed by Garratt et al. (1999). Initially, we abstract from parameter uncertainty and focus on the "future uncertainty" due purely to the stochastic nature of the model under consideration. We then extend the analysis to allow for "parameter uncertainty", and discuss its quantitative importance for probability forecasts of output growth, inflation and interest rate.

Amongst the many possible macroeconomic events of interest, in our applications we focus on the possibility of a "recession" and the likelihood of the inflation rate falling within the target range currently considered by the Monetary Policy Committee (MPC) of the Bank of England. We shall consider these and a number of related events both singly and jointly. Although only a small number of events are considered, we show that these probability forecasts can convey a considerable amount of information on the uncertainties surrounding a forecast, and correspond with those which the public uses in making decisions and in

\footnotetext{
${ }^{3}$ The name prequential is derived by combining probability forecasting with sequential prediction. See Dawid (1984, pp.278-279).

${ }^{4}$ For an academic reference, for example, see Berkowitz (1999).
} 
judging policy-makers' performance.

The lay-out of the rest of the paper is as follows. Section 2 considers the alternative approaches that are available for characterizing forecast uncertainty and notes the advantages of the use of probability forecasts in a decision theoretic context. Section 3 considers probability forecasts in more detail, discussing the concept and estimation of probability forecasts in general terms both in the presence and absence of parameter uncertainty. This section also contains a brief overview of the issues involved in evaluation of probability forecasts. The remainder of the paper is concerned with an application of the probability forecasting approach to the UK economy. Section 4 provides a brief account of inflation targeting in the UK and comments on the relationship between the fan charts published by the Bank of England and probability forecasting. The macroeconometric model used in the computation of forecast probabilities is discussed in Section 5. Section 6 presents single and joint event probability forecasts involving output growth, inflation, and interest rates, paying particular attention to the probability that inflation will fall in the range $1.5 \%-3.5 \%$, the UK government's announced target and that recession will be avoided, at different forecast horizons. We also use the estimated forecast probabilities of these two events, considered separately and jointly, to investigate the (super) neutrality hypothesis that output growth and inflation are independently distributed at different forecast horizons. Section 7 offers some concluding remarks.

\section{Alternative Approaches to Characterising Forecast Uncertainty}

All model-based forecasts are subject to four types of uncertainties:

- Measurement uncertainty (data inadequacies and measurement errors),

- Model uncertainty (including policy uncertainty),

- Parameter uncertainty (for a given model),

- Future uncertainty.

This paper focuses on future and parameter uncertainties and how to allow for them in the computation of probability forecasts. Measurement and model uncertainties pose special problems of their own and will not be addressed in this paper. ${ }^{5}$ Future uncertainty refers to the effects of unobserved future shocks on forecasts, while parameter uncertainty is concerned with the robustness of forecasts to the choice of parameter values, assuming a given forecasting model.

The standard textbook approach to taking account of future and parameter uncertainties is through the construction of forecast intervals. For the purpose of exposition, initially we abstract from parameter uncertainty and consider the following simple linear regression model:

$$
y_{t}=\mathbf{x}_{t}^{\prime} \boldsymbol{\beta}+u_{t}, \quad t=1,2, \ldots, T, T+1, \ldots, T+h,
$$

\footnotetext{
${ }^{5}$ For a discussion on the problem of model uncertainy see Draper (1990) and Chatfield (1995).
} 
where $\mathbf{x}_{t}$ is a $k \times 1$ vector of regressors, the value of which is assumed known both over the sample period, $t=1,2, \ldots, T$, and over the forecast horizon, $t=T+1, T+2, \ldots, T+h$, and where it is assumed that $u_{t} \sim N\left(0, \sigma^{2}\right)$. The optimal forecast of $y_{T+1}$ at time $T$ (in the mean squared error sense) is given by $\mathbf{x}_{T+1}^{\prime} \boldsymbol{\beta}$. In the absence of parameter uncertainty, the calculation of a probability forecast for a specified event is closely related with the calculation of a confidence interval. For example, in the regression model described above, we might be interested in the probability that the value of $y_{T+1}$ will lie below a specified threshold, say $a$; that is, we are interested in $\operatorname{Pr}\left(y_{T+1}<a \mid \Omega_{T}\right)$, where $\Omega_{T}=\left(\mathbf{y}_{T}, \mathbf{X}_{T+1}\right)$, $\mathbf{y}_{T}=\left(y_{1}, y_{2}, \ldots, y_{T}\right)^{\prime}$, and $\mathbf{X}_{T}=\left(\mathbf{x}_{1}^{\prime}, \mathbf{x}_{2}^{\prime}, \ldots, \mathbf{x}_{T}^{\prime}\right)^{\prime}$. In this simple application, denoting the standard Normal cumulative distribution function by $\Phi(\circ)$, we have

$$
\operatorname{Pr}\left(y_{T+1}<a \mid \Omega_{T}\right)=\Phi\left(\frac{a-\mathbf{x}_{T+1}^{\prime} \boldsymbol{\beta}}{\sigma}\right),
$$

while the $(1-\alpha) \%$ forecast interval for $y_{T+1}$ is given by $\mathbf{x}_{T+1}^{\prime} \boldsymbol{\beta} \pm \sigma \Phi^{-1}\left(1-\frac{\alpha}{2}\right)$.

In this case, there are obvious relationships between the two approaches. But we would argue that the probability forecasting approach is more directly relevant when forecasts are made for use in decision making contexts even in this simple case. The forecast interval provides information about the probability of certain specific events relating to $y_{T+1}$ : under the normality assumption, the point forecast provides the threshold value $a=\mathbf{x}_{T+1}^{\prime} \boldsymbol{\beta}$ for which $\operatorname{Pr}\left(y_{T+1}<a \mid \Omega_{T}\right)=0.5$; and the forecast interval provides the threshold values $c_{L}=$ $\mathbf{x}_{T+1}^{\prime} \boldsymbol{\beta}-\sigma \Phi^{-1}\left(1-\frac{\alpha}{2}\right)$, and $c_{U}=\mathbf{x}_{T+1}^{\prime} \boldsymbol{\beta}+\sigma \Phi^{-1}\left(1-\frac{\alpha}{2}\right)$ for which $\operatorname{Pr}\left(y_{T+1}<c_{L} \mid \Omega_{T}\right)=\frac{\alpha}{2}$ and $\operatorname{Pr}\left(y_{T+1}<c_{U} \mid \Omega_{T}\right)=1-\frac{\alpha}{2}$. Clearly, the thresholds values, $c_{L}$ and $c_{U}$, associated with the $(1-\alpha) \%$ forecast interval may or may not be of interest. ${ }^{6}$ Only by chance will the forecast interval calculations provide information in a way which is directly useful in specific decision making contexts.

The relationship between probability forecasts and interval forecasts becomes less transparent when parameter uncertainty is also taken into account. In the context of the above regression model, the point estimate of the forecast is given by $\widehat{y}_{T+1}=\mathbf{x}_{T+1}^{\prime} \widehat{\boldsymbol{\beta}}_{T}$, where $\widehat{\boldsymbol{\beta}}_{T}$ is the Ordinary Least Squares (OLS) estimate of $\boldsymbol{\beta}$ based on the sample of observations. The relationship between the actual value of $y_{T+1}$ and its time $T$ predictor can be written as

$$
\begin{aligned}
y_{T+1} & =\mathbf{x}_{T+1}^{\prime} \boldsymbol{\beta}+u_{T+1} \\
& =\mathbf{x}_{T+1}^{\prime} \widehat{\boldsymbol{\beta}}_{T}+\mathbf{x}_{T+1}^{\prime}\left(\boldsymbol{\beta}-\widehat{\boldsymbol{\beta}}_{T}\right)+u_{T+1},
\end{aligned}
$$

so that the forecast error, $\xi_{T+1}$, is given by

$$
\xi_{T+1}=y_{T+1}-\widehat{y}_{T+1}=\mathbf{x}_{T+1}^{\prime}\left(\boldsymbol{\beta}-\widehat{\boldsymbol{\beta}}_{T}\right)+u_{T+1} .
$$

This example shows that there are two sources of uncertainty that surround the forecast of $y_{T+1}$; namely, that relating to $\boldsymbol{\beta}$ and that relating to the distribution of $u_{T+1}$. For any given

\footnotetext{
${ }^{6}$ The association between probability forecasts and interval forecasts are even weaker when one considers joint events. For example, it would be impossible to infer the probability of the joint event of a positive output growth and an inflation rate falling within a pre-specified range from single forecast intervals. Many different such intervals will be needed for this purpose.
} 
sample of data, $\Omega_{T}, \widehat{\boldsymbol{\beta}}_{T}$ is known and can be treated as fixed. On the other hand, although $\boldsymbol{\beta}$ is assumed fixed at the estimation stage, it is unknown to the forecaster and, from this perspective, it is best viewed as a random variable at the forecasting stage. Hence, in order to compute probability forecasts which account for future as well as parameter uncertainties, we need to specify the joint probability distribution of $\boldsymbol{\beta}$ and $u_{T+1}$, conditional on $\Omega_{T}$. As far as $u_{T+1}$ is concerned, we continue to assume that

$$
u_{T+1} \mid \Omega_{T} \sim N\left(0, \sigma^{2}\right)
$$

and to keep the exposition simple, for the time being we shall assume that $\sigma^{2}$ is known and that $u_{T+1}$ is distributed independently of $\boldsymbol{\beta}$. For $\boldsymbol{\beta}$, noting that

$$
\widehat{\boldsymbol{\beta}}_{T}-\boldsymbol{\beta} \sim N\left[0, \sigma^{2}\left(\mathbf{X}_{T}^{\prime} \mathbf{X}_{T}\right)^{-1}\right]
$$

we assume that

$$
\boldsymbol{\beta} \mid \Omega_{T} \sim N\left[\widehat{\boldsymbol{\beta}}_{T}, \sigma^{2}\left(\mathbf{X}_{T}^{\prime} \mathbf{X}_{T}\right)^{-1}\right]
$$

which is akin to a Bayesian approach with non-informative priors for $\boldsymbol{\beta}$. Hence

$$
\xi_{T+1} \mid \mathbf{X}_{T}, \mathbf{x}_{T+1} \sim N\left[0, \sigma^{2}\left(1+\mathbf{x}_{T+1}^{\prime}\left(\mathbf{X}_{T}^{\prime} \mathbf{X}_{T}\right)^{-1} \mathbf{x}_{T+1}\right)\right] .
$$

The $(1-\alpha) \%$ forecast interval in this case is given by

$$
c_{L}=\mathbf{x}_{T+1}^{\prime} \widehat{\boldsymbol{\beta}}_{T}-\sigma\left\{1+\mathbf{x}_{T+1}^{\prime}\left(\mathbf{X}_{T}^{\prime} \mathbf{X}_{T}\right)^{-1} \mathbf{x}_{T+1}\right\}^{1 / 2} \Phi^{-1}\left(1-\frac{\alpha}{2}\right),
$$

and

$$
c_{U}=\mathbf{x}_{T+1}^{\prime} \widehat{\boldsymbol{\beta}}_{T}+\sigma\left\{1+\mathbf{x}_{T+1}^{\prime}\left(\mathbf{X}_{T}^{\prime} \mathbf{X}_{T}\right)^{-1} \mathbf{x}_{T+1}\right\}^{1 / 2} \Phi^{-1}\left(1-\frac{\alpha}{2}\right) .
$$

When $\sigma^{2}$ is unknown, under the standard non-informative Bayesian priors on $\left(\beta, \sigma^{2}\right)$, the appropriate forecast interval can be obtained by replacing $\Phi^{-1}\left(1-\frac{\alpha}{2}\right)$ in (4) and (5) with the $\left(1-\frac{\alpha}{2}\right) \%$ critical value of the standard t-distribution with $T-k$ degrees of freedom. Although such interval forecasts have been discussed in the econometrics literature, the particular assumptions that underlie them are not fully recognized.

Using this interpretation, the effect of parameter uncertainty on forecasts can also be obtained via stochastic simulations, by generating alternative forecasts of $y_{T+1}$ for different values of $\boldsymbol{\beta}$ (and $\sigma^{2}$ ) drawn from the conditional probability distribution of $\boldsymbol{\beta}$ given by (3). Alternatively, one could estimate probability forecasts by focusing directly on the probability distribution of $y_{T+1}$ for given values of $\mathbf{x}_{T+1}$, simultaneously taking into account both parameter and future uncertainties. For example, in the simple case where $\sigma^{2}$ is known, this can be achieved by simulating $y_{T+1}^{(j)}, j=1,2, \ldots, J$, where

$$
y_{T+1}^{(j)}=\mathbf{x}_{T+1}^{\prime} \widehat{\boldsymbol{\beta}}^{(j)}+u_{T+1}^{(j)}
$$

and $\widehat{\boldsymbol{\beta}}^{(j)}$ is the $j$-th random draw from a $N\left(\widehat{\boldsymbol{\beta}}_{T}, \sigma^{2}\left(\mathbf{X}_{T}^{\prime} \mathbf{X}_{T}\right)^{-1}\right)$ distribution and where $u_{T+1}^{(j)}$ is the $j$-th random draw from a $N\left(0, \sigma^{2}\right)$ distribution. This is an example of the "bootstrap 
predictive density" discussed in Harris (1989). Non-parametric stochastic simulation techniques can also be utilized. In large samples, this simulated distribution will be the same as that used in the calculation of the confidence intervals discussed above. However, the stochastic simulation scheme is more generally applicable and will be used in this paper. Further details are provided in the next section.

An alternative approach to allowing for the effects of future and parameter uncertainties on prediction of $y_{T+1}$ would be to follow the literature on "predictive likelihoods", where a predictive density for $y_{T+1}$ conditional on $\Omega_{T}$ and $\mathbf{x}_{T+1}$ is derived directly. ${ }^{7}$ In the case of the regression example, the problem has been studied by Levy and Perng (1986) who show that the optimal prediction density for $y_{T+1}$, in the Kullback-Leibler informationtheoretic sense, is the Student $\mathrm{t}$ distribution with $T-k$ degrees of freedom, having the location $\hat{y}_{T+1}=\mathbf{x}_{T+1}^{\prime} \widehat{\boldsymbol{\beta}}_{T}$ and the dispersion $\hat{\sigma}^{2}\left\{1+\mathbf{x}_{T+1}^{\prime}\left(\mathbf{X}_{T}^{\prime} \mathbf{X}_{T}\right)^{-1} \mathbf{x}_{T+1}\right\}$, where $\hat{\sigma}^{2}=(T-$ $k)^{-1} \sum_{t=1}^{T}\left(y_{t}-\mathbf{x}_{t}^{\prime} \widehat{\boldsymbol{\beta}}_{\mathbf{T}}\right)^{\prime}\left(y_{t}-\mathbf{x}_{t}^{\prime} \widehat{\boldsymbol{\beta}}_{\mathbf{T}}\right)$. This is the same as the Bayes predictive density of $y_{T+1} \mid \Omega_{T}$ with a non-informative prior on $\left(\boldsymbol{\beta}, \sigma^{2}\right)$. In this way Levy and Perng provide a non-Bayesian interpretation of Bayes predictive density in the context of linear regression models. However, while this is the optimal prediction density in the original linear model, Harris (1989) demonstrates that the bootstrap prediction density performs well in a number of important cases.

\section{A General Framework for Probability Forecasting}

To formalize the discussion of probability forecasts, suppose we are interested in a decision making process that requires probability forecasts of an event that involves one or more of the $m$-variable vector, $\mathbf{z}_{t}=\left(z_{1 t}, z_{2 t}, \ldots, z_{m t}\right)^{\prime}$. Assume also that the forecasts are made with reference to a parametric family of models, denoted by $M(\boldsymbol{\theta})$, and characterized by the joint density function of $\mathbf{z}_{t}$ over the estimation and the forecast periods $t=1,2, \ldots, T$, and $T+1, T+2, \ldots, T+h$, respectively. The probability model, $M(\boldsymbol{\theta})$, is a set of density functions, each describing the probability of obtaining specified values for the observed and forecasted data, and indexed by the unknown $k \times 1$ parameter vector $\boldsymbol{\theta}$ assumed to lie in the compact parameter space, $\Theta$ :

$$
M(\boldsymbol{\theta})=\left\{f\left(\mathbf{z}_{1}, \mathbf{z}_{2}, \ldots, \mathbf{z}_{T}, \mathbf{z}_{T+1}, \mathbf{z}_{T+2}, \ldots, \mathbf{z}_{T+h} ; \boldsymbol{\theta}\right), \quad \boldsymbol{\theta} \in \Theta\right\} .
$$

Throughout we shall assume that the true value of $\boldsymbol{\theta}$, which we denote by $\boldsymbol{\theta}_{0}$, is fixed and remains constant across the estimation and the prediction periods and lies in the interior of $\Theta$. We denote the maximum likelihood estimate of $\boldsymbol{\theta}_{0}$ by $\widehat{\boldsymbol{\theta}}_{T}$, and assume that $f($.$) satisfies$ the usual regularity conditions so that

$$
\sqrt{T}\left(\widehat{\boldsymbol{\theta}}_{T}-\boldsymbol{\theta}_{0}\right) \stackrel{a}{\sim} N\left(\mathbf{0}, \mathbf{V}_{\theta}\right),
$$

where $\stackrel{a}{\sim}$ stands for "asymptotically distributed as", and $\mathbf{V}_{\theta}$ is a positive definite covariance matrix. ${ }^{8}$ Under these assumptions, parameter uncertainty only arises when $T$ is finite. The

\footnotetext{
${ }^{7}$ A large number of different predictive likelihoods have been suggested in the statistics literature. Bj申rnstad (1990) provides a review and discusses 14 different versions.

${ }^{8}$ In the case of cointegrating vector autoregressive models analysed later in this paper, a more general version of this result is needed. This is because the cointegrating coefficients converge to their asymptotic
} 
case where $\boldsymbol{\theta}_{0}$ could differ across the estimation and forecast periods poses new difficulties and can be resolved in a satisfactory manner if one is prepared to formalize how $\boldsymbol{\theta}_{0}$ changes over time.

The density function $f($.$) can be decomposed in two ways. First, the sequential con-$ ditioning decomposition can be employed to write $f($.$) as the product of the conditional$ distributions on successive observations on the $\mathbf{z}_{t}$,

$$
f\left(\mathbf{z}_{1}, \mathbf{z}_{2}, \ldots, \mathbf{z}_{t} ; \boldsymbol{\theta}\right)=\prod_{s=1}^{t} f\left(\mathbf{z}_{s} \mid \mathbf{z}_{1}, \mathbf{z}_{2}, \ldots, \mathbf{z}_{s-1} ; \mathbf{z}_{0}, \boldsymbol{\theta}\right),
$$

for given initial values $\mathbf{z}_{0}$. And second, since we frequently wish to distinguish between variables which are endogenous, denoted by $\mathbf{y}_{t}$, and those which are exogenous, denoted by $\mathbf{x}_{t}$, we can write $\mathbf{z}_{t}=\left(\mathbf{y}_{t}^{\prime}, \mathbf{x}_{t}^{\prime}\right)^{\prime}$ and use the factorization:

$f\left(\mathbf{z}_{t} \mid \mathbf{z}_{1}, \mathbf{z}_{2}, \ldots, \mathbf{z}_{t-1} ; \mathbf{z}_{0}, \boldsymbol{\theta}\right)=f_{y}\left(\mathbf{y}_{t} \mid \mathbf{z}_{1}, \mathbf{z}_{2}, \ldots, \mathbf{z}_{t-1}, \mathbf{x}_{t} ; \mathbf{z}_{0}, \boldsymbol{\theta}_{y}\right) \times f_{x}\left(\mathbf{x}_{t} \mid \mathbf{z}_{1}, \mathbf{z}_{2}, \ldots, \mathbf{z}_{t-1} ; \mathbf{z}_{0}, \boldsymbol{\theta}_{x}\right)$.

Here $f_{y}\left(\mathbf{y}_{t} \mid \mathbf{z}_{1}, \mathbf{z}_{2}, \ldots, \mathbf{z}_{t-1}, \mathbf{x}_{t} ; \mathbf{z}_{0}, \boldsymbol{\theta}_{y}\right)$ is the conditional distribution of $\mathbf{y}_{t}$ given $\mathbf{x}_{t}$ and the information available at time $t-1, \Omega_{t-1}=\left(\mathbf{z}_{0}, \mathbf{z}_{1}, \mathbf{z}_{2}, \ldots, \mathbf{z}_{t-1}\right)$, and $f_{x}\left(\mathbf{x}_{t} \mid \mathbf{z}_{1}, \mathbf{z}_{2}, \ldots, \mathbf{z}_{t-1} ; \mathbf{z}_{0}, \boldsymbol{\theta}_{x}\right)$ is the marginal conditional density of $\mathbf{x}_{t}$. Note that the unknown parameters $\boldsymbol{\theta}$ are decomposed into the parameters of interest, $\boldsymbol{\theta}_{y}$, and the parameters of the marginal density of the exogenous variables, $\boldsymbol{\theta}_{x}$. In the case where $\mathbf{x}_{t}$ is strictly exogenous, knowledge of the marginal distribution of $\mathbf{x}_{t}$ does not help with the estimation of $\boldsymbol{\theta}_{y}$, and estimation of these parameters can therefore be based entirely on the conditional distribution $f_{y}\left(\mathbf{y}_{t} \mid \mathbf{x}_{t}, \Omega_{t-1} ; \boldsymbol{\theta}_{y}\right)$.

Despite this, parameter uncertainty relating to $\boldsymbol{\theta}_{x}$ can continue to be relevant for probability forecasts of the endogenous variables, $\mathbf{y}_{t}$, and forecast uncertainty surrounding the endogenous variables is affected by the way the uncertainty associated with the future path of the exogenous variables is resolved. In practice, the future values of $\mathbf{x}_{t}$ are often treated as known and fixed at pre-specified values. The resultant forecasts for $\mathbf{y}_{t}$ are then referred to as scenario forecasts, with each scenario representing a different set of known future values for the exogenous variables. This approach under-estimates the forecast uncertainties. A more plausible approach would be to treat $\mathbf{x}_{t}$ as strongly exogenous, and allow for the forecast uncertainties of the endogenous and the exogenous variables jointly. The exogeneity assumption will simplify the estimation and the forecasting tasks but does not eliminate the need for a joint treatment of future uncertainties associated with the exogenous variables and the shocks to the endogenous variables.

Now, suppose the joint event of interest is defined by

$$
\varphi_{j}\left(\mathbf{z}_{T+1}, \mathbf{z}_{T+2}, \ldots, \mathbf{z}_{T+h}\right)<a_{j} \text { for } j=1,2, \ldots, L
$$

or, equivalently,

$$
\boldsymbol{\varphi}\left(\mathbf{z}_{T+1}, \mathbf{z}_{T+2}, \ldots, \mathbf{z}_{T+h}\right)<\mathbf{a},
$$

distribution faster than the other parameters in the model. However, the general results of this section are not affected by this complication. 
where $\boldsymbol{\varphi}($.$) and \mathbf{a}$ are defined by the $L \times 1$ vectors $\boldsymbol{\varphi}()=.\left[\varphi_{1}(.), \boldsymbol{\varphi}_{\mathbf{2}}(.), \ldots, \varphi_{L}(.)\right]^{\prime}, \mathbf{a}=$ $\left(a_{1}, a_{2}, \ldots, a_{L}\right)^{\prime}, \varphi_{j}\left(\mathbf{z}_{T+1}, \mathbf{z}_{T+2}, \ldots, \mathbf{z}_{T+h}\right)$ is a scalar function of the variables over the forecast horizon $T+1, \ldots, T+h$ and $a_{j}$ is the "threshold" value associated with $\varphi_{j}($.$) . To simplify$ the exposition, we denote this joint event by $\mathfrak{A}_{\varphi}$. The (conditional) probability forecast associated with this event is given by

$$
\pi(\mathbf{a}, h ; \boldsymbol{\varphi}(.), \boldsymbol{\theta})=\operatorname{Pr}\left[\boldsymbol{\varphi}\left(\mathbf{z}_{T+1}, \mathbf{z}_{T+2}, \ldots, \mathbf{z}_{T+h}\right)<\mathbf{a} \mid \Omega_{T} ; M(\boldsymbol{\theta})\right] .
$$

In practice, we might also be interested in computing probability forecasts for a number of alternative threshold values over the range $a_{j} \in\left[a_{\min }, a_{\mathrm{max}}\right]$.

If the model is known to be $M(\boldsymbol{\theta})$ defined by (6) but the value of $\boldsymbol{\theta}$ is not known, a point estimate of $\pi(\mathbf{a}, h ; \boldsymbol{\varphi}(),. \boldsymbol{\theta})$ can be obtained by

$$
\pi\left(\mathbf{a}, h ; \boldsymbol{\varphi}(.), \widehat{\boldsymbol{\theta}}_{T}\right)=\int_{\mathfrak{A}_{\varphi}} f\left(\mathbf{z}_{T+1}, \mathbf{z}_{T+2}, \ldots, \mathbf{z}_{T+h} \mid \Omega_{T} ; \widehat{\boldsymbol{\theta}}_{T}\right) d \mathbf{z}_{T+1} \ldots d \mathbf{z}_{T+h},
$$

where $f\left(\mathbf{z}_{T+1}, \mathbf{z}_{T+2}, \ldots, \mathbf{z}_{T+h} \mid \Omega_{T} ; \widehat{\boldsymbol{\theta}}_{T}\right)$ is the joint density of $\mathbf{z}_{T+1}, \ldots, \mathbf{z}_{T+h}$ conditional on $\Omega_{T}$ and evaluated at $\boldsymbol{\theta}=\widehat{\boldsymbol{\theta}}_{T}$. This probability density function (viewed as a function of a), also known as the "profile predictive likelihood" ${ }^{9}$ takes account of future uncertainties arising from the model's stochastic structure and the future uncertainty with respect to the evolution of the model's exogenous variables. It does not, however, take account of model or parameter uncertainties, as it is computed for a given density function within $M(\boldsymbol{\theta})$ and for a fixed choice of $\boldsymbol{\theta}$, namely $\widehat{\boldsymbol{\theta}}_{T}$. To allow for parameter uncertainty, we assume that conditional on $\Omega_{T}$, the probability distribution function of $\boldsymbol{\theta}$ is given by $g\left(\boldsymbol{\theta} \mid \widehat{\theta}_{T}, \Omega_{T}\right)$. Then

$$
\tilde{\pi}(\mathbf{a}, h ; \boldsymbol{\varphi}(.))=\int_{\boldsymbol{\theta} \in \Theta} \pi(\mathbf{a}, h ; \boldsymbol{\varphi}(.), \boldsymbol{\theta}) g\left(\boldsymbol{\theta} \mid \widehat{\theta}_{T}, \Omega_{T}\right) d \boldsymbol{\theta},
$$

or, equivalently,

$$
\tilde{\pi}(\mathbf{a}, h ; \boldsymbol{\varphi}(.))=\int_{\boldsymbol{\theta} \in \Theta} \int_{\mathfrak{A}_{\varphi}} f\left(\mathbf{z}_{T+1}, \ldots, \mathbf{z}_{T+h} \mid \Omega_{T} ; \boldsymbol{\theta}\right) g\left(\boldsymbol{\theta} \mid \widehat{\theta}_{T}, \Omega_{T}\right) d \mathbf{z}_{T+1} \ldots d \mathbf{z}_{T+h} d \boldsymbol{\theta} .
$$

In practice, computation of $\tilde{\pi}\left(\mathbf{a}, h ; \boldsymbol{\varphi}(),. \widehat{\boldsymbol{\theta}}_{T}\right)$ typically needs to be carried out by stochastic simulations. For further details, see the application of Section 6 below and the associated discussion of the Appendix.

In a Bayesian context, $g\left(\boldsymbol{\theta} \mid \widehat{\theta}_{T}, \Omega_{T}\right)$ could be derived from a prior on $\boldsymbol{\theta}$ assumed given at the start of the estimation period. Alternatively, in the case where the asymptotic normal theory applies to $\widehat{\boldsymbol{\theta}}_{T}$, it may be reasonable to compute the probability density function assuming

$$
\boldsymbol{\theta} \mid \Omega_{T} ; \widehat{\boldsymbol{\theta}}_{T} \stackrel{a}{\sim} N\left(\widehat{\theta}_{T}, T^{-1} \widehat{\mathbf{V}}_{\theta}\right) .
$$

For this specification of $g\left(\boldsymbol{\theta} \mid \widehat{\theta}_{T}, \Omega_{T}\right)$, it is then easily seen that the point estimate of the probability forecast, $\pi\left(\mathbf{a}, h ; \boldsymbol{\varphi}(),. \widehat{\boldsymbol{\theta}}_{T}\right)$, and the estimate, $\tilde{\pi}(\mathbf{a}, h ; \boldsymbol{\varphi}()$.$) , that allows for pa-$ rameter uncertainty are asymptotically equivalent, for a fixed $h$, and as $T \rightarrow \infty$. The latter

\footnotetext{
${ }^{9}$ See, for example, Bj $\phi$ rnstad (1990).
} 
is the "bootstrap predictive density" described in Harris (1989) and its application to a cointegrating VAR model will be discussed in Section 4. Also, both of these estimates tend to $\pi\left(\mathbf{a}, h ; \boldsymbol{\varphi}(),. \boldsymbol{\theta}_{0}\right)$, which is the profile predictive likelihood for a known value of $\boldsymbol{\theta}_{0}$. But for a fixed $T$, the two estimates could differ substantially, as the applications in Section 6 demonstrate.

\subsection{Evaluation of Probability Forecasts}

There are two general approaches to the evaluation of probability forecasts. One is a purely statistical approach where the empirical adequacy of the probability forecasts are judged against realizations of the underlying process using the probability integral transforms proposed by Dawid (1984). ${ }^{10}$ The other a decision theoretic approach, advocated in Granger and Pesaran (2000), which bases the evaluation of the probability forecasts on their implied economic value in the context of particular decisions. To be more specific, suppose we are provided with a sequence of one-step ahead (continuous) probability density functions $p_{t}(\mathbf{z})$, $t=1,2, \ldots, n$, and the associated realizations $\mathbf{z}_{1}, \mathbf{z}_{2}, \ldots, \mathbf{z}_{n}$. The statistical approach makes use of the probability integral transforms

$$
u\left(\mathbf{z}_{t}\right)=\int_{-\infty}^{\mathbf{z}_{t}} p_{t}(\mathbf{z}) d \mathbf{z}, t=1,2, \ldots, n
$$

and tests the hypothesis that the transformed sequence $u\left(\mathbf{z}_{t}\right), t=1,2, \ldots, n$ is a random sample from $U[0,1]$. The rationale behind this test is an early result due to Rosenblatt (1952) who showed that the probability integral transforms, $u\left(\mathbf{z}_{t}\right)$, will be distributed as i.i.d. $U[0,1]$ under the null hypothesis that $p_{t}(\mathbf{z})$ coincides with the true density function of the underlying process. Standard statistical techniques can now be used to carry out the test of the i.i.d. uniformity of the probability integral transforms, $u\left(\mathbf{z}_{t}\right), t=1,2, \ldots, n$. Some useful practical considerations are discussed in Diebold, Gunther and Tay (1998). Also see Diebold, Hahn and Tay (1999) and Berkowitz (1999).

In contrast, the decision theoretic approach to forecast evaluation uses utility or cost functions that underlie the decision problem to transform the probability density functions into realized utility outcomes. Different probability density functions are then compared by their average realized utilities over the evaluation sample. For example, consider a single period decision problem where at time $t$ the decision variable $d_{t}$ is chosen so that $E\left[U\left(d_{t}, \mathbf{z}_{t+1}\right) \mid \Omega_{t}\right]$ is maximized, where $U(\cdot)$ is a globally concave utility function, and $\mathbf{z}_{t+1}$ is a vector of state variables with the conditional probability distribution function $F_{t}(\mathbf{z})=\operatorname{Pr}\left(\mathbf{z}_{t+1}<\mathbf{z} \mid \Omega_{t}\right)$. Suppose $F_{t}(\mathbf{z})$ is estimated by the probability distribution function, $P_{t}(\mathbf{z})$, and the aim is to evaluate the adequacy of $P_{t}(\mathbf{z})$ for the decision problem at hand. The realized time $t+1$ utility value associated with the use of $P_{t}(\mathbf{z})$ is given by $U\left\{d_{u}^{*}\left[P_{t}(\mathbf{z})\right], \mathbf{z}_{t+1}\right\}$, where $d_{u}^{*}\left[P_{t}(\mathbf{z})\right]$ is the optimal decision variable. For a given sequence of probability distribution functions, $P_{t}(\mathbf{z}), t=1,2, \ldots, n$ and the associated realized values $\mathbf{z}_{t+1}, t=1,2, \ldots, n$, the

\footnotetext{
${ }^{10}$ The same idea is also discussed more recently by Diebold, Gunther and Tay (1998). A general approach to forecast evaluation that could also be applied to evaluate probability forecasts is provided by West (1996).
} 
average economic value of the probability forecasts will be given by

$$
V_{n}(P(\mathbf{z}))=n^{-1} \sum_{t=1}^{n} U\left[d_{u}^{*}\left(P_{t}(\mathbf{z})\right), \mathbf{z}_{t+1}\right],
$$

which can then be compared with a similar average value obtained for an alternative estimate of $F_{t}(\mathbf{z})$. For further details see Diebold, Gunther and Tay (1998), and Granger and Pesaran (2000).

Both of these approaches require $n$ to be sufficiently large, which is more likely to be available in finance than in macroeconomic applications. Also the application of the decision theoretic approach demands a complete specification of the decision problem which has been rather rare in macro-economic policy evaluation. These are clearly important areas for future research and will be beyond the scope of the present paper.

\section{Inflation Targeting, Output Growth and Interest Rates}

Inflation targets have been set explicitly in the UK since October 1992, following the UK's exit from the ERM. The Chancellor's stated objective at the time was to achieve an annual rate of inflation of $2 \%$ or less in the long term, but to keep underlying inflation within a range of 1\%-4\%. In May 1997, the policy of targeting inflation was articulated further by the setting up of the Monetary Policy Committee (MPC), where the main objective was to meet inflation targets primarily through the setting of interest rates. Its current remit, as defined annually by the Chancellor, is to achieve an average inflation target of $2.5 \%$, with the annual rate of inflation falling in the range 1.5\%-3.5\%.

The measure of inflation used by the MPC is the Retail Price Index, excluding mortgage interest payments, (RPI-x), and the time horizon over which the inflation objective is to be achieved is not stated. Inflation rates in excess of $3.5 \%$ or below $1.5 \%$ act as a trigger by which the Governor of the Bank of England is obliged to write an open letter to the Chancellor explaining why inflation had deviated so far from the target, the policies being undertaken to correct the deviation, and how long it is expected before inflation is back on target. It should be noted that the Bank is expected to conduct monetary policy so as to support the general economic policies of the government, without damaging its primary commitment to achieving its inflation target, and the presence of a (non-voting) representative of the Treasury on the MPC provides a means for the government to express its views in this respect.

Since October 1992, the Bank of England has produced a quarterly Inflation Report which describes the Bank's assessment of likely inflation outcomes over a two-year forecast horizon. In addition to reviewing the various economic indicators necessary to place the inflation assessment into context, the Report provides an explicit projection for inflation over the two year forecast horizon, with bands presented around the central forecast to illustrate the range of inflation outcomes that are considered possible. The projection is based on the assumption of unchanged official interest rates. Since November 1997, a similar projection for output growth has also been provided in the Report, providing insights on the Bank's perception of the likely outturn for the government's general economic policies 
beyond the maintenance of price stability. For a critical assessment of the Bank's approach to allowing for model and parameter uncertainties see Wallis (1999).

One of our objectives in this paper is to provide a model-based characterization of the uncertainties that surround inflation and output growth forecasts that have come to concern many central bankers. The so-called fan charts produced by the Bank of England acknowledge the significance of forecast uncertainties in the decision making process. However, the fan chart approach, as implemented by the Bank, suffers from two major shortcomings. First, it does not seem likely that the fan charts can be replicated by independent researchers. This is largely due to the subjective manner in which uncertainty is taken into account by the Bank, which does not readily lend itself to independent analysis even though it may be justified from a real time decision-making perspective. And second, the use of fan charts is limited for the analysis of uncertainty associated with joint events. Currently, the Bank provides separate fan charts for inflation and output growth forecasts, but in reality one is generally interested in joint events involving both inflation and output growth, and it is not clear how separate fan charts can be used for such a purpose. In this paper, we address both of these issues by basing our analysis on a replicable core macroeconometric model of the UK economy, and by focussing directly on presentation of probability forecasts rather than fan charts. However, in this paper, we do not address the important issue of model uncertainty, but our approach could be adapted to deal with it following a method similar to that discussed in Draper (1990).

Our empirical analysis is based on quarterly time series observations on eight key macroeconomic variables relevant to the UK economy over the period 1965q1-1998q4 (see Table 1). In particular, we measure price inflation using the all items retail price index, output growth using real GDP at market prices, and use the 90 day Treasury Bill rate as the interest rate. The plots of the actual values of inflation, output growth and interest rates observed over the period 1965q1-1998q4 are given in Figure 1, while Tables 2 and 3 provide information on the empirical frequency distribution of various events of interest. Specifically, Table 2 gives the empirical probability distributions for the 4-quarter moving averages of output growth, inflation and interest rates, while Table 3 reports the estimates of the joint empirical probability distributions of inflation and output growth. We report frequencies based on the whole sample and also conditioning on the sub-periods 1970q1-1979q4, 1980q1-1989q4 and 1990q1-1998q4. These estimates show considerable variations across the three sub-periods, particularly as far as the events involving inflation and interest rates are concerned. For example, the empirical frequency of inflation falling below $5 \%$ is $2.5 \%, 40.0 \%$ and $83.3 \%$ over the periods 1970q1-1979q4, 1980q1-1989q4, and 1990q1-1998q4, respectively. The corresponding figures for the interest rate falling below $8 \%$ are $45.0 \%, 0.0 \%, 66.7 \%$, respectively. In contrast, the empirical distribution of the output growth seems to have been relatively stable. For example, the observed empirical frequencies of the average 4-quarterly output growth falling below $2.0 \%$ are $40.0 \%, 37.5 \%$ and $44.4 \%$, respectively. A similar picture also emerges from the analysis of the joint empirical frequencies of inflation and output growth reported in Tables 3(a)-3(d). For example, the empirical frequencies of output growth falling below $2.5 \%$ and inflation falling below $5 \%$ were $2.5 \%, 5.0 \%$ and $41.7 \%$, over the three subperiods, respectively. The empirical frequencies reported in Tables 2 and 3 provide a basis for a better understanding of the conditional probability forecasts that we will be presenting 
in Section 6.

\section{A Cointegrating VAR Model of the UK Economy}

In principle, probability forecasts can be computed using any macroeconometric model, although the necessary computations would become prohibitive in the case of most large scale macroeconometric models, particularly if the objective of the exercise is to compute the probabilities of joint events over different horizons. On the other hand, the use of small unrestricted VAR models, while computationally feasible, may not be satisfactory for the analysis of forecast probabilities over the medium term. An intermediate alternative that we shall follow here is to use cointegrating VAR models that take account of the long-run relationships that are likely to exist in a macro-economy. A model of this type has been developed by Garratt et al. (1999, 2000a). This model is based on a number of long-run relations derived from arbitrage conditions in goods and capital markets, solvency and portfolio balance conditions. The model contains five domestic variables whose developments are widely regarded as essential to a basic understanding of the U.K. economy; namely, output, the price level, the exchange rate, the nominal interest rate and real money balances. It also contains four foreign variables; namely, foreign output, the foreign interest rate, the foreign price level, and oil prices. To simplify the analysis, and to avoid working with potentially $\mathrm{I}(2)$ variables, the model is constructed using domestic and foreign prices measured relative to oil prices (in logs). As a result, there are only eight variables in the model, as listed in Table 1.

The model was originally estimated over the period 1965q1-1995q4. For forecasting purposes, we thought it would be appropriate to use a more up-to-date version of the model based on the recently published national accounts data that conforms to the European Standard of Accounts. We also thought that it would be instructive to estimate two versions of the model: one in which no restrictions are imposed on the short-run dynamics (the 'core model'), and one obtained as the outcome of a specification search in which dynamic terms are dropped from the model if they make no significant contribution to the model's fit (the 'restricted core model'). Both versions of the model embody the same long-run relationships, associated with the economic equilibrium concepts described above, in a cointegrating VAR framework. Both versions of the model also treat the relative foreign price variable as a weakly exogenous I(1) variable, and the order of the VAR model in both is chosen using familiar model selection criteria. Hence, the two versions of the model are very similar, but differ in terms of their short-term dynamic properties, with the restricted version having a more parsimonious but data-consistent specification.

The four long-run equilibrium relationships of the model are given by:

$$
\begin{gathered}
\left(p_{t}-p_{t}^{o}\right)-\left(p_{t}^{*}-p_{t}^{o}\right)-e_{t}=a_{10}+a_{11} t+\varepsilon_{1, t+1}, \\
r_{t}-r_{t}^{*}=a_{20}+\varepsilon_{2, t+1}, \\
y_{t}-y_{t}^{*}=a_{30}+\varepsilon_{3, t+1},
\end{gathered}
$$




$$
h_{t}-y_{t}=a_{40}+a_{41} t+\beta_{43} r_{t}+\beta_{45} y_{t}+\varepsilon_{4, t+1},
$$

where $p_{t}$ is the logarithm of domestic prices, $p_{t}^{*}$ is the logarithm of foreign prices, $p_{t}^{o}$ is the logarithm of oil prices, $e_{t}$ is the logarithm of nominal exchange rate (defined as the domestic price of a unit of the foreign currency, so that a depreciation of the home currency increases $\left.e_{t}\right), y_{t}$ is the logarithm of real per capita domestic output, $y_{t}^{*}$ is the logarithm of real per capita foreign output, $r_{t}$ is the domestic nominal interest rate variable, $r_{t}^{*}$ is the foreign nominal interest rate variable, $h_{t}$ is the logarithm of the real per capita money stock, and the $\varepsilon_{i, t+1}, i=1, . ., 4$, are stationary reduced form errors.

A detailed account of the framework for long run macromodelling, describing the economic theory that underlies the relationships in (11) - (14), is provided in Garratt et al. (1999). In brief, we note here that (11) is the Purchasing Power Parity (PPP) relationship, which allows for a trend in the real exchange rate, based on international goods market arbitrage; (12) is an Interest Rate Parity (IRP) relationship, and is based on arbitrage between domestic and foreign bond holdings; (13) is an "output gap" (OG) relationship, based on a stochastic version of the Solow growth model in which there is common technological progress in production at home and abroad ${ }^{11}$ and (14) is a real money balance (RMB) relationship, based on the condition that the economy must remain solvent in the long run. A fifth long-run relationship, relating to the Trade Balance (TB), is also discussed in Garratt et al.(1999). The TB relationship, and that in (14), are obtained by modelling the equilibrium portfolio balance of private sector assets. However, under certain parameter values in the TB relationship, it will be difficult to distinguish between the effects of the TB and those of the modified PPP and OG relationships. As we discuss in more detail below, this turned out to be the case in our data set, so that the empirical counter-part to the economic theory discussed in Garratt et al. (1999) is described in (11) - (14).

The four long-run relations of the model, (11) - (14), can be written compactly as

$$
\varepsilon_{t}=\boldsymbol{\beta}^{\prime} \mathbf{z}_{t-1}-\left(\mathbf{a}_{0}-\mathbf{a}_{1}\right)-\mathbf{a}_{1} t
$$

where

$$
\begin{gathered}
\mathbf{z}_{t}=\left(p_{t}-p_{t}^{o}, e_{t}, r_{t}, r_{t}^{*}, y_{t}, y_{t}^{*}, h_{t}-y_{t}, p_{t}^{*}-p_{t}^{o}\right)^{\prime} \\
\mathbf{a}_{0}=\left(a_{10}, a_{20}, a_{30}, a_{40}\right)^{\prime}, \mathbf{a}_{1}=\left(a_{11}, 0,0, a_{41}\right), \\
\boldsymbol{\varepsilon}_{t}=\left(\varepsilon_{1 t}, \varepsilon_{2 t}, \varepsilon_{3 t}, \varepsilon_{4 t}\right)^{\prime},
\end{gathered}
$$

and

$$
\boldsymbol{\beta}^{\prime}=\left(\begin{array}{cccccccc}
1 & -1 & 0 & 0 & 0 & 0 & 0 & -1 \\
0 & 0 & 1 & -1 & 0 & 0 & 0 & 0 \\
0 & 0 & 0 & 0 & 1 & -1 & 0 & 0 \\
0 & 0 & -\beta_{43} & 0 & -\beta_{45} & 0 & 1 & 0
\end{array}\right)
$$

We partition $\mathbf{z}_{t}=\left(\mathbf{y}_{t}^{\prime}, p_{t}^{*}-p_{t}^{o}\right)^{\prime}$, where $\mathbf{y}_{t}=\left(p_{t}-p_{t}^{o}, e_{t}, r_{t}, r_{t}^{*}, y_{t}, y_{t}^{*}, h_{t}-y_{t}\right)^{\prime}$ is treated as an I(1) vector of endogenous variables and $x_{t}=p_{t}^{*}-p_{t}^{o}$ is treated as a weakly exogenous

\footnotetext{
${ }^{11}$ Our use of the term 'output gap relationship' to describe (13) should not be confused with the more usual use of the term which relates more specifically to the difference between a country's actual and potential output levels (although clearly the two uses of the term are related).
} 
$\mathrm{I}(1)$ variable, in the sense that changes in $p_{t}^{*}-p_{t}^{o}$ have a direct influence on $\mathbf{y}_{t}$, but $p_{t}^{*}-p_{t}^{o}$ is not affected by error correction terms which measure the extent of disequilibria in the UK economy. We then embody $\varepsilon_{t}$ in an otherwise unrestricted $V A R(s-1)$ in $\Delta \mathbf{y}_{t}$ :

$$
\Delta \mathbf{y}_{t}=-\boldsymbol{\alpha} \varepsilon_{t}+\sum_{i=1}^{s-1} \Psi_{y i} \Delta \mathbf{z}_{t-i}+\boldsymbol{\psi} \Delta\left(p_{t}^{*}-p_{t}^{o}\right)+\mathbf{v}_{y t}
$$

where $\mathbf{v}_{y t}$ is an $7 \times 1$ vector of serially uncorrelated shocks, $\boldsymbol{\alpha}$ is an $7 \times 4$ matrix of errorcorrection coefficients, $\left\{\Psi_{y i}, i=1,2, \ldots, s-1\right\}$ are $7 \times 8$ matrices of short-run coefficients, and $\boldsymbol{\psi}$ is an $7 \times 1$ vector representing the impact effects of changes in foreign prices relative to the oil price on $\Delta \mathbf{y}_{t}$. Using equation (15), we have

$$
\Delta \mathbf{y}_{t}=\boldsymbol{\alpha}\left(\mathbf{a}_{0}-\mathbf{a}_{1}\right)+\boldsymbol{\alpha} \mathbf{a}_{1} t-\boldsymbol{\alpha} \boldsymbol{\xi}_{t}+\sum_{i=1}^{s-1} \Psi_{y i} \Delta \mathbf{z}_{t-i}+\boldsymbol{\psi} \Delta\left(p_{t}^{*}-p_{t}^{o}\right)+\mathbf{v}_{y t},
$$

where $\boldsymbol{\xi}_{t}=\boldsymbol{\beta}^{\prime} \mathbf{z}_{t-1}$ are the error correction terms. The above specification embodies the economic theory's long-run predictions by construction, in contrast to the more usual approach where the starting point is an unrestricted VAR model, with some vague priors about the nature of the long-run relations.

For forecasting, we also need to specify the marginal model for the exogenous $I(1)$ variable(s). For this purpose, we use

$$
\Delta x_{t}=\sum_{i=1}^{s-1} \Psi_{x i} \Delta \mathbf{z}_{t-i}+c_{x 0}+v_{x t}
$$

where $\Psi_{x i}$ 's are unknown $(1 \times 8)$ coefficient matrices and $\mathbf{c}_{x 0}$ is a scalar and, by construction, $\mathbf{v}_{y t}$ and $\mathbf{v}_{x t}$ are uncorrelated so that $\left[\begin{array}{c}\mathbf{v}_{y t} \\ v_{x t}\end{array}\right] \sim \operatorname{iid}\left\{\mathbf{0}, \Sigma_{v}=\left[\begin{array}{cc}\Sigma_{v_{y}} & \mathbf{0} \\ \mathbf{0} & \Sigma_{v_{x}}\end{array}\right]\right\}$.

Combining (18) and (19), we obtain the following Vector Error Correction model in $\mathbf{z}_{t}$ :

$$
\Delta \mathbf{z}_{t}=-\Pi \mathbf{z}_{t-1}+\sum_{i=1}^{s-1} \Gamma_{i} \Delta \mathbf{z}_{t-i}+\mathbf{b}_{0}+\mathbf{b}_{1} t+\mathbf{u}_{t}
$$

where

$$
\Psi_{i}=\left[\begin{array}{c}
\Psi_{y i} \\
\Psi_{x i}
\end{array}\right], \mathbf{c}_{0}=\left[\begin{array}{c}
\boldsymbol{\alpha}\left(\mathbf{a}_{0}-\mathbf{a}_{1}\right) \\
c_{x 0}
\end{array}\right], \mathbf{c}_{1}=\left[\begin{array}{c}
\boldsymbol{\alpha} \mathbf{a}_{1} \\
0
\end{array}\right], \mathbf{v}_{t}=\left[\begin{array}{c}
\mathbf{v}_{y t} \\
v_{x t}
\end{array}\right]
$$

and

$$
\mathbf{A}=\left[\begin{array}{cc}
\mathbf{I}_{m_{y}} & -\boldsymbol{\psi} \\
\mathbf{0} & \mathbf{I}_{m_{x}}
\end{array}\right], \Pi=\mathbf{A}^{-1}\left[\begin{array}{c}
\boldsymbol{\alpha} \boldsymbol{\beta}^{\prime} \\
\mathbf{0}
\end{array}\right], \Gamma_{i}=\mathbf{A}^{-1} \Psi_{i}, \mathbf{b}_{0}=\mathbf{A}^{-1} \mathbf{c}_{0}, \mathbf{b}_{1}=\mathbf{A}^{-1} \mathbf{c}_{1}, \mathbf{u}_{t}=\mathbf{A}^{-1} \mathbf{v}_{t}
$$

Estimation of the parameters of the model, (18), can be carried out using the longrun structural modelling approach described in Pesaran and Shin (1999) and Pesaran, Shin and Smith (2000). With this approach, having selected the order of the underlying $V A R$ 
model (using model selection criteria such as the Akaike Information Criterion $(A I C)$ or the Schwartz Bayesian Criterion $(S B C)$ ), we test for the number of cointegrating relations among the 8 variables in $\mathbf{z}_{t}$. When performing this task, and in all the subsequent empirical analysis, we work in the context of a $V A R$ model in which the intercepts $\boldsymbol{\alpha}\left(\mathbf{a}_{0}-\mathbf{a}_{1}\right)$ are freely determined but the trend coefficients are restricted so that $\boldsymbol{\alpha} \mathbf{a}_{1}=\Pi \boldsymbol{\gamma}$, where $\Pi=\boldsymbol{\alpha} \boldsymbol{\beta}^{\prime}$ and $\gamma$ is an $8 \times 1$ vector of unknown coefficients. These restrictions ensure that the solution of the model in levels of $\mathbf{z}_{t}$ will not contain quadratic trends. We then compute Maximum Likelihood $(M L)$ estimates of the model's parameters subject to exact and over-identifying restrictions on the long-run coefficients. ${ }^{12}$ If there is empirical support for the existence of four long-run relationships, as suggested by theory, exact identification in our model requires four restrictions on each of the four cointegrating vectors (each row of $\boldsymbol{\beta}$ ), or a total of sixteen restrictions on $\boldsymbol{\beta}$. These represent only a subset of the restrictions suggested by economic theory as characterized in (16), however. Estimation of the model subject to all the (exactand over-identifying) restrictions given in (16) enables a test of the validity of the overidentifying restrictions, and hence the economic theory, to be carried out. Of course, it also provides the means for generating point forecasts and probability forecasts.

\subsection{The Estimated Model}

The entire exercise described above was conducted by Garratt et al. (1999) using UK data over the period 1965q1-1995q4. To check the robustness of the estimated model, and to enable more up-to-date forecasts to be considered, we carried the long-run structural modelling exercise using data over the period 1965q1-1998q4. ${ }^{13}$ Having first confirmed that a $V A R(2)$ model is appropriate, as was the case in the original modelling exercise, the cointegration tests were then carried out and the results of these tests are presented in Table 4. These provide mixed evidence on the number of cointegrating vectors existing among the series: working at the $95 \%$ level of significance, the statistics indicate that there are four cointegrating vectors according to the test based on the trace of the stochastic matrix, but that there is just one cointegrating relationship according to the test based on the maximal eigenvalue statistic. This is in contrast with the results obtained by Garratt et al. (1999) where they found marginal support for five independent long-run relationships. ${ }^{14}$ We therefore proceed on the assumption that there exists four cointegrating relations among the variables.

On this basis, the core model was estimated first subject to sixteen restrictions which exactly identify the system, and then subject to these and further eighteen over-identifying restrictions as suggested by the economic theory. ${ }^{15}$ The test statistic takes the value of

\footnotetext{
${ }^{12}$ The computations were carried out using Pesaran and Pesaran's (1997) Microfit 4.0.

${ }^{13}$ The extended data set requires use of revised figures for some variables, based on the European Standard of Accounts (ESA). The results of this paper and Garratt et al. (1999) are not directly comparable therefore.

${ }^{14}$ In the earlier work, evidence for the fifth cointegrating relationship was less strong than for the others. There was some support for the use of four cointegrating relationships even in Garratt et al. (1999) therefore.

${ }^{15}$ When over identifying our system we impose three zero restrictions on the four time trends in the long run. Economic theory suggests no time trend in both the IRP and OG relationships (see equations (12)-(13)) providing two restrictions. However theory allows for the possibility of a time trend in the PPP relationship, whilst not specifying whether or not a time trend should be present in the RMB relationship. Hence we
} 
40.26, and although the statistic is asymptotically distributed as the chi-squared variate with eighteen degrees of freedom, the appropriate critical values need to be calculated using bootstrap techniques to take into account the relatively small sample of data used in this modelling exercise. These provide critical values of $74.55(90 \%)$ and $80.52(95 \%)$ and on the basis of such a test, therefore, there is no evidence with which to reject the assumed restrictions suggested by economic theory. The estimated long-run relationships, and the associated error correction specification for the model, are presented in Table 5. It is worth noting that, even apart from the absence of the TB relationship, there are some interesting differences between the estimated long-run relationships of Table 5 and those described in Garratt et al. (1999). Notably, the PPP relationship now holds, while it required a modification (relating to oil price movements) in the version developed by Garratt et al. (1999). Further, in the RMB relationship, the estimated parameter on the interest rate is larger in the present version of the model than was obtained previously (the estimate here is $\begin{gathered}39.03 \\ (11.34)\end{gathered}$ compared to $\underset{(5.00)}{20.33}$, where standard errors are in parentheses).

In order to evaluate the fit of the core model reported in Table 5, we can compare the $\bar{R}^{2}$ of these equations with those of a benchmark univariate ARMA model estimated on the first difference of the seven endogenous variables in the model. For each variable, the benchmark model is chosen from the class of $A R M A(s, q), s, q=0,1, \ldots, 4$ models using the $A I C$. This comparison shows that, broadly speaking, the error correction equations in the core model outperforms the associated benchmark models, in some cases to a substantial degree. The error correction equation for domestic prices (relative to oil prices) explains around 70 per cent of the total variation in $\Delta p_{t}$ compared with 60 per cent for the corresponding benchmark model. ${ }^{16}$ For the domestic output growth equation, $\bar{R}^{2}=0.24$ as compared with 0.02 for the benchmark model. Similar comments apply to all of the remaining equations, indicating that the fit of the equations of the core model relating to foreign output growth, domestic and foreign interest rates, real money balances and the exchange rate equation all display good explanatory power relative to their $A R M A$ counterparts.

Having obtained the estimated core model, the more parsimonious 'restricted core' model is obtained undertaking a specification search in which insignificant coefficients on short-run dynamic terms have been set to zero. In this case, the cointegrating relations are taken as given (and equal to those of the core model), and the seven error correction regressions are estimated using the SURE method. In all, forty-one zero restrictions are imposed on the short-run parameters to obtain the restricted core model. The log-likelihood ratio statistic for testing these restrictions turned out to be 56.89 , which is just below the $95 \%$ critical value of the chi-squared distribution with 41 degrees of freedom. The error correction specifications of the restricted core model are provided in Table 6 . Comparison with Table 5 shows that the omission of the dynamic terms has relatively little impact on the model: the standard errors associated with the parameter estimates have been reduced, so that significance levels

allow both the trend terms in the PPP and RMB relationships to be estimated but impose a third zero restriction on the trend term in the PPP relationship (as it was not significantly different from zero). These three restrictions, plus the thirty-one contained in (16), make up the total number of restrictions, eighteen of which are over-identifying restrictions.

${ }^{16}$ The $\bar{R}^{2}$ reported for the $\Delta\left(p_{t}-p_{t}^{o}\right)$ equation in Table 4 refers to $\Delta p_{t}$, which is directly comparable to the $\bar{R}^{2}$ obtained for the univariate benchmark model which is estimated on $\Delta p_{t}$. 
are typically higher, but the point estimates of those parameters which are significantly different from zero in the two tables are broadly the same. Given this, one might expect the point forecasts based on the two models to be broadly comparable, so that differences in probability forecasts will be attributable mainly to the effects of parameter uncertainty.

In order to compute forecasts from the model, we need to supplement the estimated relationships of the model described above with a model for the exogenous variables. We therefore assume that the oil price level remains unchanged in the future (so that there is no uncertainty related to forecasts arising from this source), while foreign prices relative to the oil price are modelled by the following autoregressive distributive lag, $\operatorname{ARDL}(2,2)$, specification: ${ }^{17}$

$$
\begin{aligned}
& \Delta\left(p_{t}^{*}-p_{t}^{o}\right)= \begin{array}{c}
0.003 \\
(0.001) \\
0.9901
\end{array}+\begin{array}{c}
0.5227 \\
(0.083)
\end{array} \Delta\left(p_{t-1}^{*}-p_{t-1}^{o}\right)+{ }_{(0.080)}^{0.3008} \Delta\left(p_{t-2}^{*}-p_{t-2}^{o}\right) \\
& \begin{array}{c}
(0.002) \\
\left(0 p_{t}^{o}+{ }_{(0.082)}^{0.5270} \Delta p_{t-1}^{o}+{ }_{(0.079)}^{0.3020}\right.
\end{array} p_{t-2}^{o}+\widehat{u}_{t}^{*}, \\
& \bar{R}_{\Delta p^{*}}^{2}=0.7548, \hat{\sigma}_{u *}=0.0038, \chi_{S C}^{2}[4]=13.34, \chi_{F F}^{2}[1]=0.72, \chi_{N}^{2}[2]=8.48, \chi_{H}^{2}[1]=8.13 .
\end{aligned}
$$

The model was again obtained using data over the period 1965q1-1998q4 and is of the same form (and has similar parameter estimates) as that presented in Garratt et al. (1999) obtained over the shorter sample. Generating values for $\widehat{u}_{t}^{*}$ over the forecast horizon by random draws from a $N\left(0, \hat{\sigma}_{u *}\right)$ distribution, $(21)$ can be used recursively to obtain forecasts of $\Delta\left(p_{t}^{*}-p_{t}^{o}\right)$, and hence of $\Delta p_{t}^{*}$ and $p_{t}^{*}$, given that it is assumed that oil prices are constant over the forecasting horizon.

\section{Probability Forecasts of Inflation, Output Growth and Interest Rates}

In this section, we consider probability forecasts of a number of events of interest using the unrestricted and the restricted versions of the long-run structural model developed in the previous section. Initially, we present plots of estimated predictive distribution functions for inflation, output growth and interest rates at a number of selected forecast horizons using the unrestricted model estimated over 1965q1-98q4 as set out in Table 5. These plots provide us with the necessary information with which to compute probabilities of a variety of (single) events, and demonstrate the usefulness of probability forecasts in conveying the future and parameter uncertainties that surround the point forecasts. But our substantive discussion of the probability forecasts will focus on the central events of interest in macroeconomic policymaking in the UK; namely, keeping the rate of inflation within the announced government target range of $1.5 \%$ to $3.5 \%$, and avoiding recessions. We define a recession as an event where the average four-quarterly rate of change in GDP is negative. Other concepts of recessions,

\footnotetext{
${ }^{17}$ This specification was chosen from all $A R D L\left(s_{1}, s_{2}\right), s_{1}, s_{2} \leq 4$ models according to the Akaike model selection criterion. Note that the $\bar{R}^{2}$ for the $\Delta\left(p_{t}^{*}-p_{t}^{o}\right)$ equation is computed with respect to $\Delta p_{t}^{*}$. Standard errors are given in paranthesis.
} 
such as two successive negative quarterly growth rates, could also be considered. ${ }^{18}$ However, we do not expect the probability estimates presented in this section will be much affected by which one of these notions is adopted.

\subsection{Point and Interval Forecasts}

Before reporting the probability forecasts it is worth briefly outlining the broad properties of the point forecasts generated by the unrestricted model of Table 5. This should help place the probability forecasts in the traditional context where point and (occasionally) interval forecasts are provided. All the forecasts are generated on the assumption that oil prices follow a random walk without a drift and, since the estimation period ends in $1998 \mathrm{q} 4$, the forecasts are therefore computed assuming oil prices are set at their 1998q4 level (namely at $\$ 11.85$ per barrel $(\mathrm{p} / \mathrm{b}))$. The likely consequences of the much higher oil prices experienced more recently on the probability forecasts will be discussed briefly at the end of this section.

The point forecasts of foreign price inflation, computed using (21), are predicted on average to be around $5.6 \%$ per annum over the period $1999 \mathrm{q} 1-2004 \mathrm{q} 4$, as compared to the average annual figure of $6.8 \%$ achieved over the estimation period, 1965q1-1998q4. This lower average inflation forecast is in line with recent experience, since over the period 1985q1$1998 \mathrm{q} 4$, the average rate of foreign inflation amounted to around $5.5 \%$. Table 7 provides the corresponding point forecasts for domestic inflation rates, output growth and interest rates over the period 1999q1-2004q4 together with their $95 \%$ confidence intervals. These forecasts refer to 4-quarterly moving averages. The inflation forecasts are computed as, $p_{T+h}-p_{T+h-4}$, where $p_{T}$ refers to the log of retail price index in the base quarter, $1998 q 4$, and $p_{T+h}, h=1,2, \ldots$, the corresponding indices for the subsequent quarters. ${ }^{19}$ Similarly, the 4-quarter moving average of output growth and the level of interest rates are computed as $\ln \left(G D P_{T+h} / G D P_{T+h-4}\right)$ and $\left(r_{T+h}+r_{T+h-1}+r_{T+h-2}+r_{T+h-3}\right) / 4$, respectively. The GDP growth predictions were obtained from the forecasts of per capita output, $y_{T+h}$, generated from the core model and assuming a population growth of $0.21 \%$ per annum.

As can be seen from Table 7 , the average annual rate of inflation is predicted to fall slightly in 1999q2 before rising steadily thereafter. These point forecasts are higher than the inflation rates realized during 1999 and tend to be higher than the current consensus inflation forecasts. But they are subject to a wide margin of uncertainty as reflected in the forecast intervals. Output growth is predicted to be positive throughout the forecast horizon, falling in 1999 but then rising to around 2.0-2.10\% thereafter. Annual average interest rates are predicted to be around $5.2 \%$ in the first quarter of 2000 and falling slowly thereafter. Once again these forecasts are subject to a high degree of uncertainty. For example, while the point forecast of inflation is predicted to lie above the government central inflation target of $2.5 \%$, the annual rate of inflation in $2000 \mathrm{q} 1$ is predicted (at $95 \%$ level) to lie in the range -1.74 to +9.45 . Similarly the annual rate of output growth in $2000 \mathrm{q} 1$ is predicted to lie in the interval -1.56 to +5.17 ; a very wide range indeed. But it is difficult to evaluate the significance of these forecast intervals for policy analysis. As we have argued, a more appropriate approach

\footnotetext{
${ }^{18}$ See, for example, Harding and Pagan (2000) .

${ }^{19}$ In interpreting the probability estimates in this section, it should be born in mind that the inflation target is expressed in terms of RPI-x, while the core model uses the RPI as a measure of inflation.
} 
would be to directly focus on the uncertainty associated with the events of interest, and this is the topic that we shall turn to now.

\subsection{Predictive Distribution Functions}

In the case of single events, probability forecasts are generally represented by means of probability distribution functions. Figures $2 \mathrm{a}-2 \mathrm{c}$ give the estimates of these functions for the 4-quarterly moving averages of inflation, output growth and the interest rate for a number of selected quarters over the forecast horizon, 1999q1-2004q4. These estimates are computed using the parametric stochastic simulation technique described in some detail in the Appendix and take account of future and parameter uncertainty. We shall refer to them as the bootstrap predictive density (BPD) estimates.

Figure 2a, presents the BPD estimates for the probability of average inflation falling below threshold values ranging from $-2 \%$ to $+10 \%$ per annum at four selected forecast horizons. It is clear that the estimated probability distribution functions all shift uniformly to the right of the graph as longer forecast horizons are considered, indicating that the probability of inflation falling below a given threshold declines with the forecast horizon. For example, the forecast probability that inflation lies below 3.5\% becomes progressively smaller at longer forecast horizons, falling from approximately $80 \%$ in $1999 \mathrm{q} 1$ to $5 \%$ in $2004 \mathrm{q} 4$. These forecast probabilities are in line with the historical evidence. The empirical frequencies of inflation obtained over different ranges across different sample periods are set out in Table 2a. Over the whole sample period, 1965q1-1998q4, the average annual rate of inflation fell below $3.5 \%$ only in $22.8 \%$ of the quarters. The same figure during the 1990 s was much higher and amounted to $61.1 \%$. Whether we consider the probability forecasts presented in Figure 2a as realistic very much depends on how one views the current policies as having been effective in bringing about appropriate structural changes to the UK economy.

Figure $2 \mathrm{~b}$ relates to four-quarter moving average of output growth, $\ln \left(G D P_{T+h} / G D P_{T+h-4}\right)$, and should be viewed in the light of the fact that output growth, although falling, was relatively high in the last quarters of 1998 and that moderate levels of growth are also forecast over the longer term. Hence, the estimate of the probability of a recession in $1999 \mathrm{q} 1$ is $8 \%$, falling to $3 \%$ in 1999q4, before rising to around 7-8\% over the long run. It is worth noting that historically (over the period 1965q1-1998q4) the unconditional probability of a recession has been around $13.2 \%$ (see Table $2 \mathrm{~b}$ ).

Finally, Figure 2c gives the bootstrap predictive distribution functions for the four-quarter moving average of the level of interest rates. The shape of the plot for $1999 \mathrm{q} 1$ is dominated by the relatively high interest rates experienced during the last 3 quarters of 1998 . The plot registers a small probability of 0.13 for the average annual rate of interest to fall below $6 \%$, but this probability starts to rise steadily in subsequent years.

\subsection{Probability Forecasts of Events of Interest}

In addition to providing estimates of the probability distribution functions, it is often useful to compute probability estimates of events of particular interest. Here we consider two such 
events:

$A$ : Four-quarterly moving average rate of inflation lies in the range $1.5 \%$ to $3.5 \%$, and

$B$ : Four-quarterly moving average rate of output growth is positive.

\subsubsection{Inflation}

Figure 3a presents alternative estimates of $\operatorname{Pr}\left(A_{T+h} \mid \Omega_{T}\right)$ at different forecast horizons $h=1,2,3, \ldots$. The probability estimates themselves are given in Table 8 . This figure provides two sets of probability estimates: the BPD's that allow for parameter uncertainty and the profile predictive likelihoods (PPL) described earlier which only take account of the future uncertainty. There are important differences between the two sets of estimates at least at some forecast horizons, and this demonstrates the importance of allowing for parameter uncertainty in probability forecasting.

Of more economic significance here, however, the plots also provide a direct indication of the probability that the Bank of England will achieve inflation rates within the announced target range both in the short run and in the medium to the long run. The probability estimates are not encouraging and except for the immediate future are rather low. The probability that inflation will fall within the target range is estimated to be quite high in 1999, but it then falls steadily towards zero. The BPD estimates that allow for parameter uncertainty are generally lower than the PPL estimates that do not take account of parameter uncertainty. These results correspond with those in Figure $2 \mathrm{a}$ which showed that the probability of four-quarter average inflation being above $3.5 \%$ is relatively low in the very short run $(0.25$ in $1999 \mathrm{q} 1)$, but that this probability rises rapidly over time, reaching $50 \%$ in 2000q1 and 90\% in 2002q2. Again, it is important to place these estimates in their historical contexts by comparing them with the corresponding empirical frequencies reported in Table 2a. Over the sample as a whole, inflation fell within the range $[1.5 \%, 3.5 \%]$ on just $15.4 \%$ of occasions, and again most of these occurred in the latter part of the sample.

These results appear very discouraging from the point of view of the Bank of England. They show that, taking into account stochastic uncertainty, the uncertainty surrounding the evolution of the exogenous variables and the uncertainty surrounding the estimated parameters of the model, the probability that the Bank can achieve the government inflation objectives is very slim indeed over reasonable time horizons. Of course, the probability forecasts have not taken into account model uncertainty, and it is possible that the model that we have estimated, and on which the probability forecasts are based, is the wrong model. Alternatively, it is possible that our model represents a reasonable characterization of the historical core relationships of the UK macroeconomy but that a structural break occurred towards the end of the sample which would render the probability forecasts based on our model inappropriate. We have checked the statistical properties of our estimated model and there seems no evidence to suggest that such a structural break has taken place in our sample. However, it is widely argued that a structural break occurred in the determination of UK inflation in the nineties when the monetary authorities switched to a policy of inflation targeting, and the establishment of the Bank of England as an independent body implementing monetary policy in 1997 was certainly a break with previous policy arrangements. If this 
were the case, it would be difficult to establish statistically whether the break has occurred or not, given the short period of time that has elapsed since the hypothesised break. The conclusion drawn from our probability forecasts, therefore, is simply this: that the Bank's inflation target is unlikely to be achieved in the medium to long term if the underlying macroeconomic structure, as captured by our macroeconometric model, remains unchanged. Hence, in the long run pursuit of the Government's inflation policy, it is important that appropriate policy changes are put in place. Whether this has already been done is rather difficult to establish or refute using econometric techniques of the type advocated in this paper.

\subsubsection{Output Growth}

Figure 3b plot the estimates of $\operatorname{Pr}\left(B_{T+h} \mid \Omega_{T}\right)$; namely, the probability that the four quarter moving average of output growth exceeds $0 \%$ at $T+h, h=1,2, \ldots$ In this case, the BPD estimates are systematically below the PPL estimates, showing once again the importance of allowing for parameter uncertainty. However, both sets of estimates suggest a relatively high probability that a recession can be avoided. Using the BPD estimates, conditional on the available information at the end of $1998 \mathrm{q}$, the probability that a recession can be avoided is estimated to be around 0.90 in $1999 \mathrm{q} 1$, falling to 0.86 in $2001 \mathrm{q} 1$ and rising thereafter towards 1. It is worth emphasising that these estimates are computed conditional on the information available at the end of 1998 and need to be adapted recursively for a "real time" analysis. But such an exercise is beyond the scope of the present paper.

\subsubsection{Joint Events involving Inflation and Output Growth}

Figure 3c provides illustrations of the probability forecasts relating to the joint event that the four-quarter moving average of inflation lies within the target range of $[1.5 \%, 3.5 \%]$ and, at the same time, recession is avoided; namely, $\operatorname{Pr}\left(A_{T+h} \cap B_{T+h} \mid \Omega_{T}\right), h=1,2, \ldots$. The BPD estimates are again below the PPL estimates, but only over the medium term; over the long horizon, the reverse is true. These probability forecasts are similar in shape and magnitude to those of Figure 3a that relate to $\operatorname{Pr}\left(A_{T+h} \mid \Omega_{T}\right)$. This is not surprising as the probability of a recession is estimated to be relatively small at most forecast horizons, so that one would expect the plots in Figure 3c to be only a little lower and of a similar shape to those in Figure 3a. However, this is not to understate the potential usefulness of computing the probability of joint events. In a decision-making context, it is often the joint events that matter. A firm's decisions to invest generally depend on growth prospects and financial stability. The probability forecasts provided in Figure 3c provide the type of probabilistic information required for such decisions. Moreover, this information would be difficult to derive from confidence intervals of the sort typically provided. This is because these two events are unlikely to be independent of each other at all forecast horizons and for all types of inflationary experiences. 


\subsection{A Neutrality Index}

The single and joint event probabilities can also be employed to shed light on the hypothesis of the long-run neutrality, viewed as the stochastic independence of output growth and inflation. Under the neutrality hypothesis at all forecast horizons, we have: ${ }^{20}$

$$
\operatorname{Pr}\left(\tilde{A}_{T+h} \mid \Omega_{T}\right)=\frac{\operatorname{Pr}\left(\tilde{A}_{T+h} \cap \tilde{B}_{T+h} \mid \Omega_{T}\right)}{\operatorname{Pr}\left(\tilde{B}_{T+h} \mid \Omega_{T}\right)}, \quad \text { or } \quad \frac{\operatorname{Pr}\left(\tilde{A}_{T+h} \mid \Omega_{T}\right) \operatorname{Pr}\left(\tilde{B}_{T+h} \mid \Omega_{T}\right)}{\operatorname{Pr}\left(\tilde{A}_{T+h} \cap \tilde{B}_{T+h} \mid \Omega_{T}\right)}=1 .
$$

where $\tilde{A}_{T+h}$ is the event that the $h$-period average rate of inflation lies in the range $1.5 \%$ to $3.5 \%$, and $\tilde{B}_{T+h}$ denotes the event that the $h$-period average rate of output growth is positive. Therefore, the extent to which there are departures from the neutrality hypothesis can be measured by the probability ratio

$$
I_{h}=\frac{\operatorname{Pr}\left(\tilde{A}_{T+h} \mid \Omega_{T}\right) \operatorname{Pr}\left(\tilde{B}_{T+h} \mid \Omega_{T}\right)}{\operatorname{Pr}\left(\tilde{A}_{T+h} \cap \tilde{B}_{T+h} \mid \Omega_{T}\right)},
$$

which we call the "Neutrality Index". The estimates of the neutrality index are given in Figure 3d. They are close to unity for most forecast horizons, indicating that the departure from neutrality is relatively minor in the present application.

The neutrality index is a function of the forecast horizon, $h$, and for given events $\tilde{A}$ and $\tilde{B}$ can be viewed as a probabilistic characterization of the generalized impulse response function discussed in Koop et al. (1996). The use of probabilities for this purpose is attractive on a number of grounds. The neutrality (or the independence) index, $I_{h}$, is well defined so long as the probability of the events $\tilde{A}$ and $\tilde{B}$ do not take the extreme values of 0 and 1 . The evolution over time of $I_{h}$ provides important information on short-run as well as the long-run properties of the underlying model. It is also relatively easy to allow for the effect of parameter uncertainty on $I_{h}$. As Figure 3d shows for the evolution of $I_{h}$ in this application parameter uncertainty does not seem to be an important consideration.

\subsection{Comparison of Event Probabilities across Alternative Models and Estimation Periods}

In this Section, we consider the robustness of the event probability forecasts described above, based on the unrestricted core model (see Table 5), by comparing these forecasts with the corresponding probabilities obtained from three alternative models. Specifically, we shall consider the probability estimates based on (i) the restricted core model estimated over the whole sample period 1965q1-1998q4 and presented in Table 6; (ii) a version of the unrestricted model of Table 5 estimated over the more recent period, 1985q1-1998q4 (the 'unrestricted 1985-98 model'); and (iii) a restricted version of the model estimated over the period 1985q1-1998q4.

To obtain the restricted and the unrestricted 1985-98 versions of the model we started with the cointegrating relationships from the 1965-98 versions summarized in Tables 5 and 6. This procedure is justified on the grounds that these long-run relationships might not

\footnotetext{
${ }^{20}$ We assume that the events $A$ and $B$ are defined such that $\operatorname{Pr}(A)>0$ and $\operatorname{Pr}(B)>0$.
} 
be reliably estimated on a sample size of 56 observations. ${ }^{21}$ Therefore, the 'unrestricted 1985-98 model' has the same form as the model set out in Table 5, incorporating the same long-run relationship, but has different short-run coefficients. Importantly, the underlying error-correction regressions also allow for different intercepts to be estimated across different sample periods. This provides a flexible modelling framework which is potentially capable of taking account of intercept shifts that could have come about due to possible regime changes in the conduct of the monetary policy during the recent past. ${ }^{22}$

Figures 4a-4d give the plots of the estimates of $\operatorname{Pr}\left(A_{T+h} \mid \Omega_{T}\right), \operatorname{Pr}\left(B_{T+h} \mid \Omega_{T}\right), \operatorname{Pr}\left(A_{T+h} \cap\right.$ $\left.B_{T+h} \mid \Omega_{T}\right)$, and $I_{h}$ defined in equation $(22)$, for $h=1,2, \ldots$, based on the unrestricted and restricted versions of the 1965-98 model. Figures 5a-5d present the probability estimates based on the unrestricted 1965-98 and unrestricted 1985-98 models. The probability estimates themselves are provided in Table 9 . Figure 4 shows that the imposition of the restrictions on the short-run dynamics has relatively little effect on the various estimated event probabilities, with the two sets of estimates lying very close to each other. Figure 5, on the other hand, shows that the estimates obtained from the whole-sample and the recentsample models are different in important ways, especially at short forecast horizons. The Bank is substantially more likely to achieve inflation rates within the acceptable range over the next two years according to the probabilities generated by the 1985-98 version model when compared to those from the whole-sample model. According to the 1965-98 model, the single event probability, $\operatorname{Pr}\left(A_{T+h} \mid \Omega_{T}\right)$, takes the value 0.66 in $1999 \mathrm{q} 1$, falling to 0.41 after 4 quarters, to 0.21 after two years, and to 0.08 over long horizons. The recent-sample model provides corresponding probability estimates of $0.89,0.58,0.22$, and 0.16 . While the Bank is unlikely to achieve its targets over the longer horizons according to both sets of figures, therefore, the prospects of achieving its aims over the shorter, one-two year horizons, are much brighter according to the estimates computed using the 1985-98 model.

The probability forecasts presented in the paper have not taken into account model uncertainty. The results presented in Figure 5 suggest that this form of uncertainty, including the effects of changing estimation periods necessary to capture the effects of possible regime shifts and structural breaks, can be important.

\subsection{Probability Forecasts Under a Higher Oil Price Scenario}

In this section we briefly consider the effects of the recent sharp increases in oil prices on our probability estimates. The average quarterly oil prices during 1999q1-2000q1 increased from $\$ 11.79 \mathrm{p} / \mathrm{b}$ in $1999 \mathrm{q} 1$ to $\$ 16.37 \mathrm{p} / \mathrm{b}$ in $1999 \mathrm{q} 2, \$ 20.66 \mathrm{p} / \mathrm{b}$ in $1999 \mathrm{q} 3, \$ 23.74 \mathrm{p} / \mathrm{b}$ in $1999 \mathrm{q} 4$ and seems to have stablised to around $\$ 25 \mathrm{p} / \mathrm{b}$ during $2000 \mathrm{q} 2$. Oil prices are notoriously difficult to predict, but it is generally believed that the current relatively high level of oil prices are unlikely to be sustainable in the longer run. We shall therefore assume that oil prices will

\footnotetext{
${ }^{21}$ Given the sensitivity of forecasts to changes in intercepts and trends, we re-estimated the coefficient on the time trend in the RMB relationship. It turned out that this coefficient was not significantly different from zero when the core model was estimated over the 1985q1-1998q4 period. This restriction was, therefore, imposed in the 1985-1998 model. This is in line with Jansen's (1996) observations on the slowdown in the rate of technological progress in the payment system in the UK.

${ }^{22}$ The restricted version of the 1985-98 model was obtained using a similar procedure as to the one followed in deriving the restricted version of the 1965-98 model from its unrestricted counter part.
} 
remain at their present high levels of $\$ 25$ for the rest of 2000 but fall back to the lower level of $\$ 18 \mathrm{p} / \mathrm{b}$ over the subsequent periods. The probability estimates of the joint event that the four-quarter moving average of inflation lies within the target range of $[1.5 \%, 3.5 \%]$ and, at the same time, recession is avoided; namely, $\operatorname{Pr}\left(A_{T+h} \cap B_{T+h} \mid \Omega_{T}\right), h=1,2, \ldots$, under this oil price scenario are shown in Figures $6 \mathrm{a}$ and $6 \mathrm{~b}$ (calculated using the unrestricted model estimated over the periods 1965q1-1998q4 and 1985q1-1998q4, respectively). As might be expected, the higher oil prices reduce the probability of the joint event of interest, at least in the short to the medium run. The long run probabilities are, however, hardly affected by the move from the low to the high oil price scenario.

\section{Concluding Comments}

One of the many problems economic forecasters and policy makers face is conveying to the public the degree of uncertainty associated with point forecasts. Policy makers recognise that their announcements, in addition to providing information on policy objectives, can themselves initiate responses which effect the macroeconomic outcome. This means that Central Bank Governors are reluctant to discuss either pessimistic possibilities, as this might induce recession, or more optimistic possibilities, since this might induce inflationary pressures. There is therefore an incentive for policy makers to seek ways of making clear statements regarding the range of potential macroeconomic outcomes for a given policy, and the likelihood of the occurrence of these outcomes, in a manner which avoids these difficulties.

In this paper, we have argued for the use of probability forecasts as a method of charaterising the uncertainty around forecasts from a macroeconomic model believing this to be superior to the conventional way of trying to deal with this problem through the use of confidence intervals. We argue that the use of probability forecasts has an intuitive appeal, enabling the forecaster (or users of forecasts) to specify the relevant "threshold values" which define the event of interest (e.g. a threshold value corresponding to an inflation target of 2.5\%). This is in contrast to the use of confidence intervals which define threshold values only implicitly, through the specification of the confidence interval widths, and these thresholds may or may not represent thresholds of interest. A further advantage of the use of probability forecasts compared with the use of confidence intervals and over other more popular methods is the flexibility of probability forecasts, as illustrated by the ease with which the probability of joint events can be analysed. Hence, for example, we can consider the likelihood of achieving a stated inflation target whilst simultaneously achieving a given level of output growth and we can convey this information in a single number. In situations where the utility of loss functions are non-quadratic and/or the constraints are non-linear the whole predictive probability distribution function rather than its mean is required for decision making. This paper shows how such predictive distribution functions can be obtained in the case of long-run structural models, and illustrates its feasibility in the case of a small macroeconometric model of the UK.

Our application yields a number of potentially important results. It shows that without appropriate structural changes in the conduct of the monetary and fiscal policies the chances of the Bank of England meeting the Treasury's announced inflation target in the long run seem rather slim; although the probability of the inflation target being met in the short run 
is estimated to be quite high, around 70 per cent. Whether the required structural changes have been put in place or are in the process of being implemented is difficult to tell. But the recent substantial rises in oil prices and increased uncertainties surrounding financial markets should serve as warning signals against undue complacency.

\section{A Appendix: Computation of Probability Forecasts by Stochastic Simulation Techniques in the Case of the Cointegrating VAR Models}

In this Appendix, we consider some of the computational difficulties that will typically be encountered in the calculation of probability forecasts and note how these can be circumvented through the use of stochastic simulation methods. These methods involve repeatedly simulating the future values of the variables under study, $\mathbf{z}_{t}$, (say $S$ times), using the assumed stochastic structure of the data generating process, to obtain $\mathbf{z}_{T+h}^{(i)}(\widehat{\boldsymbol{\theta}}), h=1,2, \ldots$, and $i=1,2, \ldots, S$. On each simulation, the occurrence or non-occurrence of the event of interest is noted and, eventually, the probability of the event occurring can be calculated as the proportion of the $S$ simulations in which the event was observed to occur. We illustrate the use of these methods below in the context of the general vector error correcting model used in the paper.

For forecasting purposes we first write the error correction model (20) in the following form

$$
\mathbf{z}_{t}=\sum_{j=1}^{s} \Phi_{j} \mathbf{z}_{t-s}+\mathbf{b}_{0}+\mathbf{b}_{1} t+\mathbf{u}_{t}, t=1,2, \ldots, T
$$

where

$$
\Phi_{1}=\mathbf{I}_{m}-\Pi+\Gamma_{1}, \Phi_{i}=\Gamma_{i}-\Gamma_{i-1}, i=2,3, \ldots, s-1, \Phi_{s}=-\Gamma_{s-1},
$$

and $\mathbf{u}_{t}$ is assumed to be a serially uncorrelated iid vector of shocks with zero means and a positive definite covariance matrix, $\Sigma$. In what follows, we consider the calculation of probability forecasts using (A.1), first assuming that the parameters are known and then taking into account parameter uncertainty.

Forecasts in the absence of parameter uncertainty Suppose that the ML estimators of $\Phi_{j}, j=1, \ldots, s, \mathbf{b}_{0}, \mathbf{b}_{1}$ and $\Sigma$ are given and denoted by $\hat{\Phi}_{j}, j=1, \ldots, s, \hat{\mathbf{b}}_{0}, \hat{\mathbf{b}}_{1}$ and $\hat{\Sigma}$, respectively. Then the point estimates of the $h$-step ahead forecasts of $\mathbf{z}_{T+h}$ conditional on $\Omega_{T}$, which we denote by $\hat{\mathbf{z}}_{T+h}$, can be obtained recursively by

$$
\hat{\mathbf{z}}_{T+h}=\sum_{j=1}^{s} \hat{\Phi}_{j} \hat{\mathbf{z}}_{T+h-j}+\hat{\mathbf{b}}_{0}+\hat{\mathbf{b}}_{1}(t+h), h=1,2, \ldots,
$$


where the initial values, $\mathbf{z}_{T}, \mathbf{z}_{T-1}, \ldots, \mathbf{z}_{T-s+1}$, are given. To obtain probability forecasts using stochastic simulation methods, we need to simulate the values of $\mathbf{z}_{T+h}$ by

$$
\mathbf{z}_{T+h}^{(i)}=\sum_{j=1}^{s} \hat{\Phi}_{i} \mathbf{z}_{T+h-j}^{(i)}+\hat{\mathbf{b}}_{0}+\hat{\mathbf{b}}_{1}(t+h)+\mathbf{u}_{T+h}^{(i)}, h=1,2, \ldots, i=1,2, \ldots, S
$$

where superscript ' $(i)^{\prime}$ ' refers to the $i$-th replication, and $\mathbf{z}_{T}^{(i)}=\mathbf{z}_{T}, \mathbf{z}_{T-1}^{(i)}=\mathbf{z}_{T-1}, \ldots, \mathbf{z}_{T-s+1}^{(i)}=$ $\mathbf{z}_{T-s+1}$ for all $i$. The $\mathbf{u}_{T+h}^{(i)}$ 's can be drawn by parametric or nonparametric methods as described in section B below. The probability of the event $\boldsymbol{\varphi}\left[\mathbf{z}_{T+1}^{(s)}(\widehat{\boldsymbol{\theta}}), \mathbf{z}_{T+2}^{(s)}(\widehat{\boldsymbol{\theta}}), \ldots, \mathbf{z}_{T+h}^{(s)}(\widehat{\boldsymbol{\theta}})\right]<$ a, can then be computed as

$$
\pi(\mathbf{a}, h ; \boldsymbol{\varphi}(.), \widehat{\boldsymbol{\theta}})=\frac{1}{S} \sum_{i=1}^{S} I\left\{\mathbf{a}-\boldsymbol{\varphi}\left[\mathbf{z}_{T+1}^{(s)}(\widehat{\boldsymbol{\theta}}), \mathbf{z}_{T+2}^{(s)}(\widehat{\boldsymbol{\theta}}), \ldots, \mathbf{z}_{T+h}^{(s)}(\widehat{\boldsymbol{\theta}})\right]\right\},
$$

where $I(\cdot)$ is an indicator function which takes the value of unity if $\mathbf{a}-\boldsymbol{\varphi}\left[\mathbf{z}_{T+1}^{(s)}(\widehat{\boldsymbol{\theta}}), \mathbf{z}_{T+2}^{(s)}(\widehat{\boldsymbol{\theta}}), \ldots, \mathbf{z}_{T+h}^{(s)}(\widehat{\boldsymbol{\theta}})\right]>\mathbf{0}$, and zero otherwise.

Forecasts in the presence of parameter uncertainty To allow for parameter uncertainty, we first use the simulation methods to obtain $R$ simulated values of within sample values of $\mathbf{z}_{t}, t=1,2, \ldots, T$, denoted by $\mathbf{z}_{t}^{(r)}$,

$$
\mathbf{z}_{t}^{(r)}=\sum_{j=1}^{s} \hat{\Phi}_{i} \mathbf{z}_{t-j}^{(r)}+\hat{\mathbf{b}}_{0}+\hat{\mathbf{b}}_{1} t+\mathbf{u}_{t}^{(r)}, t=1,2, \ldots, T, r=1, . ., R ;
$$

where actual observations on the initial values, $\mathbf{z}_{-1}, \ldots, \mathbf{z}_{-s}$ are used for this purpose. Again, the $\mathbf{u}_{t}^{(r)}$ 's can be drawn either by parametric or nonparametric methods. Having obtained the $R$ set of the simulated in-sample values, $\left\{\mathbf{z}_{1}^{(r)}, \mathbf{z}_{2}^{(r)}, \ldots, \mathbf{z}_{T}^{(r)}\right\}$, the $V A R(s)$ model (A.1) is re-estimated $R$ times to obtain new maximum likelihood estimates, $\hat{\Phi}_{j}^{(r)}, j=1,2, \ldots, s$, $\hat{\mathbf{b}}_{0}^{(r)}, \hat{\mathbf{b}}_{1}^{(r)}$ and $\hat{\Sigma}^{(r)}, r=1,2, \ldots, R$. On each occasion, we undertake similar exercises to that described in the previous sub-section to obtain measures of the probability forecast, denoted simply by $\pi^{(r)}, r=1,2, \ldots, R$. Then, the empirical mean of the probability forecast is obtained by

$$
\bar{\pi}=\frac{1}{R} \sum_{r=1}^{R} \pi^{(r)}
$$

and the associated $100 \alpha \%$ lower and upper confidence bands computed as the $R \alpha$-th smallest and largest values of $\pi^{(r)}, r=1,2, \ldots, R$, respectively. ${ }^{23}$

\footnotetext{
${ }^{23}$ We can also obtain the empirical mean of the point forecasts by

$$
\overline{\mathbf{z}}_{T+h}=\frac{1}{R} \sum_{r=1}^{R} \frac{1}{S} \sum_{i=1}^{S} \mathbf{z}_{T+h}^{(i, r)}, h=1,2, \ldots
$$

and construct their associated $100 \alpha \%$ lower and upper confidence bands as the $R S \alpha$-th smallest and largest values of $\mathbf{z}_{T+h}^{(i, r)}, i=1,2, \ldots, S, r=1,2, \ldots, R$, respectively.
} 


\section{B Generating Simulated Errors}

In this section, we briefly comment on the alternative methods that can be used to simulate errors for use in the stochastic simulations and the bootstrap exercises described above, allowing for the contemporaneous correlations that exist across the errors in the different equations of the model. The first is parametric method where the errors are drawn from an assumed probability distribution function. Alternatively, one could employ a non-parametric procedure. These are slightly more complicated and are based on re-sampling techniques in which the simulated errors are obtained by a random draw from the observed errors (see, for example, Hall (1992)).

In what follows the application of these two approaches to generate forecast probabilities at different horizons, $T+h, h=1,2, \ldots, H$, will now be described.

Parametric Approach In our application of the parametric approach we assume that the errors are drawn from a multivariate Normal distribution with zero mean and the covariance matrix, $\Sigma$. The procedure makes use of the matrix $\mathbf{P}$, where $\mathbf{P}^{-1}$ is the lower triangular Choleski decomposition of $\Sigma$ such that $\Sigma=\mathbf{P P}^{\prime}$. In this case, $\boldsymbol{\varepsilon}_{t}=\mathbf{P}^{-1} \mathbf{u}_{t}$ is an $m \times 1$ vector of standard normal disturbances. To obtain simulated errors for $m$ variables over $h$ periods, say, we generate $m h$ draws from the standard normal distribution, denoted by $\left\{\boldsymbol{\varepsilon}_{T+1}, \boldsymbol{\varepsilon}_{T+2}, \ldots, \boldsymbol{\varepsilon}_{T+h}\right\}$, and these are used to obtain $\left\{\mathbf{u}_{T+1}, \mathbf{u}_{T+1}, \ldots, \mathbf{u}_{T+h}\right\}$ via the transformation $\mathbf{u}_{T+h}=\mathbf{P} \boldsymbol{\varepsilon}_{T+h}$.

Non-Parametric Approaches The most obvious non-parametric approach to generating simulated errors, $\mathbf{u}_{T+h}$, which we shall denote 'Method 1', is simply to take $h$ random draws from the observed errors $\left\{\mathbf{u}_{1}, \ldots, \mathbf{u}_{T}\right\}$, replacing the chosen error vector after each draw. The simulated errors thus obtained clearly have precisely the same distribution and covariance structure as that observed in the original sample. However, this method is susceptible to the criticism, discussed below, that serial independence is introduced at longer forecast horizons since there is a set of just $T$ observations from which we sample each time.

An alternative non-parametric method for generating simulated errors, 'Method 2', makes use of the Choleski decomposition of the estimated covariance employed in the parametric approach. Having identified the matrix $\mathbf{P}$ for which $\Sigma=\mathbf{P P}^{\prime}$, we can obtain a set of $m T$ transformed error terms $\left\{\boldsymbol{\varepsilon}_{1}, \ldots, \boldsymbol{\varepsilon}_{T}\right\}$ where $\boldsymbol{\varepsilon}_{t}=\mathbf{P}^{-1} \mathbf{u}_{t}, t=1, \ldots, T$. The $m T$ individual error terms are uncorrelated with each other, but retain the distributional information (relating to extreme values, and so on) contained in the original observed errors. A set of $m h$ simulated errors can be obtained through random draw, with replacement, from the transformed errors, and these can be arranged into a set of $m \times 1$ vectors $\left\{\boldsymbol{\varepsilon}_{T+1}, \ldots, \boldsymbol{\varepsilon}_{T+h}\right\}$ which can be used to obtain $\left\{\mathbf{u}_{T+1}, \ldots, \mathbf{u}_{T+h}\right\}$ using $\mathbf{u}_{T+h}=\mathbf{P} \boldsymbol{\varepsilon}_{T+h}$. Given that the $\mathbf{P}$ matrix is used to generate the simulated errors, it is clear that the $\mathbf{u}_{T+h}$ again have the same covariance structure as the original estimated errors. And being based on errors drawn at random from the transformed originals, these generated simulations will also display the same distributional features. Further, given that the re-sampling occurs from the $m T$ transformed error terms, Method 2 also has the advantage over Method 1 that the serial dependence introduced through sampling with replacement will be problematic only at longer time horizons. 
Choice of Approach The non-parametric approaches described above have the advantage over the parametric approach that they make no distributional assumptions on the error terms, and are better able to capture the uncertainties arising from (possibly rare) extreme observations. However, they suffer the disadvantage that they require random sampling with replacement. Replacement is essential as otherwise the draws at longer forecast horizons are effectively 'truncated' and unrepresentative. On the other hand, for a given sample size, it is clear that re-sampling from the observed errors with replacement inevitably introduces serial dependence in the simulated forecast errors at longer horizons as the same observed errors are drawn repeatedly. When generating simulated errors over a forecast horizon, therefore, this provides an argument for the use of non-parametric methods over shorter forecast horizons, but suggests that a greater reliance might be placed on the parametric approach at longer time horizons. 


\section{Table 1}

\section{List of Variables and their Descriptions in the Core Model}

$y_{t}$ : natural logarithm of the UK real per capita GDP at market prices $(1995=100)$.

$p_{t}$ : natural logarithm of the UK Retail Price Index, All Items $(1995=100)$.

$r_{t}$ : is computed as $r_{t}=0.25 \ln \left(1+R_{t} / 100\right)$, where $R_{t}$ is the 90 day Treasury Bill average discount rate per annum.

$h_{t}$ : natural logarithm of UK real per capita M0 money stock $(1995=100)$.

$e_{t}$ : natural logarithm of the nominal Sterling effective exchange rate $(1995=100)$.

$y_{t}^{*}$ : natural logarithm of the foreign (Total OECD) real per capita GDP at market prices $(1995=100)$.

$p_{t}^{*}$ : natural logarithm of the foreign (Total OECD Consumer Price Index) $(1995=100)$.

$r_{t}^{*}$ : is computed as $r_{t}^{*}=0.25 \ln \left(1+R_{t}^{*} / 100\right)$, where $R_{t}^{*}$ is the weighted average of 90 day interest rates per annum in the United States, Germany, Japan and France.

$p_{t}^{o}$ : natural logarithm of oil prices, measured as the Average Price of Crude Oil.

$t$ : time trend, taking the values $1,2,3, \ldots$, in $1965 q 1,1965 q 2,1965 q 3, \ldots$, respectively.

Notes: The data set used in the probability forecasting exercise is based on the European Standard of Accounts. For more detail of the data sources and a description of the construction of the series see the Data Appendix in Garratt et al. (2000b). 
Table 2a

Empirical Frequencies of Inflation Falling Below Selected Thresholds

\begin{tabular}{|c||c|c|c|c|c|c|c|c|c|c|c|}
\hline \multicolumn{1}{|c||}{} & \multicolumn{10}{c|}{ Thresholds (per cent) } \\
\cline { 2 - 12 } Sample Period & 1.5 & 2.5 & 3.5 & 5.0 & 6.0 & 7.0 & 8.0 & 9.0 & 10.0 & 15.0 & 20.0 \\
\hline \hline $1970 q 1-1979 q 4$ & 0.0 & 0.0 & 0.0 & 2.5 & 7.5 & 12.5 & 30.0 & 40.0 & 52.5 & 72.5 & 90.0 \\
\hline $1980 q 1-1989 q 4$ & 0.0 & 0.0 & 10.0 & 40.0 & 55.5 & 62.5 & 75.0 & 77.5 & 77.5 & 92.5 & 100 \\
\hline $1990 q 1-1998 q 4$ & 2.8 & 22.2 & 61.1 & 83.3 & 86.1 & 86.1 & 88.9 & 91.7 & 100 & 100 & 100 \\
\hline \hline $1965 q 1-1998 q 4$ & 1.5 & 7.4 & 22.8 & 44.9 & 55.1 & 59.6 & 69.1 & 73.5 & 79.4 & 89.7 & 97.1 \\
\hline
\end{tabular}

Notes: The figures show the percentage of the time the 4-quarter moving average of inflation was below the stated threshold values over the specified periods.

Table 2b

Empirical Frequencies of Output Growth Falling Below Selected Thresholds

\begin{tabular}{|c||c|c|c|c|c|c|c|c|c|c|}
\hline \multicolumn{1}{|c||}{} & \multicolumn{10}{c|}{ Thresholds (per cent) } \\
\cline { 2 - 11 } Sample Period & -2.0 & -1.0 & -0.5 & 0.00 & 1.00 & 2.00 & 2.50 & 3.00 & 4.00 & 5.00 \\
\hline \hline $1970 q 1-1979 q 4$ & 5.0 & 12.5 & 15.0 & 15.0 & 17.5 & 40.0 & 52.5 & 70.0 & 85.0 & 90.0 \\
\hline $1980 q 1-1989 q 4$ & 10.0 & 12.5 & 12.5 & 12.5 & 20.0 & 37.5 & 42.5 & 50.0 & 72.5 & 92.5 \\
\hline $1990 q 1-1998 q 4$ & 2.8 & 8.3 & 16.7 & 19.4 & 27.8 & 44.4 & 58.3 & 69.4 & 91.7 & 100 \\
\hline \hline $1965 q 1-1998 q 4$ & 5.1 & 9.6 & 12.5 & 13.2 & 19.1 & 38.2 & 51.5 & 64.7 & 83.1 & 94.9 \\
\hline
\end{tabular}

Notes: As in Table 2a but with respect to 4-quarter moving average of output growth.

Table 2c

Empirical Frequencies of Interest Rates Falling Below Selected Thresholds

\begin{tabular}{|c||c|c|c|c|c|c|c|c|c|c|c|}
\hline \multicolumn{1}{|c||}{} & \multicolumn{10}{c|}{ Thresholds (per cent) } \\
\cline { 2 - 12 } Sample Period & 5 & 6 & 7 & 8 & 9 & 10 & 11 & 12 & 13 & 14 & 15 \\
\hline \hline $1970 q 1-1979 q 4$ & 5.0 & 12.5 & 27.5 & 45.0 & 52.5 & 60.0 & 80.0 & 95.0 & 97.5 & 100 & 100 \\
\hline $1980 q 1-1989 q 4$ & 0.0 & 0.0 & 0.0 & 0.0 & 10.0 & 35.0 & 52.5 & 65.0 & 77.5 & 90.0 & 95.0 \\
\hline $1990 q 1-1998 q 4$ & 2.8 & 27.8 & 58.3 & 66.7 & 69.4 & 75.0 & 80.6 & 83.3 & 86.1 & 88.9 & 100 \\
\hline \hline $1965 q 1-1998 q 4$ & 2.2 & 16.9 & 34.6 & 45.6 & 51.5 & 62.5 & 75.0 & 83.8 & 89.0 & 94.1 & 98.5 \\
\hline
\end{tabular}

Notes: As in Table 2a but with respect to 4-quarter moving average of interest rates. 
Table 3a

Bivariate Empirical Frequencies of Output Growth and Inflation: 1965q1- 1998q4

(per cent)

\begin{tabular}{|c||c|c|c|c|c|c|c|c|c|c||c|}
\hline \multicolumn{1}{|c||}{$\operatorname{Pr}(\Delta p<b)$} & -2 & -1 & -0.5 & 0 & 1 & 2 & 2.5 & 3 & 4 & 5 & $\infty$ \\
\hline \hline 1.5 & 0 & 0 & 0 & 0 & 0 & 1.5 & 1.5 & 1.5 & 1.5 & 1.5 & 1.5 \\
\hline 2.5 & 0 & 0 & 0 & 0 & 0 & 1.0 & 3.7 & 5.1 & 6.6 & 7.4 & 7.4 \\
\hline 3.5 & 0 & 0 & 0 & 0 & 1.5 & 4.4 & 8.8 & 11.8 & 17.6 & 21.3 & 22.8 \\
\hline 5 & 0 & 0.7 & 2.2 & 2.9 & 5.1 & 11.8 & 19.1 & 25.7 & 36.8 & 42.6 & 44.9 \\
\hline 6 & 0.7 & 1.5 & 2.9 & 3.7 & 5.9 & 14.0 & 23.5 & 30.9 & 44.9 & 52.9 & 55.1 \\
\hline 7 & 0.7 & 1.5 & 2.9 & 3.7 & 5.9 & 14.7 & 24.3 & 33.1 & 47.1 & 57.4 & 59.6 \\
\hline 8 & 0.7 & 1.5 & 2.9 & 3.7 & 6.6 & 17.6 & 27.2 & 38.2 & 55.1 & 66.2 & 69.1 \\
\hline 9 & 0.7 & 2.2 & 3.7 & 4.4 & 7.4 & 19.1 & 30.1 & 41.1 & 58.1 & 69.1 & 73.5 \\
\hline 10 & 0.7 & 2.2 & 4.4 & 5.1 & 8.8 & 22.8 & 34.6 & 46.3 & 64.0 & 75.0 & 79.4 \\
\hline 15 & 2.9 & 5.9 & 8.1 & 8.8 & 14.0 & 30.1 & 42.6 & 54.4 & 72.8 & 84.6 & 89.7 \\
\hline 20 & 4.4 & 8.1 & 11.0 & 11.8 & 18.9 & 35.3 & 48.5 & 61.8 & 80.1 & 91.9 & 97.1 \\
\hline \hline$\infty$ & 5.1 & 9.6 & 12.5 & 13.2 & 19.1 & 38.2 & 51.5 & 64.7 & 83.1 & 94.9 & 100.0 \\
\hline
\end{tabular}

Notes: The figures in the tables indicate the percentage of the specified period in which the joint event that the 4-quarter moving average of output growth falls below a threshold value and the 4-quarter moving average of inflation falls below a given threshold value. The last column and row, represent the marginal distributions for the single event probability of inflation and output growth respectively.

Table 3b

Bivariate Empirical Frequencies of Output Growth and Inflation: 1970q1- 1979q4 (per cent)

\begin{tabular}{|c||c|c|c|c|c|c|c|c|c|c||c|}
\hline \multicolumn{1}{|c||}{$\operatorname{Pr}(\Delta p<b)$} & \multicolumn{10}{c|}{$\operatorname{Pr}(\Delta y<a)$} \\
\cline { 2 - 13 } & -2 & 1.0 & -0.5 & 0 & 1 & 2 & 2.5 & 3 & 4 & 5 & $\infty$ \\
\hline \hline 1.5 & 0 & 0 & 0 & 0 & 0 & 0 & 0 & 0 & 0 & 0 & 0 \\
\hline 2.5 & 0 & 0 & 0 & 0 & 0 & 0 & 0 & 0 & 0 & 0 & 0 \\
\hline 3.5 & 0 & 0 & 0 & 0 & 0 & 0 & 0 & 0 & 0 & 0 & 0 \\
\hline 5 & 0 & 0 & 0 & 0 & 0 & 2.5 & 2.5 & 2.5 & 2.5 & 2.5 & 2.5 \\
\hline 6 & 0 & 0 & 0 & 0 & 0 & 2.5 & 5.0 & 5.0 & 7.5 & 7.5 & 7.5 \\
\hline 7 & 0 & 0 & 0 & 0 & 0 & 2.5 & 5.0 & 10.0 & 12.5 & 12.5 & 12.5 \\
\hline 8 & 0 & 0 & 0 & 0 & 0 & 2.5 & 5.0 & 15.0 & 25.0 & 27.5 & 30.0 \\
\hline 9 & 0 & 0 & 0 & 0 & 0 & 5.0 & 10.0 & 20.0 & 30.0 & 32.5 & 40.0 \\
\hline 10 & 0 & 0 & 0 & 0 & 0 & 10.0 & 17.5 & 30.0 & 42.5 & 45.0 & 52.5 \\
\hline 15 & 2.5 & 5 & 5 & 5.0 & 5.0 & 20.0 & 30.0 & 42.5 & 57.5 & 62.5 & 72.5 \\
\hline 20 & 2.5 & 7.5 & 10 & 10.0 & 10.0 & 30.0 & 42.5 & 60.0 & 75.0 & 80.0 & 90 \\
\hline \hline$\infty$ & 5.0 & 12.5 & 15.0 & 15.0 & 17.5 & 40.0 & 52.5 & 70.0 & 85.0 & 90.0 & 100 \\
\hline
\end{tabular}

See the notes for Table 3a. 
Table 3c

Bivariate Empirical Frequencies of Output Growth and Inflation:1980q1- 1989q4

(per cent)

\begin{tabular}{|c||c|c|c|c|c|c|c|c|c|c||c|}
\hline \multicolumn{1}{|c||}{$\operatorname{Pr}(\Delta p<b)$} & \multicolumn{10}{c|}{$\operatorname{Pr}(\Delta y<a)$} \\
\hline \hline 1.5 & 0 & -1 & -0.5 & 0 & 1 & 2 & 2.5 & 3 & 4 & 5 & $\infty$ \\
\hline 2.5 & 0 & 0 & 0 & 0 & 0 & 0 & 0 & 0 & 0 & 0 & 0.0 \\
\hline 3.5 & 0 & 0 & 0 & 0 & 0 & 0 & 0 & 0 & 2.5 & 5.0 & 10.0 \\
\hline 5 & 0 & 0 & 0 & 0 & 0 & 5.0 & 5.0 & 7.5 & 22.5 & 32.5 & 40.0 \\
\hline 6 & 0 & 0 & 0 & 0 & 0 & 7.5 & 10.0 & 15.0 & 35.0 & 47.5 & 55.5 \\
\hline 7 & 0 & 0 & 0 & 0 & 0 & 7.5 & 10.0 & 15.0 & 35.0 & 55.0 & 62.5 \\
\hline 8 & 0 & 0 & 0 & 0 & 2.5 & 15.0 & 17.5 & 25.0 & 47.5 & 67.5 & 75.0 \\
\hline 9 & 0 & 0 & 0 & 0 & 2.5 & 15.0 & 20.0 & 27.5 & 50.0 & 70.0 & 77.5 \\
\hline 10 & 0 & 0 & 0 & 0 & 2.5 & 15.0 & 20.0 & 27.5 & 50.0 & 70.0 & 77.5 \\
\hline 15 & 5 & 7.5 & 7.5 & 7.5 & 15.0 & 30.0 & 35.0 & 42.5 & 65.0 & 85.0 & 92.5 \\
\hline 20 & 10 & 12.5 & 12.5 & 12.5 & 20.0 & 37.5 & 42.5 & 50.0 & 72.5 & 92.5 & 100.0 \\
\hline \hline$\infty$ & 10 & 12.5 & 12.5 & 12.5 & 20.0 & 37.5 & 42.5 & 50.0 & 72.5 & 92.5 & 100.0 \\
\hline
\end{tabular}

See the notes for Table 3a.

Table 3d

Bivariate Empirical Frequencies of Output Growth and Inflation:1990q1-1998q4 (per cent)

\begin{tabular}{|c||c|c|c|c|c|c|c|c|c|c||c|}
\hline \multicolumn{1}{|c||}{$\operatorname{Pr}(\Delta p<b)$} & \multicolumn{10}{c|}{$\operatorname{Pr}(\Delta y<a)$} \\
\cline { 2 - 12 } & -2.0 & -1.0 & -0.5 & 0 & 1 & 2 & 2.5 & 3 & 4 & 5 & $\infty$ \\
\hline \hline 1.5 & 0 & 0 & 0 & 0 & 0 & 0 & 2.8 & 2.8 & 2.8 & 2.8 & 2.8 \\
\hline 2.5 & 0 & 0 & 0 & 0 & 0 & 2.8 & 11.1 & 13.9 & 19.4 & 22.2 & 22.2 \\
\hline 3.5 & 0 & 0 & 0 & 0 & 2.8 & 13.9 & 25.0 & 33.3 & 52.8 & 61.1 & 61.1 \\
\hline 5 & 0 & 2.8 & 8.3 & 11.1 & 16.7 & 27.8 & 41.7 & 52.8 & 75.0 & 83.3 & 83.3 \\
\hline 6 & 2.8 & 5.6 & 11.1 & 13.9 & 19.4 & 30.6 & 44.4 & 55.6 & 77.8 & 86.1 & 86.1 \\
\hline 7 & 2.8 & 5.6 & 11.1 & 13.9 & 19.4 & 30.6 & 44.4 & 55.6 & 77.8 & 86.1 & 86.1 \\
\hline 8 & 2.8 & 5.6 & 11.1 & 13.9 & 19.4 & 33.3 & 47.2 & 58.3 & 80.6 & 88.9 & 88.9 \\
\hline 9 & 2.8 & 8.3 & 13.9 & 16.7 & 22.2 & 36.1 & 50.0 & 61.1 & 83.3 & 91.7 & 91.7 \\
\hline 10 & 2.8 & 8.3 & 16.7 & 19.4 & 27.8 & 44.4 & 58.3 & 69.4 & 91.7 & 100.0 & 100.0 \\
\hline 15 & 2.8 & 8.3 & 16.7 & 19.4 & 27.8 & 44.4 & 58.3 & 69.4 & 91.7 & 100.0 & 100.0 \\
\hline 20 & 2.8 & 8.3 & 16.7 & 19.4 & 27.8 & 44.4 & 58.3 & 69.4 & 91.7 & 100.0 & 100.0 \\
\hline \hline$\infty$ & 2.8 & 8.3 & 16.7 & 19.4 & 27.8 & 44.4 & 58.3 & 69.4 & 91.7 & 100.0 & 100.0 \\
\hline
\end{tabular}

See the notes for Table 3a. 
Table 4

Cointegration Rank Statistics for the Core Model: 1965q1-1998q4

$$
\left(p_{t}-p_{t}^{o}, e_{t}, r_{t}, r_{t}^{*}, y_{t}, y_{t}^{*}, h_{t}-y_{t}, p_{t}^{*}-p_{t}^{o}\right)
$$

\begin{tabular}{|c|c||c|c|c||c|c|c|}
\hline \multicolumn{2}{|l||}{} & \multicolumn{3}{c||}{ Trace } & \multicolumn{3}{c|}{ Max } \\
\hline$H_{0}$ & $H_{1}$ & Statistic & $95 \% \mathrm{cv}$ & $90 \% \mathrm{cv}$ & Statistic & $95 \% \mathrm{cv}$ & $90 \% \mathrm{cv}$ \\
\hline$r=0$ & $r=1$ & 212.71 & 163.01 & 157.02 & 60.81 & 52.62 & 49.70 \\
\hline$r \leq 1$ & $r=2$ & 151.91 & 128.79 & 123.33 & 44.02 & 46.97 & 44.01 \\
\hline$r \leq 2$ & $r=3$ & 107.88 & 97.83 & 93.13 & 33.22 & 40.89 & 37.92 \\
\hline$r \leq 3$ & $r=4$ & 74.66 & 72.10 & 68.04 & 28.76 & 34.70 & 32.12 \\
\hline$r \leq 4$ & $r=5$ & 45.89 & 49.36 & 46.00 & 24.59 & 28.72 & 26.10 \\
\hline$r \leq 5$ & $r=6$ & 21.31 & 30.77 & 27.96 & 16.18 & 22.16 & 19.79 \\
\hline$r \leq 6$ & $r=7$ & 5.13 & 15.44 & 13.31 & 5.13 & 15.44 & 13.31 \\
\hline
\end{tabular}

Notes: The underlying $V A R$ model is of order 2 and contains unrestricted intercepts and restricted trend coefficients, with $p_{t}^{*}-p_{t}^{o}$ treated as exogenous $I(1)$ variable. The statistics are computed using 136 observations for the period 1965Q1-1998q4. "Trace" and "Max" represent Johansen's log-likelihood-based trace and maximum eigenvalue statistics, respectively, and 'cv' stands for critical value of the tests, which are obtained from Pesaran, Shin and Smith (2000). 


\section{Table 5}

Error Correction Specification for the Core Model: 1965q1-1998q4

\begin{tabular}{|c|c|c|c|c|c|c|c|}
\hline Equation & $\Delta\left(p_{t}-p_{t}^{o}\right)$ & $\Delta e_{t}$ & $\Delta r_{t}$ & $\Delta r_{t}^{*}$ & $\Delta y_{t}$ & $\Delta y_{t}^{*}$ & $\Delta\left(h_{t}-y_{t}\right)$ \\
\hline$\hat{\varepsilon}_{1, t}$ & $\begin{array}{r}-.005 \\
(.006) \\
\end{array}$ & $\begin{array}{l}.051^{\dagger} \\
(.023)\end{array}$ & $\begin{array}{l}.002 \\
(.002) \\
\end{array}$ & $\begin{array}{l}.001^{*} \\
(.001) \\
\end{array}$ & $\begin{array}{l}.014^{\dagger} \\
(.007)\end{array}$ & $\begin{array}{l}.018^{\dagger} \\
(.003)\end{array}$ & $\begin{array}{l}-.013 \\
(.010)\end{array}$ \\
\hline$\hat{\varepsilon}_{2, t}$ & $\begin{array}{l}-.568^{\dagger} \\
(.301) \\
\end{array}$ & $\begin{array}{c}1.383 \\
(1.17) \\
\end{array}$ & $\begin{array}{l}.037 \\
(.095) \\
\end{array}$ & $\begin{array}{l}.114^{\dagger} \\
(.043)\end{array}$ & $\begin{array}{l}1.052^{\dagger} \\
(.338)\end{array}$ & $\begin{array}{l}.767^{\dagger} \\
(.164) \\
\end{array}$ & $\begin{array}{l}-.369 \\
(.519) \\
\end{array}$ \\
\hline$\hat{\varepsilon}_{3, t}$ & $\begin{array}{l}.054^{\dagger} \\
(.029)\end{array}$ & $\begin{array}{l}-.183 \\
(.111) \\
\end{array}$ & $\begin{array}{l}-.012 \\
(.009) \\
\end{array}$ & $\begin{array}{l}-.005 \\
(.004) \\
\end{array}$ & $\begin{array}{c}-.141^{\dagger} \\
(.032)\end{array}$ & $\begin{array}{l}-.009 \\
(.015) \\
\end{array}$ & $\begin{array}{l}.110^{\top} \\
(.049)\end{array}$ \\
\hline$\hat{\varepsilon}_{4, t}$ & $\begin{array}{l}.020^{\dagger} \\
(.007)\end{array}$ & $\begin{array}{l}-.055 \\
(.028) \\
\end{array}$ & $\begin{array}{c}-.005^{\dagger} \\
(.002)\end{array}$ & $\begin{array}{l}-.001 \\
(.001) \\
\end{array}$ & $\begin{array}{c}-.038^{\dagger} \\
(.008)\end{array}$ & $\begin{array}{l}-.024^{\dagger} \\
(.004)\end{array}$ & $\begin{array}{l}-.001 \\
(.012) \\
\end{array}$ \\
\hline$\Delta\left(p_{t-1}-p_{t-1}^{o}\right)$ & $\begin{array}{l}.533^{\dagger} \\
(.080)\end{array}$ & $\begin{array}{l}.540^{*} \\
(.311)\end{array}$ & $\begin{array}{c}.039 \\
(.025)\end{array}$ & $\begin{array}{c}.009 \\
(.011)\end{array}$ & $\begin{array}{l}.137 \\
(.090)\end{array}$ & $\begin{array}{l}.111^{\dagger} \\
(.044)\end{array}$ & $\begin{array}{r}-.486^{\dagger} \\
(.138)\end{array}$ \\
\hline$\Delta e_{t-1}$ & $\begin{array}{c}.002 \\
(.023) \\
\end{array}$ & $\begin{array}{l}.226^{\dagger} \\
(.092)\end{array}$ & $\begin{array}{l}-.007 \\
(.007) \\
\end{array}$ & $\begin{array}{l}-.002 \\
(.003) \\
\end{array}$ & $\begin{array}{l}.010 \\
(.027) \\
\end{array}$ & $\begin{array}{l}.009 \\
(.013) \\
\end{array}$ & $\begin{array}{l}.022 \\
(.041) \\
\end{array}$ \\
\hline$\Delta r_{t-1}$ & $\begin{array}{l}.694^{\dagger} \\
(.320) \\
\end{array}$ & $\begin{array}{l}-1.469 \\
(1.244) \\
\end{array}$ & $\begin{array}{l}.142 \\
(.101) \\
\end{array}$ & $\begin{array}{l}-.073 \\
(.045) \\
\end{array}$ & $\begin{array}{l}.649^{*} \\
(.360)\end{array}$ & $\begin{array}{c}.221 \\
(.174) \\
\end{array}$ & $\begin{array}{l}-.726 \\
(.551) \\
\end{array}$ \\
\hline$\Delta r_{t-1}^{*}$ & $\begin{array}{c}-1.260^{\dagger} \\
(.624)\end{array}$ & $\begin{array}{c}3.619 \\
(2.422) \\
\end{array}$ & $\begin{array}{l}.654^{\dagger} \\
(.197)\end{array}$ & $\begin{array}{l}.459^{\dagger} \\
(.088)\end{array}$ & $\begin{array}{c}.575 \\
(.702) \\
\end{array}$ & $\begin{array}{c}.637 \\
(.340) \\
\end{array}$ & $\begin{array}{l}-.863 \\
(1.07) \\
\end{array}$ \\
\hline$\Delta y_{t-1}$ & $\begin{array}{l}.210^{\dagger} \\
(.097)\end{array}$ & $\begin{array}{l}.0168 \\
(.378) \\
\end{array}$ & $\begin{array}{l}-.019 \\
(.031) \\
\end{array}$ & $\begin{array}{l}.016 \\
(.014) \\
\end{array}$ & $\begin{array}{l}-.046 \\
(.109)\end{array}$ & $\begin{array}{c}.049 \\
(.053) \\
\end{array}$ & $\begin{array}{l}-.229 \\
(.168)\end{array}$ \\
\hline$\Delta y_{t-1}^{*}$ & $\begin{array}{l}-.084 \\
(.176) \\
\end{array}$ & $\begin{array}{l}-.773 \\
(.684) \\
\end{array}$ & $\begin{array}{l}-.062 \\
(.056) \\
\end{array}$ & $\begin{array}{l}.047^{*} \\
(.025) \\
\end{array}$ & $\begin{array}{r}.009 \\
(.198) \\
\end{array}$ & $\begin{array}{l}.071 \\
(.096) \\
\end{array}$ & $\begin{array}{l}.687^{\dagger} \\
(.303)\end{array}$ \\
\hline$\Delta\left(h_{t-1}-y_{t-1}\right)$ & $\begin{array}{c}.053 \\
.056)\end{array}$ & $\begin{array}{c}.347 \\
(.219)\end{array}$ & $\begin{array}{l}.029 \\
(.018)\end{array}$ & $\begin{array}{l}.017 \\
(.008)\end{array}$ & $\begin{array}{c}.086 \\
(.063)\end{array}$ & $\begin{array}{l}-.013 \\
(.031)\end{array}$ & $\begin{array}{l}-.243^{\dagger} \\
(.097)\end{array}$ \\
\hline$\Delta\left(p_{t}^{*}-p_{t}^{o}\right)$ & $\begin{array}{l}1.004^{\dagger} \\
(.005)\end{array}$ & $\begin{array}{c}.022 \\
(.018) \\
\end{array}$ & $\begin{array}{l}-.001 \\
(.001) \\
\end{array}$ & $\begin{array}{c}-.001^{*} \\
(.001) \\
\end{array}$ & $\begin{array}{l}.012^{\dagger} \\
(.005)\end{array}$ & $\begin{array}{c}.002 \\
(.002) \\
\end{array}$ & $\begin{array}{c}-.024^{\dagger} \\
(.008)\end{array}$ \\
\hline$\Delta\left(p_{t-1}^{*}-p_{t-1}^{o}\right)$ & $\begin{array}{c}-.541^{\dagger} \\
(.080) \\
\end{array}$ & $\begin{array}{l}-.525 \\
(.311) \\
\end{array}$ & $\begin{array}{l}-.038 \\
(.025) \\
\end{array}$ & $\begin{array}{l}-.01 \\
(.011) \\
\end{array}$ & $\begin{array}{l}-.145 \\
(.090) \\
\end{array}$ & $\begin{array}{r}-.116^{\dagger} \\
(.043) \\
\end{array}$ & $\begin{array}{l}.502^{\dagger} \\
(.138) \\
\end{array}$ \\
\hline$\overline{\bar{R}}^{2}$ & .669 & .104 & .106 & .334 & .239 & .412 & .278 \\
\hline Benchmark $\bar{R}^{2}$ & 0.604 & .032 & .082 & .229 & .023 & .243 & .00 \\
\hline$\hat{\sigma}$ & .008 & .005 & .003 & .001 & .009 & .005 & .014 \\
\hline$\chi_{S C}^{2}[4]$ & 1.61 & 0.39 & 3.51 & $11.68^{\dagger}$ & 3.28 & 1.13 & 5.44 \\
\hline$\chi_{F F}^{2}[1]$ & 0.37 & 0.14 & 0.86 & $5.26^{\dagger}$ & 0.08 & 3.25 & 0.56 \\
\hline$\chi_{N}^{2}[2]$ & $55.89^{\dagger}$ & $11.58^{\dagger}$ & $12.65^{\dagger}$ & $27.96^{\dagger}$ & $104.28^{\dagger}$ & $8.98^{\dagger}$ & $27.83^{\dagger}$ \\
\hline$\chi_{H}^{2}[1]$ & 0.28 & 1.57 & 4.75 & $8.04^{\dagger}$ & 0.65 & .92 & 0.09 \\
\hline
\end{tabular}

Notes: The four error correction terms are given by

$$
\begin{aligned}
& \widehat{\varepsilon}_{1, t+1}=p_{t}-p_{t}^{*}-e_{t}-4.9985 \\
& \widehat{\varepsilon}_{2, t+1}=r_{t}-r_{t}^{*}-0.0056, \quad \widehat{\varepsilon}_{3, t+1}=y_{t}-y_{t}^{*}+0.0305 \\
& \widehat{\varepsilon}_{4, t+1}=h_{t}-y_{t}+{ }_{(11.34)}^{39.0293} r_{t}+{ }_{(0.001)}^{0.00715} t+0.3086
\end{aligned}
$$

Standard errors are given in parenthesis. "*" indicates significance at the $10 \%$ level, and "†" indicates significance at the $5 \%$ level. The diagnostics are chi-squared statistics for serial correlation (SC), functional form (FF), normality (N) and heteroscedasticity (H). The $\bar{R}^{2}$ for the $\Delta\left(p_{t}-p_{t}^{o}\right)$ equations refers to the $\Delta p_{t}$ equation.

The benchmark $\bar{R}^{2 \prime} s$ are computed using univariate ARIMA (p,1,q) models where $\mathrm{p}$ and $\mathrm{q}$ are estimated by searching over $\mathrm{p}, \mathrm{q}=0,1,2,3$ and 4 , using AIC as the model selection criteria. 
Table 6

Error Correction Specification for the Restricted Core Model: 1965q1-1998q4

\begin{tabular}{|c|c|c|c|c|c|c|c|}
\hline Equation & $\Delta\left(p_{t}-p_{t}^{o}\right)$ & $\Delta e_{t}$ & $\Delta r_{t}$ & $\Delta r_{t}^{*}$ & $\Delta y_{t}$ & $\Delta y_{t}^{*}$ & $\Delta\left(h_{t}-y_{t}\right)$ \\
\hline$\hat{\varepsilon}_{1, t}$ & $\begin{array}{l}-.006 \\
(.005) \\
\end{array}$ & $\begin{array}{l}.037^{*} \\
(.019) \\
\end{array}$ & $\begin{array}{c}.001 \\
(.002) \\
\end{array}$ & $\begin{array}{l}.001^{*} \\
(.001)\end{array}$ & $\begin{array}{l}.015^{\dagger} \\
(.005)\end{array}$ & $\begin{array}{l}.018^{\dagger} \\
(.003)\end{array}$ & $\begin{array}{l}-.002 \\
(.010) \\
\end{array}$ \\
\hline$\hat{\varepsilon}_{2, t}$ & $\begin{array}{r}-.589^{\dagger} \\
(.267) \\
\end{array}$ & $\begin{array}{c}.601 \\
(1.01) \\
\end{array}$ & $\begin{array}{l}.005 \\
(.083)\end{array}$ & $\begin{array}{l}.114^{\dagger} \\
(.043)\end{array}$ & $\begin{array}{l}.989^{\dagger} \\
(.291) \\
\end{array}$ & $\begin{array}{l}.767^{\dagger} \\
(.164)\end{array}$ & $\begin{array}{l}.049 \\
(.451)\end{array}$ \\
\hline$\hat{\varepsilon}_{3, t}$ & $\begin{array}{l}.052^{*} \\
(.028) \\
\end{array}$ & $\begin{array}{l}-.183^{*} \\
(.107) \\
\end{array}$ & $\begin{array}{l}-.007 \\
(.009) \\
\end{array}$ & $\begin{array}{l}-.005 \\
(.004) \\
\end{array}$ & $\begin{array}{c}-.127^{\dagger} \\
(.031) \\
\end{array}$ & $\begin{array}{l}-.009 \\
(.015) \\
\end{array}$ & $\begin{array}{l}.079^{*} \\
(.048) \\
\end{array}$ \\
\hline$\hat{\varepsilon}_{4, t}$ & $\begin{array}{l}.019^{\dagger} \\
(.006)\end{array}$ & $\begin{array}{l}-.039^{*} \\
(.021) \\
\end{array}$ & $\begin{array}{r}-.003^{\dagger} \\
(.002) \\
\end{array}$ & $\begin{array}{l}-.001 \\
(.001) \\
\end{array}$ & $\begin{array}{l}-.032^{\dagger} \\
(.006) \\
\end{array}$ & $\begin{array}{c}-.024^{\dagger} \\
(.004) \\
\end{array}$ & $\begin{array}{r}-.017^{*} \\
(.009) \\
\end{array}$ \\
\hline$\Delta\left(p_{t-1}-p_{t-1}^{o}\right)$ & $\begin{array}{l}.546^{\dagger} \\
(.072)\end{array}$ & - & - & - & - & $\begin{array}{l}.092^{\dagger} \\
(.037)\end{array}$ & $\begin{array}{r}-.336^{\dagger} \\
(.114)\end{array}$ \\
\hline$\Delta e_{t-1}$ & - & $\begin{array}{l}.213^{\dagger} \\
(.076)\end{array}$ & - & - & - & - & \\
\hline$\Delta r_{t-1}$ & $\begin{array}{l}.714^{\dagger} \\
(.289) \\
\end{array}$ & - & - & - & $\begin{array}{l}.411^{*} \\
(.257) \\
\end{array}$ & - & - \\
\hline$\Delta r_{t-1}^{*}$ & $\begin{array}{c}-1.163^{\dagger} \\
(.529)\end{array}$ & - & $\begin{array}{l}.594^{\dagger} \\
(.158)\end{array}$ & $\begin{array}{l}.419^{\dagger} \\
(.084)\end{array}$ & - & $\begin{array}{l}.755^{\dagger} \\
(.271)\end{array}$ & - \\
\hline$\Delta y_{t-1}$ & $\begin{array}{l}.151^{\dagger} \\
(.071)\end{array}$ & - & - & - & - & $\begin{array}{l}.078^{\dagger} \\
(.037) \\
\end{array}$ & - \\
\hline$\Delta y_{t-1}^{*}$ & - & - & - & $\begin{array}{l}.057^{\dagger} \\
(.025)\end{array}$ & - & - & - \\
\hline$\Delta\left(h_{t-1}-y_{t-1}\right)$ & - & - & - & $\begin{array}{l}.011^{\dagger} \\
(.006) \\
\end{array}$ & $\begin{array}{l}.114^{\dagger} \\
(.046) \\
\end{array}$ & - & $\begin{array}{r}-.199^{\dagger} \\
(.079) \\
\end{array}$ \\
\hline$\Delta\left(p_{t}^{*}-p_{t}^{o}\right)$ & $\begin{array}{l}1.005^{\dagger} \\
(.004)\end{array}$ & - & - & - & $\begin{array}{l}.009^{\dagger} \\
(.005)\end{array}$ & - & $\begin{array}{c}-.027^{\dagger} \\
(.008)\end{array}$ \\
\hline$\Delta\left(p_{t-1}^{*}-p_{t-1}^{o}\right)$ & $\begin{array}{l}-.556^{\dagger} \\
(.072) \\
\end{array}$ & - & - & - & - & $\begin{array}{r}-.095^{\dagger} \\
(.037) \\
\end{array}$ & $\begin{array}{l}.346^{\dagger} \\
(.113) \\
\end{array}$ \\
\hline $\bar{R}^{2}$ & .673 & .071 & .101 & .316 & .231 & .413 & .261 \\
\hline$\hat{\sigma}$ & .008 & .005 & .003 & .001 & .009 & .004 & .014 \\
\hline
\end{tabular}

Notes: The four error correction terms are given by

$$
\begin{aligned}
& \widehat{\varepsilon}_{1, t+1}=p_{t}-p_{t}^{*}-e_{t}-4.9985 \\
& \widehat{\varepsilon}_{2, t+1}=r_{t}-r_{t}^{*}-0.0056, \quad \widehat{\varepsilon}_{3, t+1}=y_{t}-y_{t}^{*}+0.0305, \\
& \widehat{\varepsilon}_{4, t+1}=h_{t}-y_{t}+{ }_{(11.34)}^{39.0293} r_{t}+{ }_{(0.001)}^{0.00715} t+0.3086
\end{aligned}
$$

Estimated using SURE. Standard errors are given in parenthesis. "** indicates significance at the $10 \%$ level, and "†" indicates significance at the $5 \%$ level. The diagnostics are chi-squared statistics for serial correlation (SC), functional form $(\mathrm{FF})$, normality (N) and heteroscedasticity (H). The $\bar{R}^{2}$ for the $\Delta\left(p_{t}-p_{t}^{o}\right)$ equations refers to the $\Delta p_{t}$ equation. 


\section{Table 7}

\section{Point and Interval Forecasts of Inflation, Output Growth and Interest Rates}

(Unrestricted Model, 65q1-98q4)

\begin{tabular}{|c|c|c|c|}
\hline & Inflation (\%pa) & Output Growth (\%pa) & Interest Rate \\
\hline izon & $\Delta p_{T+h}$ & $\Delta \ln \left(G D P_{T+h}\right)$ & $R_{T+h}$ \\
\hline $1999 \mathrm{q} 1$ & $2.927(4.498,1.356)$ & $1.223(2.989,-0.544)$ & $6.252(6.781,5.726)$ \\
\hline $1999 \mathrm{q} 2$ & $2.890(5.747,0.033)$ & $1.195(3.439,-1.048)$ & $5.734(6.673,4.802)$ \\
\hline $1999 \mathrm{q} 3$ & $952(7.0$ & $1.199(3.837,-1.440)$ & $5.350(6.674,4.043)$ \\
\hline $1999 q 4$ & $3.358(8.550,-1.834)$ & $1.612(4.645,-1.422)$ & $5.253(6.941,3.592)$ \\
\hline $2000 \mathrm{q} 1$ & $1(9.4$ & $801(5.165,-1.563)$ & $5.202(7.163,3.276)$ \\
\hline $2000 \mathrm{q} 2$ & $.221(10.081,-1.638)$ & $1.929(5.641,-1.782)$ & $5.166(7.324,3.052)$ \\
\hline $2000 \mathrm{q} 3$ & $437(10.4$ & $2.043(6.003,-1.916)$ & $5.148(7$. \\
\hline $2000 \mathrm{q} 4$ & $681(10.7$ & $6.232,-1.992)$ & $5.143(7$. \\
\hline $2001 q 1$ & $92(10.9$ & $2.158(6.356,-2.039)$ & $5.145(7.6$ \\
\hline $2001 \mathrm{q} 2$ & $9(11.1$ & $2.165(6.410,-2.080)$ & $5.150(7$. \\
\hline $2001 \mathrm{q} 3$ & $883(11.2$ & $2.149(6 . .422,-2.124)$ & $5.155(7$. \\
\hline $2001 q 4$ &,-1 & $2.121(6.412,-2.171)$ & $5,2.545)$ \\
\hline $2002 q 1$ & $068(11.5$ & $2.087(6.391,2.217)$ & $5.153(7$. \\
\hline $2002 q 2$ & $154(11.6$ & $2.054(6.367,-2.258)$ & $5.142(7$. \\
\hline $2002 \mathrm{q} 3$ & -1 . & $2.025(6.344,-2.293)$ & $5.124(7.911,2.409)$ \\
\hline $2002 q 4$ & $308(11.7$ & $2.003(6.325,-2.319)$ & $5.100(7.916,2.358)$ \\
\hline $2003 \mathrm{q} 1$ & $374(11.8$ & $1.986(6.311,-2.338)$ & $5.072(7$. \\
\hline $2003 \mathrm{q} 2$ & $431(11.919,-1.057)$ & $1.976(6.301,-2.350)$ & $5.038(7.908,2.245)$ \\
\hline $2003 \mathrm{q} 3$ & $481(11.9$ & $1.970(6.297,-2.358)$ & $5.002(7.898,2.184)$ \\
\hline $2003 q 4$ & $524(12.021,-0.9$ & $1.967(6.295,-2.361)$ & $4.964(7.884,2.122)$ \\
\hline $2004 q 1$ & $610(12.062,-0.940)$ & $1.968(6.297,-2.361)$ & $4.923(7.869,2.058)$ \\
\hline $2003 q^{2}$ & $593(12.098,-0.911)$ & $1.970(6.299,-2.359)$ & $4.882(7.852,1.993)$ \\
\hline $2004 \mathrm{q} 3$ & $5.621(12.129,-0.886)$ & $1.974(6.304,-2.356)$ & $4.839(7.834,1.928)$ \\
\hline $2004 q 4$ & $5.646(12.156,-0.864)$ & $1.978(6.309,-2.353)$ & $4.796(7.816,1.862)$ \\
\hline
\end{tabular}

Notes: Forecasts are based on the unrestricted model of Table 5. The first set of numbers reported in each column are the point forecasts and the numbers in parenthesis are the upper and lower $95 \%$ confidence intervals, respectively. The point forecasts refer to the 4-quarter moving average rate of inflation defined as $100\left[\left(p_{T+h}-p_{T+h-4}\right)\right]$, where $p_{T}$ is the natural logarithm of the retail price index in $1998 \mathrm{q} 4$ and $p_{T+h}$, $\mathrm{h}=1,2, \ldots$, are the figures for the subsequent quarters. The point forecasts for output growth refer to the 4-quarter moving average growth rate defined as $100\left[\ln \left(G D P_{T+h} / G D P_{T+h-4}\right)\right]$, where $G D P_{T}$ is the real Gross Domestic Product in 1998q1, and $G D P_{T+h}, \mathrm{~h}=1,2, . .$, . are the GDP figures for the subsequent quarters computed from the forecasts of per capita output, $y_{T+h}$, assuming a population growth of $0.21 \%$ per annum. The point forecasts for interest rates refer to the 4-quarter moving average forecast value of the 90-day Treasury average discount rate, $R_{T+h}$, defined as $R_{T+h}=100\left[\exp \left(4 \widetilde{r}_{T+h}\right)-1\right]$ where $\widetilde{r}_{T+h}=\left(r_{T+h}+r_{T+h-1}+r_{T+h-2}+r_{T+h-3}\right) / 4$. 
Table 8. Probability Estimates of Single and Joint Events

Involving Inflation and Output Growth (Unrestricted Model, 65q1-98q4)

\begin{tabular}{|c|c|c|c|c|c|c|c|}
\hline \multirow{2}{*}{$\begin{array}{l}\text { Forecast } \\
\text { Horizon }\end{array}$} & \multicolumn{2}{|c|}{$\operatorname{Pr}(1.5<\Delta p<3.5)$} & \multicolumn{2}{|c|}{$\operatorname{Pr}(\Delta \ln (G D P)>0)$} & \multirow[t]{2}{*}{$\operatorname{Pr}$} & \multicolumn{2}{|c|}{$\begin{array}{c}\Delta \ln (G D P)>0 \\
1.5<\Delta p<3.5\end{array}$} \\
\hline & PPL & $\mathrm{BPD}$ & PPL & $\mathrm{BPD}$ & & PPL & $\mathrm{BPD}$ \\
\hline 1999q1 & 0.714 & 0.693 & 0.916 & 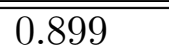 & & 0.663 & 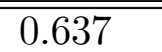 \\
\hline $1999 \mathrm{q} 2$ & 0.721 & 0.646 & 0.911 & 0.877 & & 0.666 & 0.580 \\
\hline $1999 \mathrm{q} 3$ & 0.725 & 0.576 & 0.918 & 0.868 & & 0.673 & 0.512 \\
\hline $1999 q 4$ & 0.631 & 0.455 & 0.970 & 0.920 & & 0.619 & 0.427 \\
\hline $2000 q 1$ & 0.385 & 0.311 & 0.899 & 0.864 & & 0.361 & 0.282 \\
\hline $2000 \mathrm{q} 2$ & 0.299 & 0.251 & 0.921 & 0.877 & & 0.288 & 0.234 \\
\hline $2000 \mathrm{q} 3$ & 0.244 & 0.215 & 0.927 & 0.877 & & 0.237 & 0.202 \\
\hline $2000 \mathrm{q} 4$ & 0.210 & 0.190 & 0.930 & 0.879 & & 0.204 & 0.180 \\
\hline $2001 q 1$ & 0.179 & 0.168 & 0.935 & 0.879 & & 0.175 & 0.161 \\
\hline $2001 q 2$ & 0.160 & 0.151 & 0.938 & 0.878 & & 0.157 & 0.146 \\
\hline $2001 q 3$ & 0.136 & 0.136 & 0.937 & 0.878 & & 0.133 & 0.132 \\
\hline $2001 q 4$ & 0.120 & 0.121 & 0.935 & 0.880 & & 0.118 & 0.118 \\
\hline $2002 q 1$ & 0.105 & 0.109 & 0.933 & 0.882 & & 0.103 & 0.106 \\
\hline $2002 q 2$ & 0.089 & 0.098 & 0.928 & 0.884 & & 0.088 & 0.096 \\
\hline $2002 q 3$ & 0.085 & 0.089 & 0.935 & 0.888 & & 0.082 & 0.087 \\
\hline $2002 q 4$ & 0.075 & 0.081 & 0.927 & 0.891 & & 0.073 & 0.079 \\
\hline $2003 q 1$ & 0.070 & 0.075 & 0.925 & 0.895 & & 0.069 & 0.074 \\
\hline $2003 q 2$ & 0.059 & 0.071 & 0.930 & 0.898 & & 0.058 & 0.069 \\
\hline $2003 q 3$ & 0.055 & 0.067 & 0.926 & 0.902 & & 0.054 & 0.066 \\
\hline $2003 q 4$ & 0.055 & 0.064 & 0.926 & 0.905 & & 0.054 & 0.063 \\
\hline $2004 q 1$ & 0.049 & 0.062 & 0.931 & 0.908 & & 0.048 & 0.060 \\
\hline $2003 q 2$ & 0.049 & 0.059 & 0.927 & 0.910 & & 0.048 & 0.058 \\
\hline $2004 q 3$ & 0.048 & 0.057 & 0.934 & 0.913 & & 0.048 & 0.055 \\
\hline $2004 q 4$ & 0.042 & 0.055 & 0.927 & 0.915 & & 0.041 & 0.054 \\
\hline
\end{tabular}

Notes: The probability estimates for output growth refer to the 4-quarter moving averages defined as $\operatorname{Pr}\left[\ln \left(G D P_{T+h} / G D P_{T+h-4}\right)>0\right]$, where $G D P_{T}$ is the real Gross Domestic Product in 1998q4 and $G D P_{T+h}, \mathrm{~h}=1,2, \ldots$, are the GDP figures for the subsequent quarters computed from the forecasts of per capita output, assuming a population growth of $0.21 \%$ per annum. The probability estimates for inflation are the 4-quarter moving average defined as $\operatorname{Pr}\left(1.5<p_{T+h}-p_{T+h-4}<3.5\right)$, where $p$ is the natural logarithm of the retail price index. The estimates given under the heading PPL are based on the "Profile Predictive Likelihood" and do not allow for parameter uncertainty. The estimates under the heading BPD are based on the "Bootstrap Predictive Density" and account for parameter uncertainty. The parameter uncertainty (when applicable) is taken into account through the parametric re-sampling draws from the historic residuals with 400 replications, whereas the future uncertainty is taken into account using parametric stochastic draws from the in-sample residuals with 10,000 replications for PPL and/or 1,000 replications for BPD. See the Appendix for further details. 
Table 9. Probability Estimates of Single and Joint Events

Involving Inflation and Output Growth (Unrestricted Model, 85q1-98q4)

\begin{tabular}{|c|c|c|c|c|c|c|c|}
\hline \multirow{2}{*}{$\begin{array}{l}\text { Forecast } \\
\text { Horizon }\end{array}$} & \multicolumn{2}{|c|}{$\operatorname{Pr}(1.5<\Delta p<3.5)$} & \multicolumn{2}{|c|}{$\operatorname{Pr}(\Delta \ln (G D P)>0)$} & \multirow[t]{2}{*}{$\operatorname{Pr}$} & \multicolumn{2}{|c|}{$\begin{array}{c}\Delta \ln (G D P)>0 \\
1.5<\Delta p<3.5\end{array}$} \\
\hline & $\mathrm{PPL}$ & $\mathrm{BPD}$ & $\mathrm{PPL}$ & $\mathrm{BPD}$ & & PPL & $\mathrm{BPD}$ \\
\hline$\overline{1999 q 1}$ & 0.935 & 0.895 & 0.998 & $\overline{0.994}$ & & 0.933 & $\overline{00.889}$ \\
\hline $1999 \mathrm{q} 2$ & 0.941 & 0.773 & 1.00 & 0.981 & & 0.941 & 0.759 \\
\hline $1999 \mathrm{q} 3$ & 0.945 & 0.674 & 1.00 & 0.944 & & 0.944 & 0.642 \\
\hline $1999 \mathrm{q} 4$ & 0.933 & 0.578 & 1.00 & 0.939 & & 0.934 & 0.556 \\
\hline $2000 \mathrm{q} 1$ & 0.542 & 0.395 & 1.00 & 0.903 & & 0.541 & 0.379 \\
\hline $2000 \mathrm{q} 2$ & 0.426 & 0.351 & 0.923 & 0.853 & & 0.424 & 0.331 \\
\hline $2000 \mathrm{q} 3$ & 0.286 & 0.287 & 0.990 & 0.838 & & 0.283 & 0.272 \\
\hline $2000 \mathrm{q} 4$ & 0.173 & 0.224 & 0.985 & 0.828 & & 0.171 & 0.213 \\
\hline $2001 \mathrm{q} 1$ & 0.123 & 0.197 & 0.976 & 0.817 & & 0.121 & 0.186 \\
\hline $2001 \mathrm{q} 2$ & 0.103 & 0.185 & 0.970 & 0.825 & & 0.101 & 0.174 \\
\hline $2001 \mathrm{q} 3$ & 0.086 & 0.178 & 0.961 & 0.834 & & 0.083 & 0.168 \\
\hline $2001 \mathrm{q} 4$ & 0.078 & 0.175 & 0.959 & 0.846 & & 0.076 & 0.167 \\
\hline $2002 q 1$ & 0.080 & 0.174 & 0.960 & 0.858 & & 0.077 & 0.166 \\
\hline $2002 q^{2}$ & 0.079 & 0.174 & 0.964 & 0.872 & & 0.076 & 0.167 \\
\hline $2002 q 3$ & 0.086 & 0.174 & 0.971 & 0.888 & & 0.083 & 0.168 \\
\hline $2002 q 4$ & 0.089 & 0.173 & 0.974 & 0.902 & & 0.087 & 0.168 \\
\hline $2003 q 1$ & 0.098 & 0.175 & 0.977 & 0.915 & & 0.097 & 0.171 \\
\hline $2003 q^{2}$ & 0.100 & 0.174 & 0.983 & 0.928 & & 0.098 & 0.170 \\
\hline $2003 \mathrm{q} 3$ & 0.103 & 0.173 & 0.985 & 0.940 & & 0.101 & 0.169 \\
\hline $2003 q^{4}$ & 0.119 & 0.172 & 0.991 & 0.949 & & 0.118 & 0.169 \\
\hline $2004 q 1$ & 0.113 & 0.169 & 0.994 & 0.957 & & 0.112 & 0.166 \\
\hline $2003 q^{2}$ & 0.124 & 0.166 & 0.993 & 0.962 & & 0.124 & 0.165 \\
\hline $2004 q 3$ & 0.121 & 0.165 & 0.996 & 0.966 & & 0.121 & 0.163 \\
\hline $2004 q 4$ & 0.115 & 0.164 & 0.996 & 0.969 & & 0.115 & 0.162 \\
\hline
\end{tabular}

See the notes to Table 8 . 
Figure 1. Inflation, Output Growth and Interest Rates: 1965q1-1998q4

Fig 1a: Four Quarter Moving Average Inflation

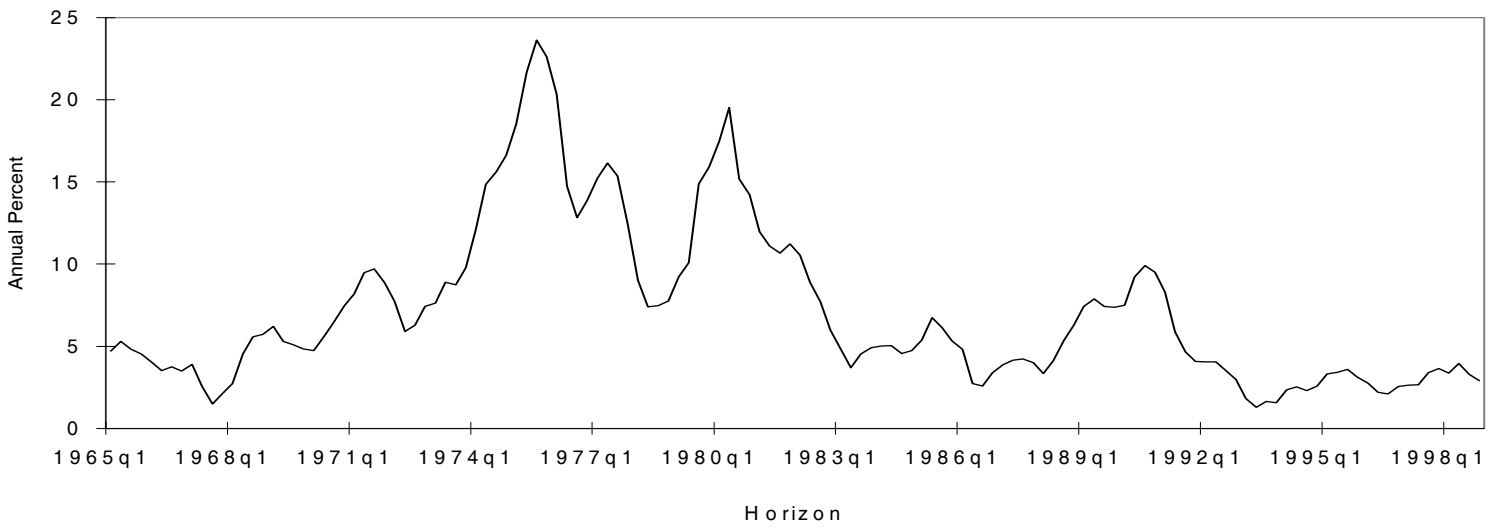

Fig 1 b: Four Quarter Moving Average Output Growth

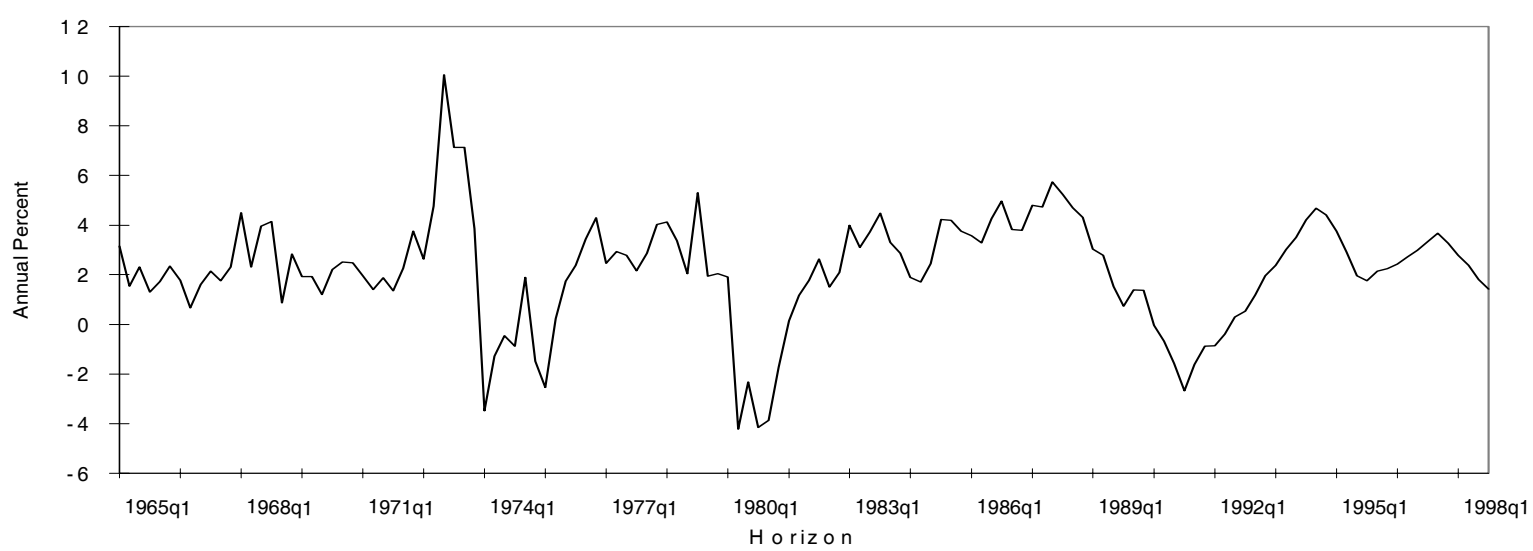

Fig 1 c: Four Quarter Moving Average Interest Rates

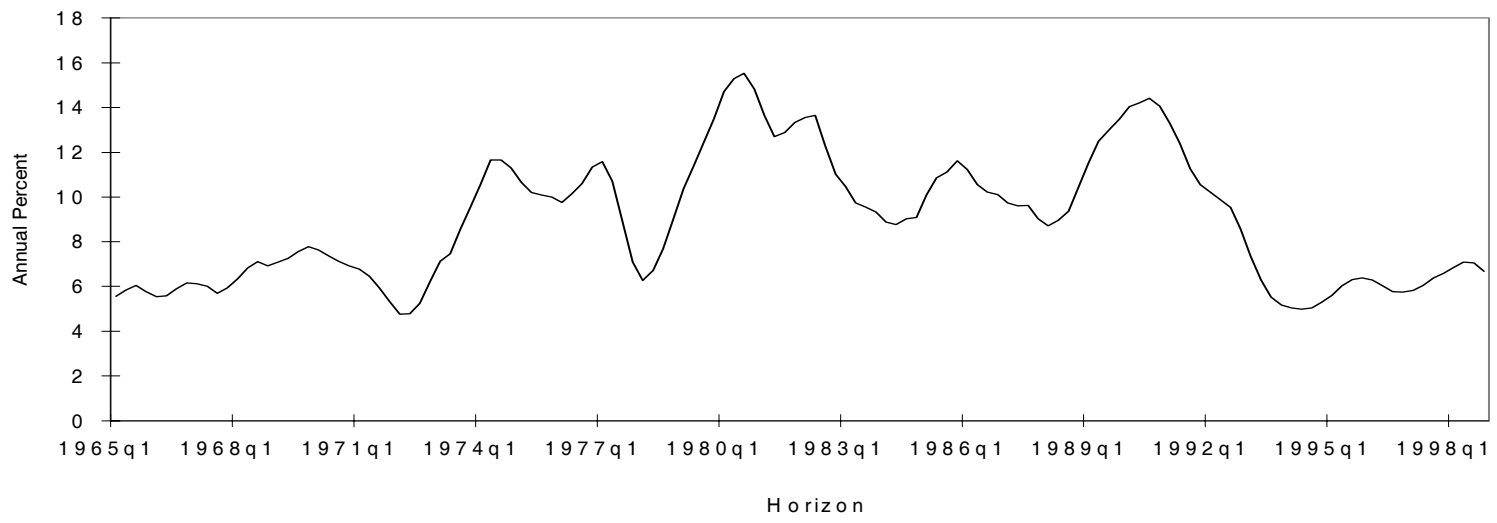


Figure 2a. Bootstrap Predictive Distribution Functions for Inflation Forecasts at Different Horizons

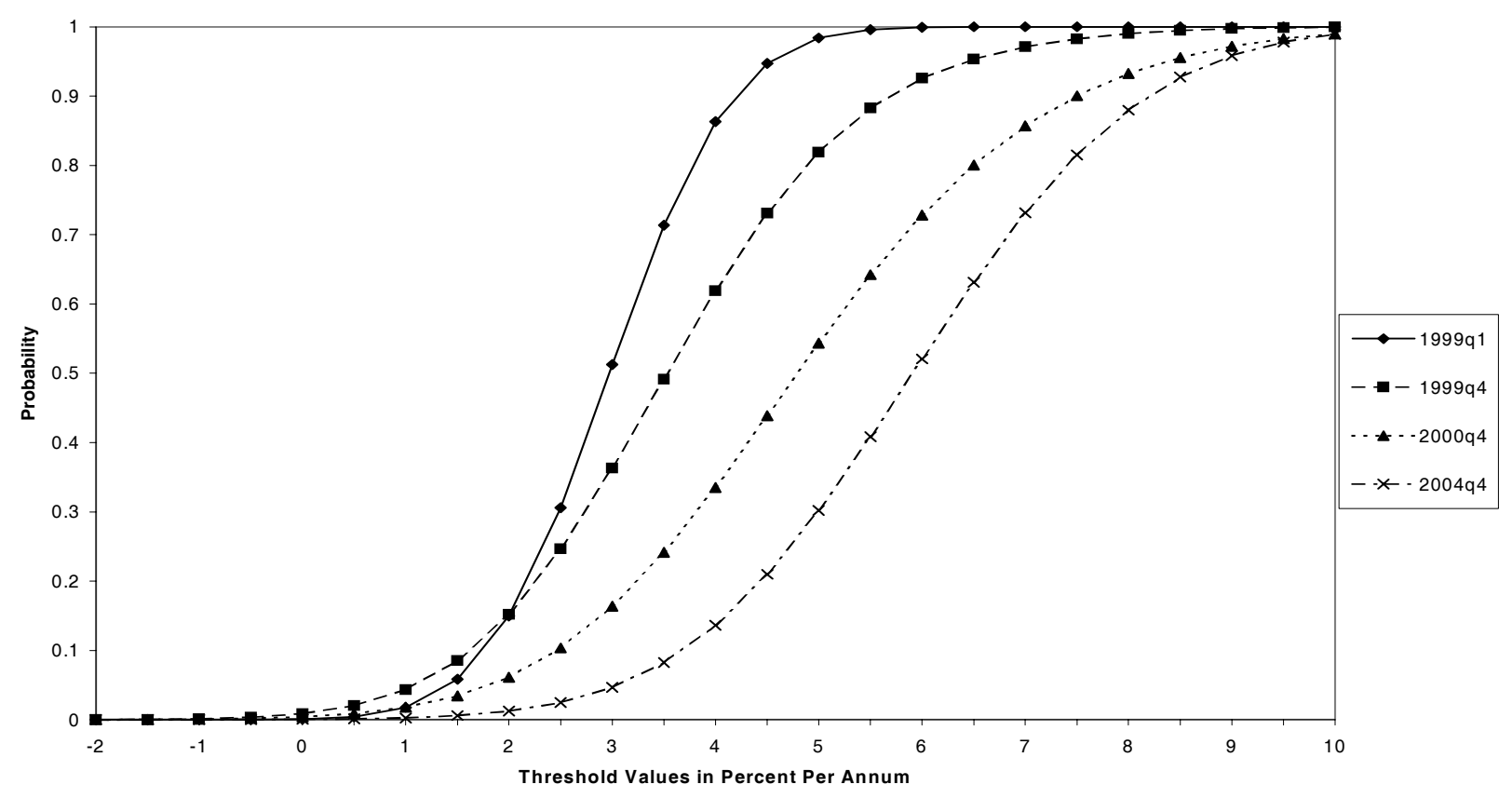

Figure 2b. Bootstrap Predictive Distribution Functions for

Output Growth Forecasts at Different Horizons

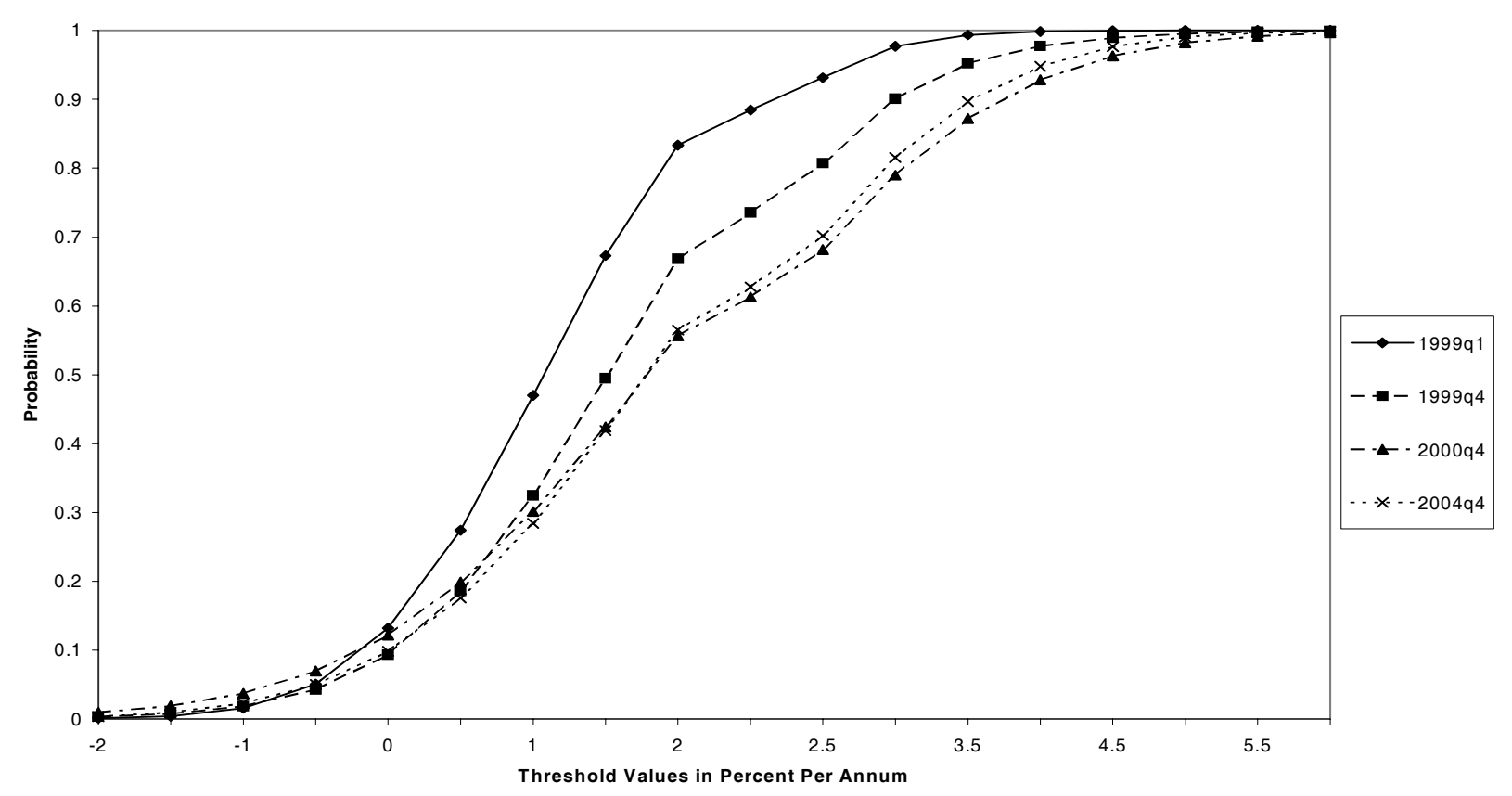


Figure 2c. Bootstrap Predictive Distribution Functions for Interest Rate Forecasts at Different Horizons

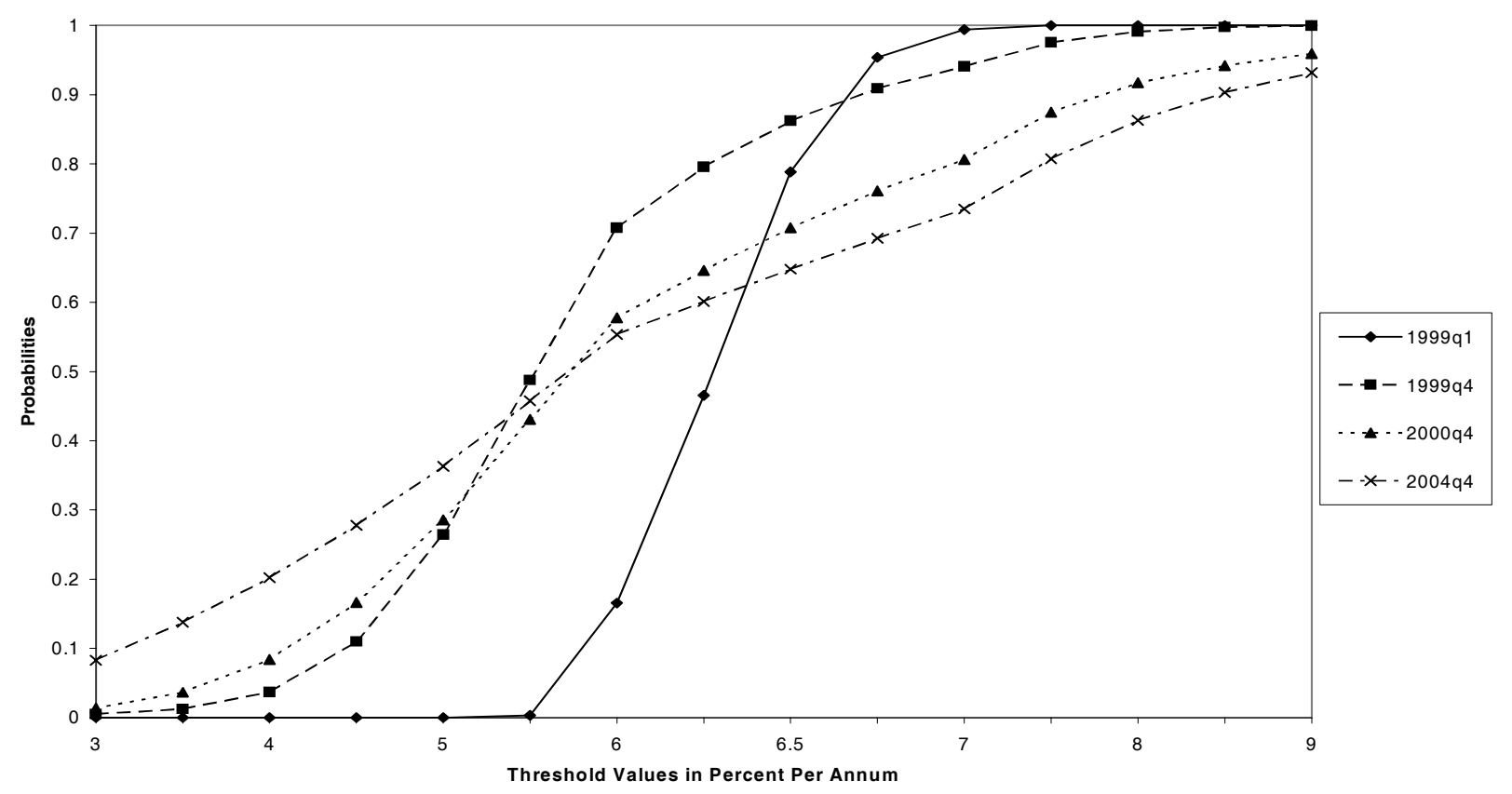


Figure 3a. Probability Estimates of Inflation Falling between $1.5 \%$ and $3.5 \%$

(Unrestricted Model, 65q1-98q4)

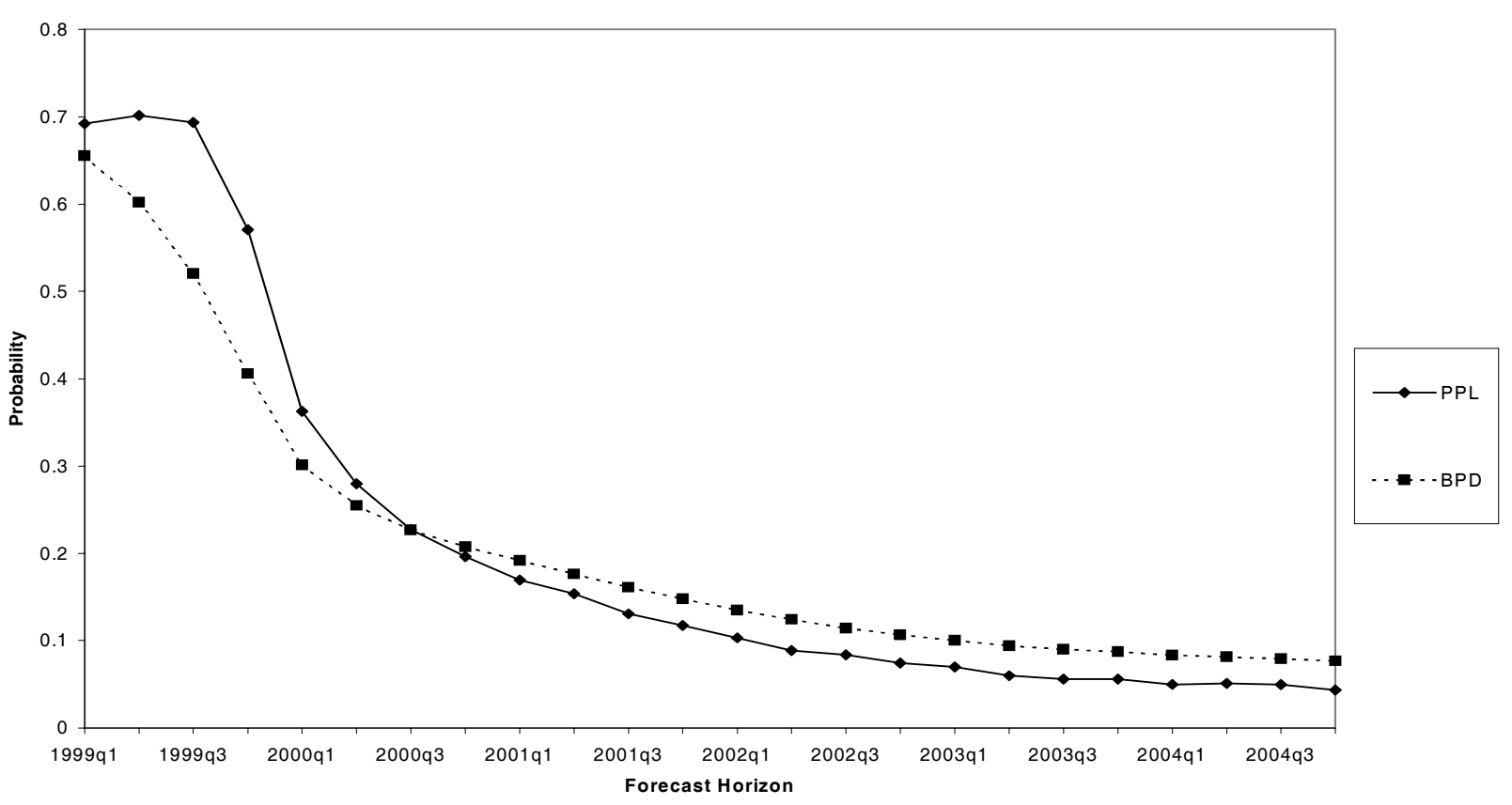

Figure 3b. Probability Estimates of Output Growth being Positive

(Unrestricted Model, 65q1-98q4)

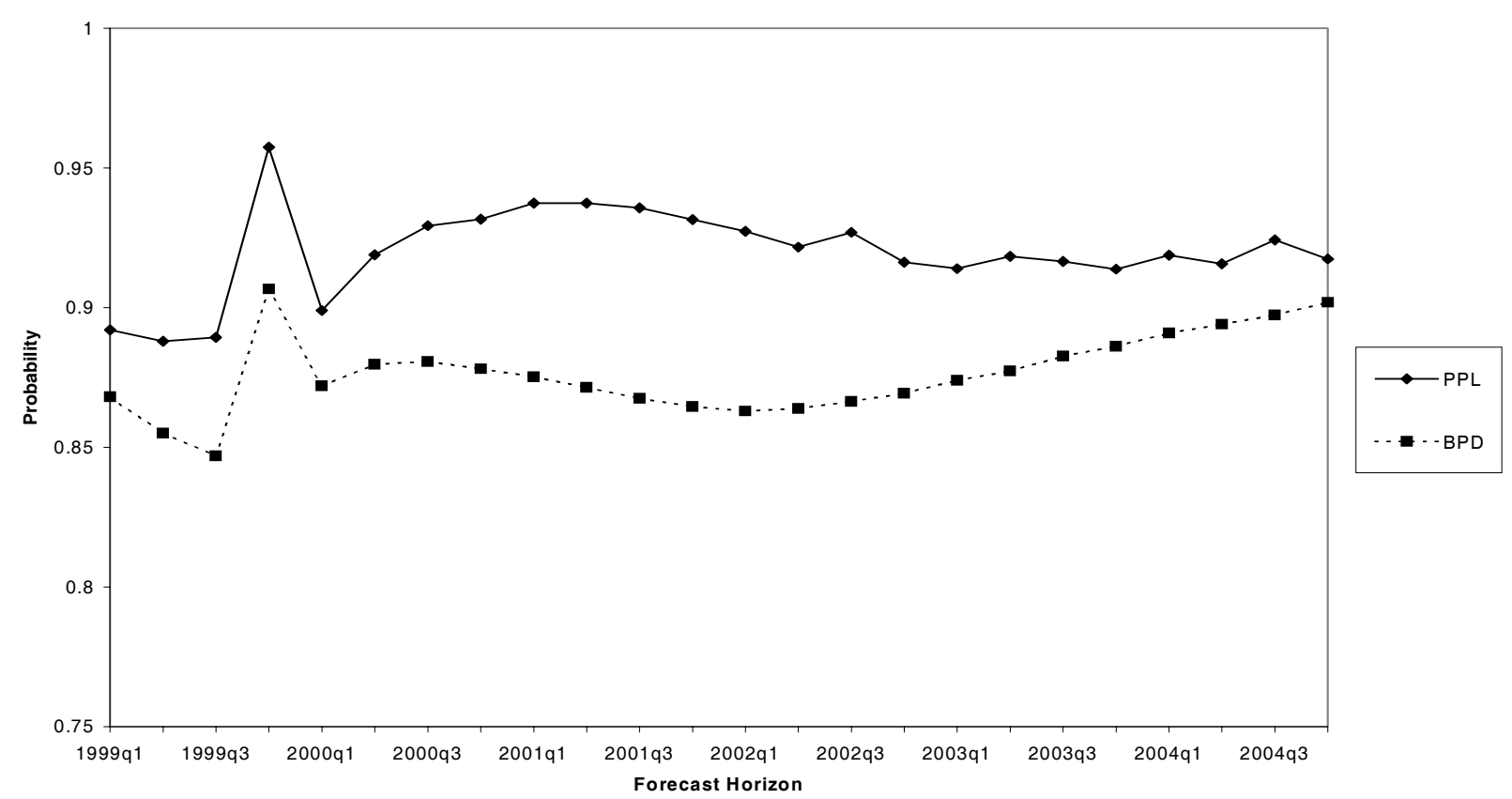


Figure 3c. Probability Estimates of Inflation Falling between 1.5\% and 3.5\% and Output Growth being Positive (Unrestricted Model, 65q1-98q4)

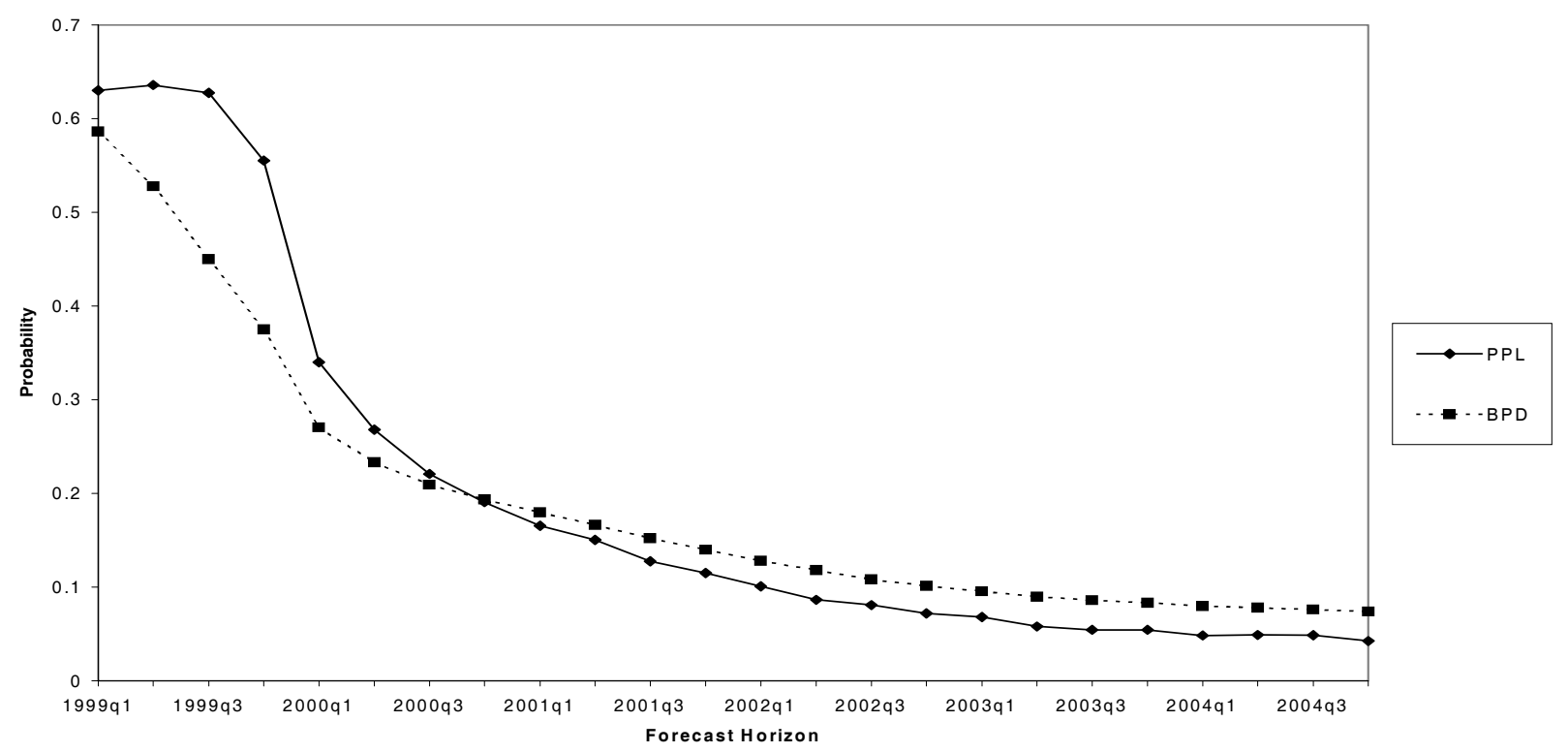

Figure 3d. The Neutrality Index, $\frac{\operatorname{Pr}(\Delta \ln (G D P)>0 \%) \cdot \operatorname{Pr}(1.5 \%<\Delta p<3.5 \%)}{\operatorname{Pr}(\Delta \ln (G D P)>0 \%, 1.5 \%<\Delta p<3.5 \%)}$

(Unrestricted Model, 65q1-98q4)

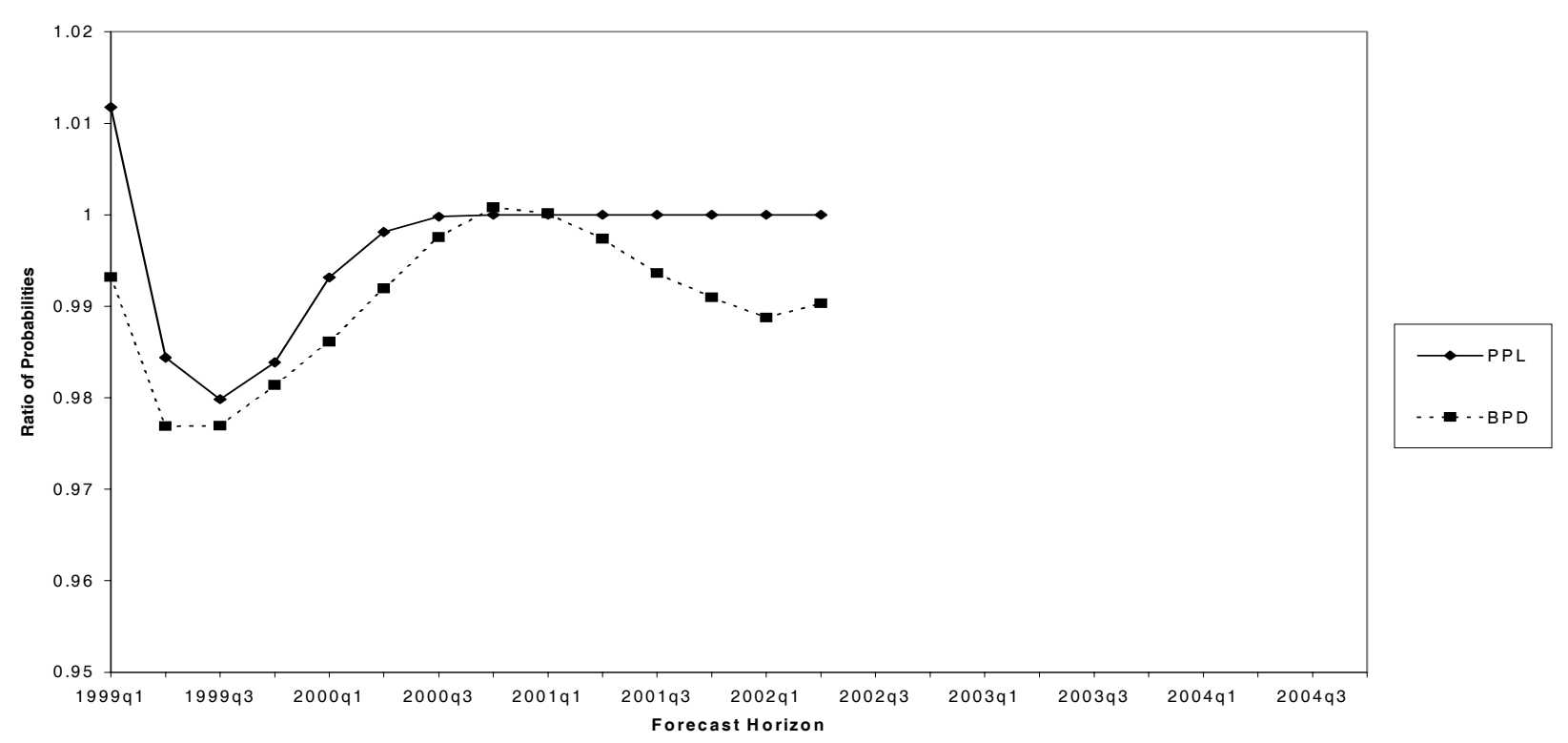


Figure 4a. BPD Probability Estimates of Inflation Falling between $1.5 \%$ and $3.5 \%$ (Restricted and Unrestricted Models, 65q1-98q4)

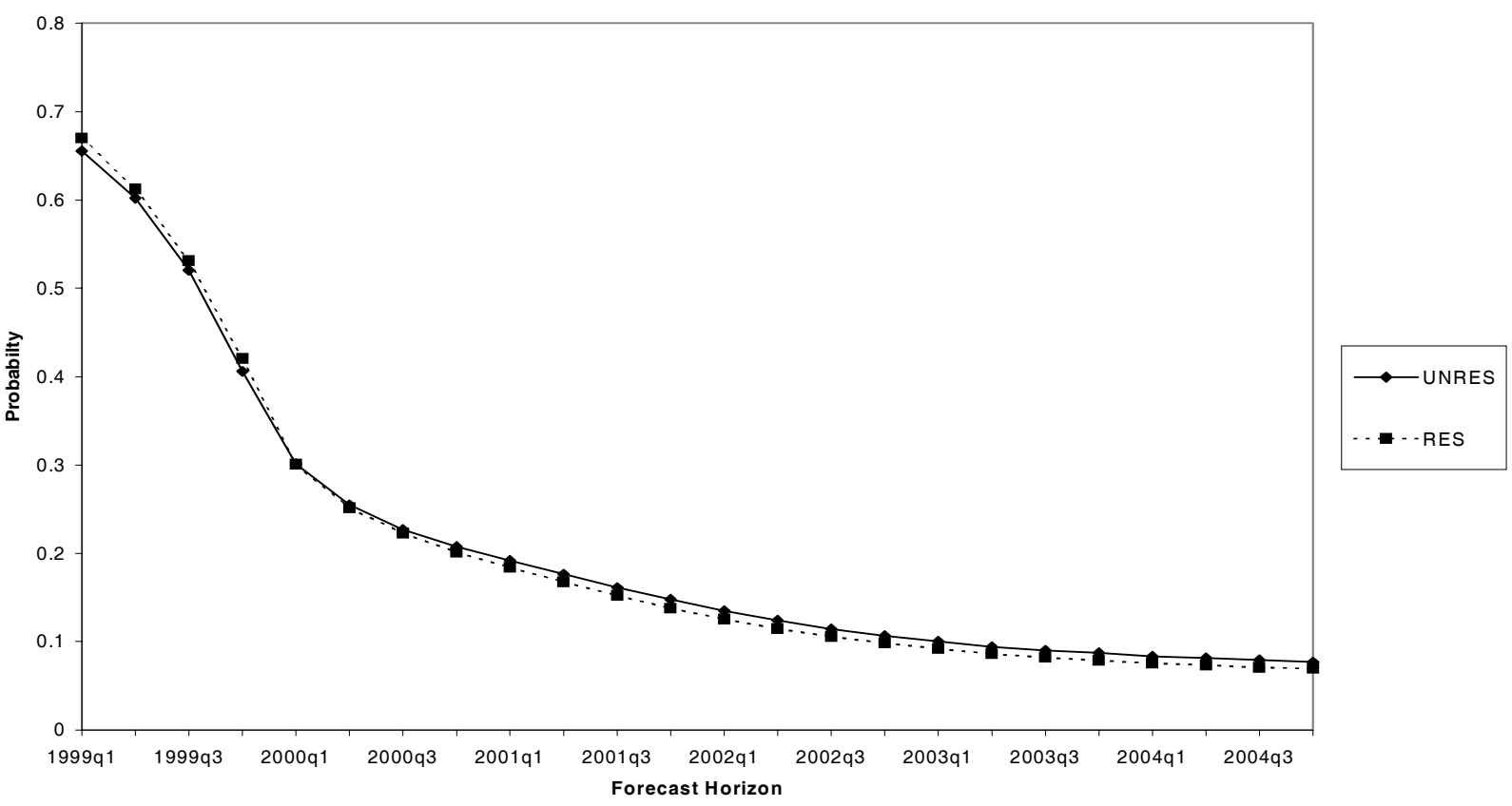

Figure 4b. BPD Probability Estimates of Output Growth being Positive (Restricted and Unrestricted Models, 65q1-98q4)

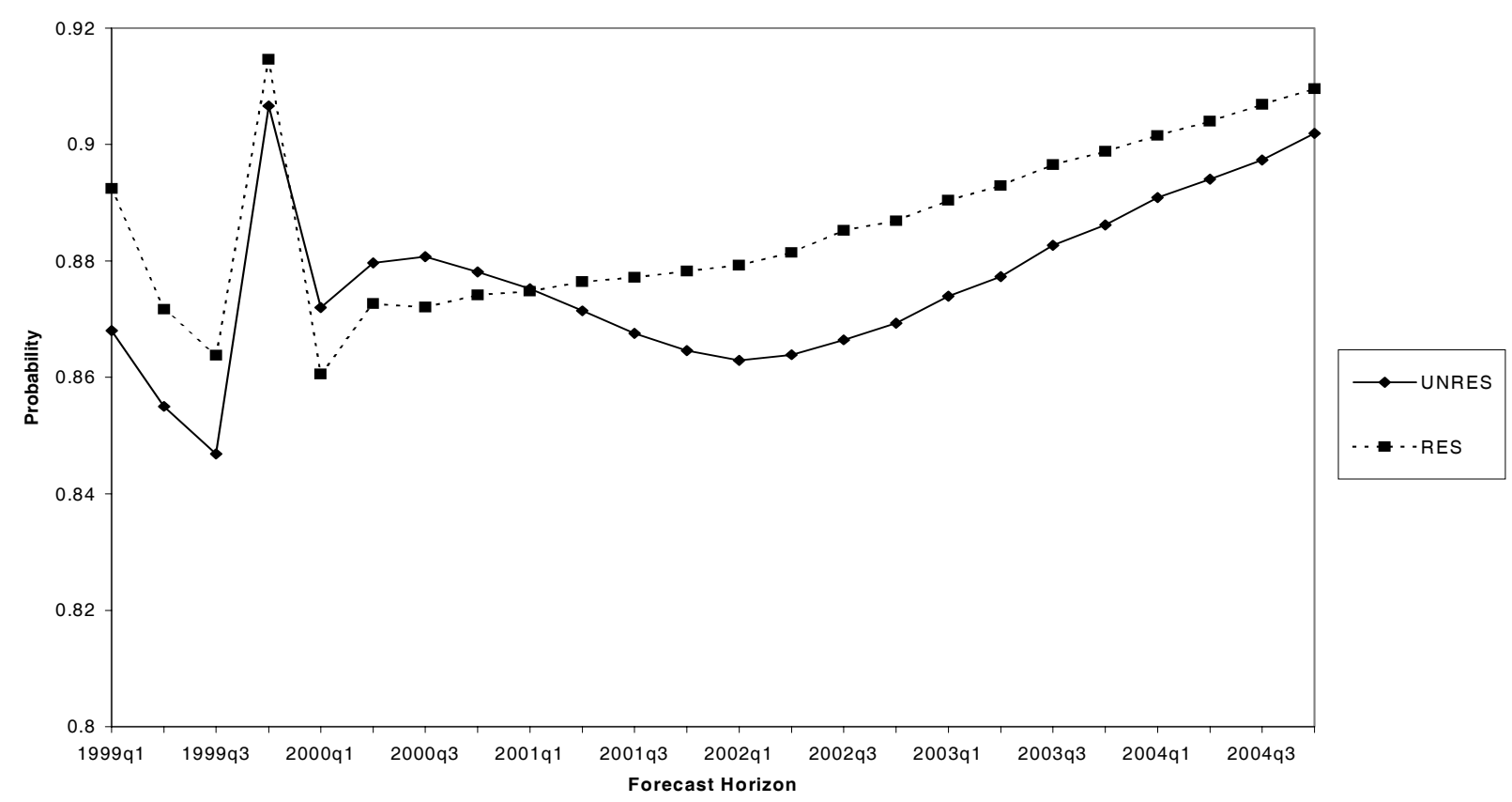


Figure 4c. BPD Probabilities of Inflation Falling between $1.5 \%$ and $3.5 \%$ and Positive Output Growth (Restricted and Unrestricted Models, 65q1-98q4)

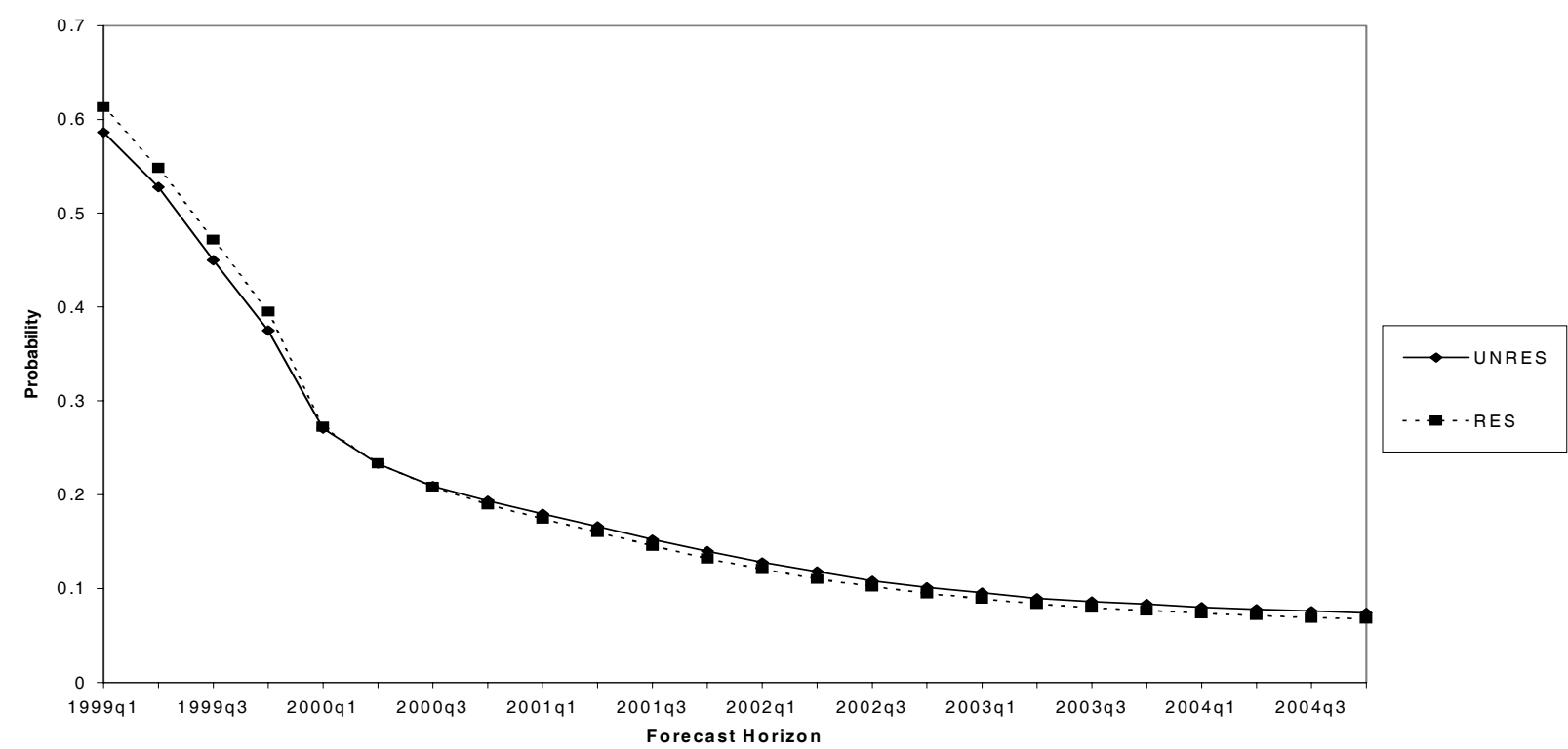

Figure 4d. The BPD-based Neutrality Index, $\frac{\operatorname{Pr}(\Delta \ln (G D P)>0 \%) . \operatorname{Pr}(1.5 \%<\Delta p<3.5 \%)}{\operatorname{Pr}(\Delta \ln (G D P)>0 \%, 1.5 \%<\Delta p<3.5 \%)}$ (Restricted and Unrestricted Models, 65q1-98q4)

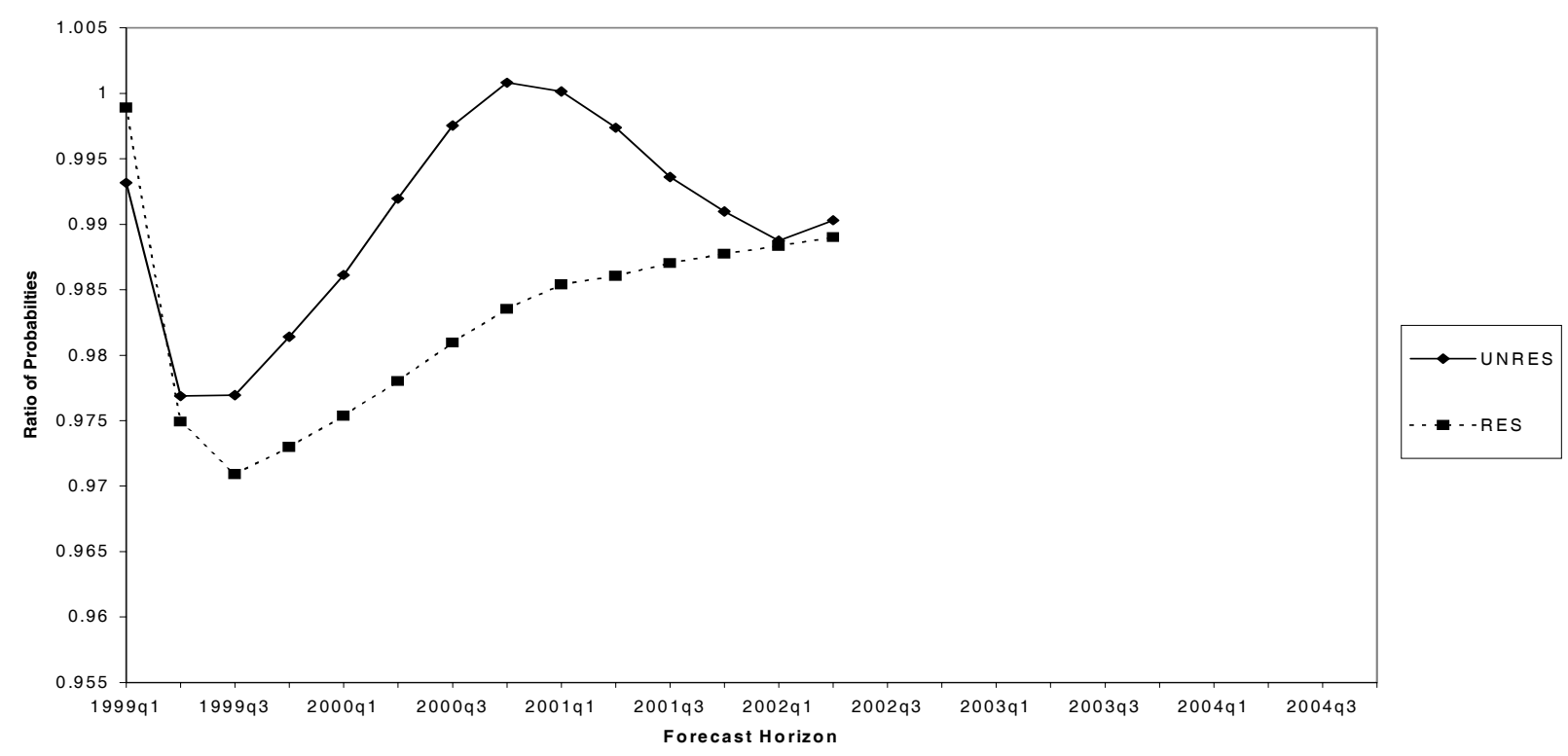


Figure 5a. BPD Probability Estimates of Inflation Falling between $1.5 \%$ and $3.5 \%$ (Unrestricted Models Estimated Over 65q1-98q4 and 85q1-98q4)

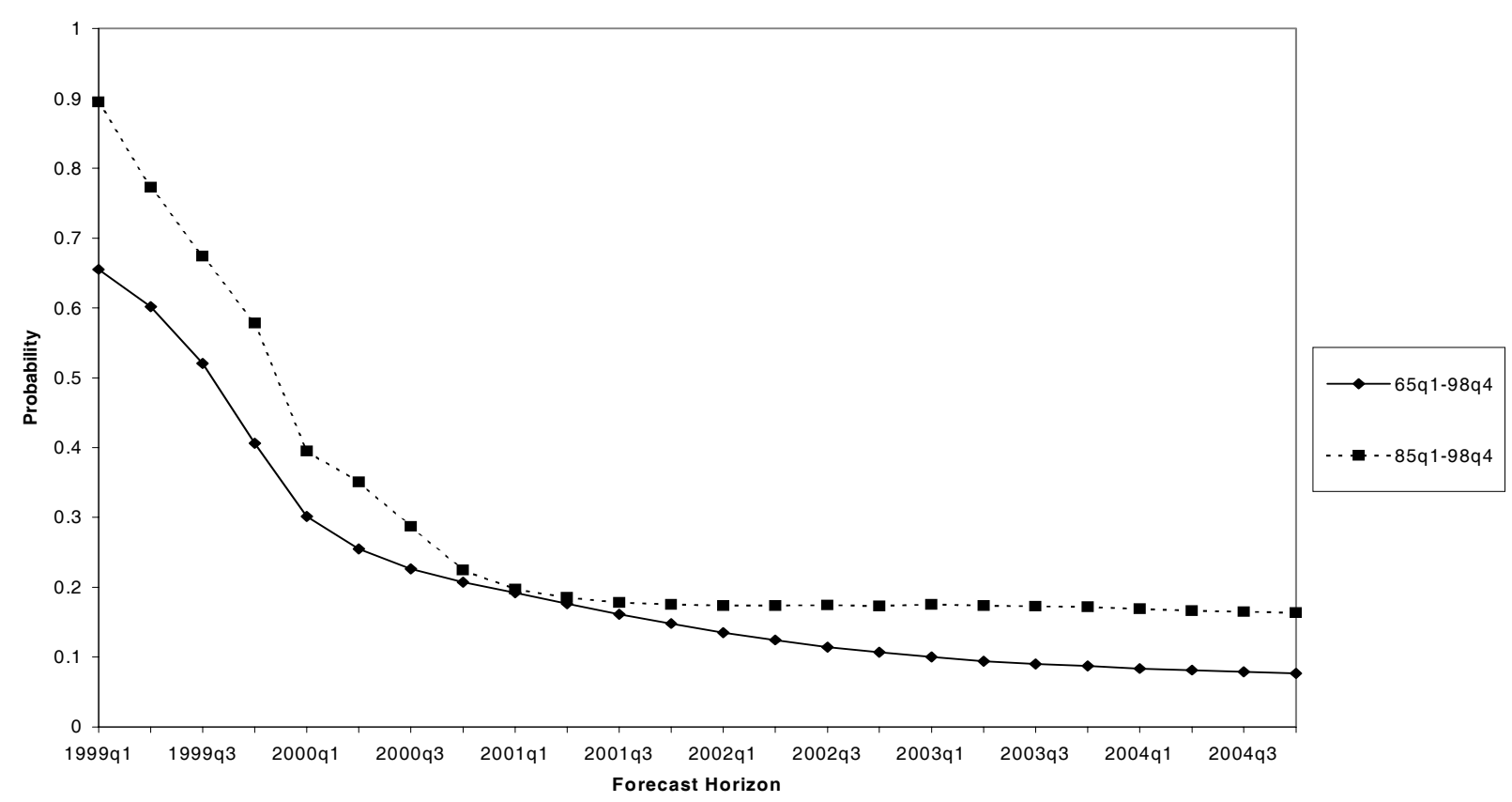

Figure 5b. BPD Probability Estimates of Output Growth Being Positive (Unrestricted Models Estimated Over 65q1-98q4 and 85q1-98q4 )

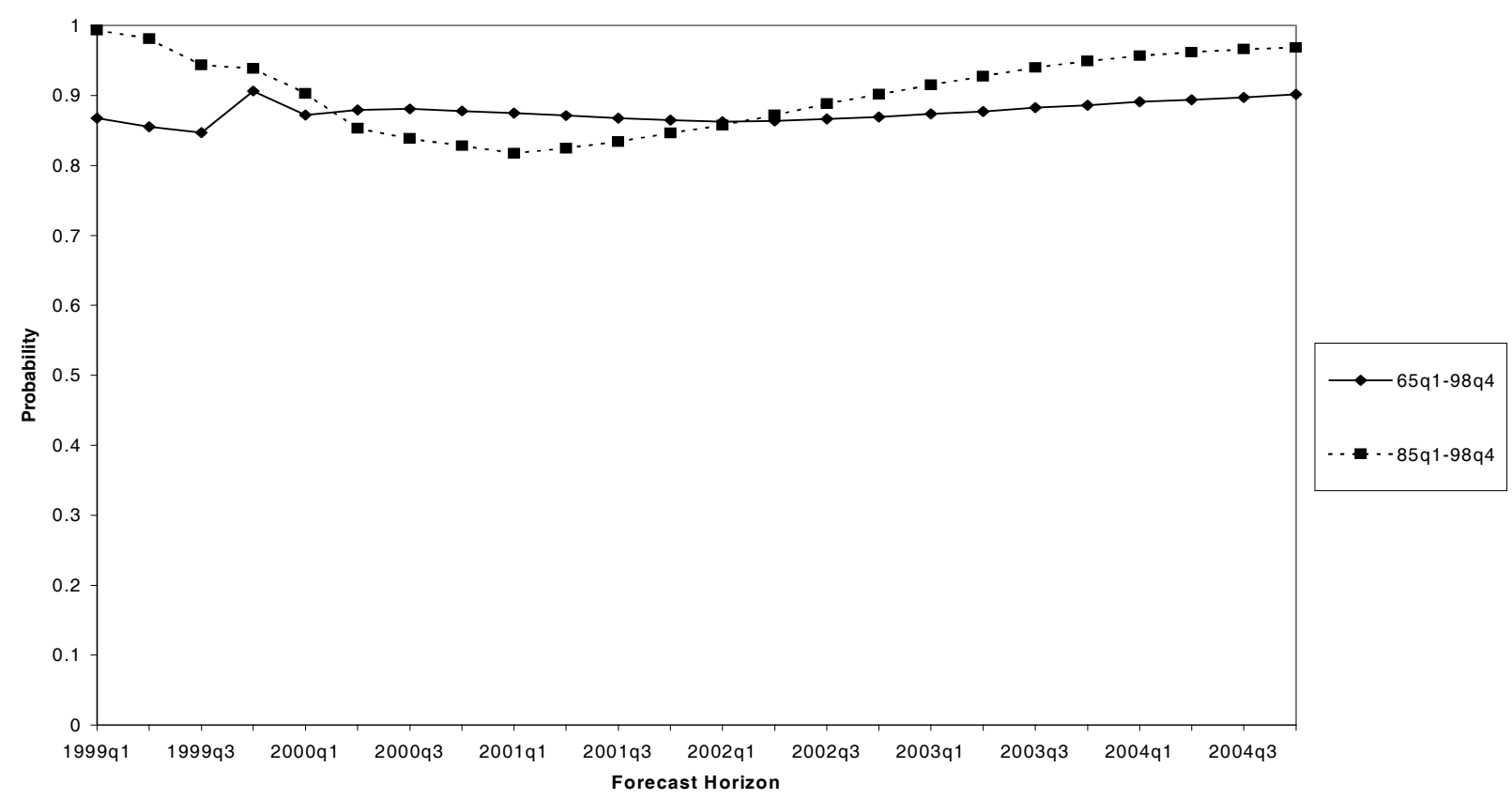


Figure 5c. BPD Probabilities of Inflation Falling between $1.5 \%$ and $3.5 \%$ and Positive Output Growth (Unrestricted Models Over 65q1-98q4 and 85q1-98q4)

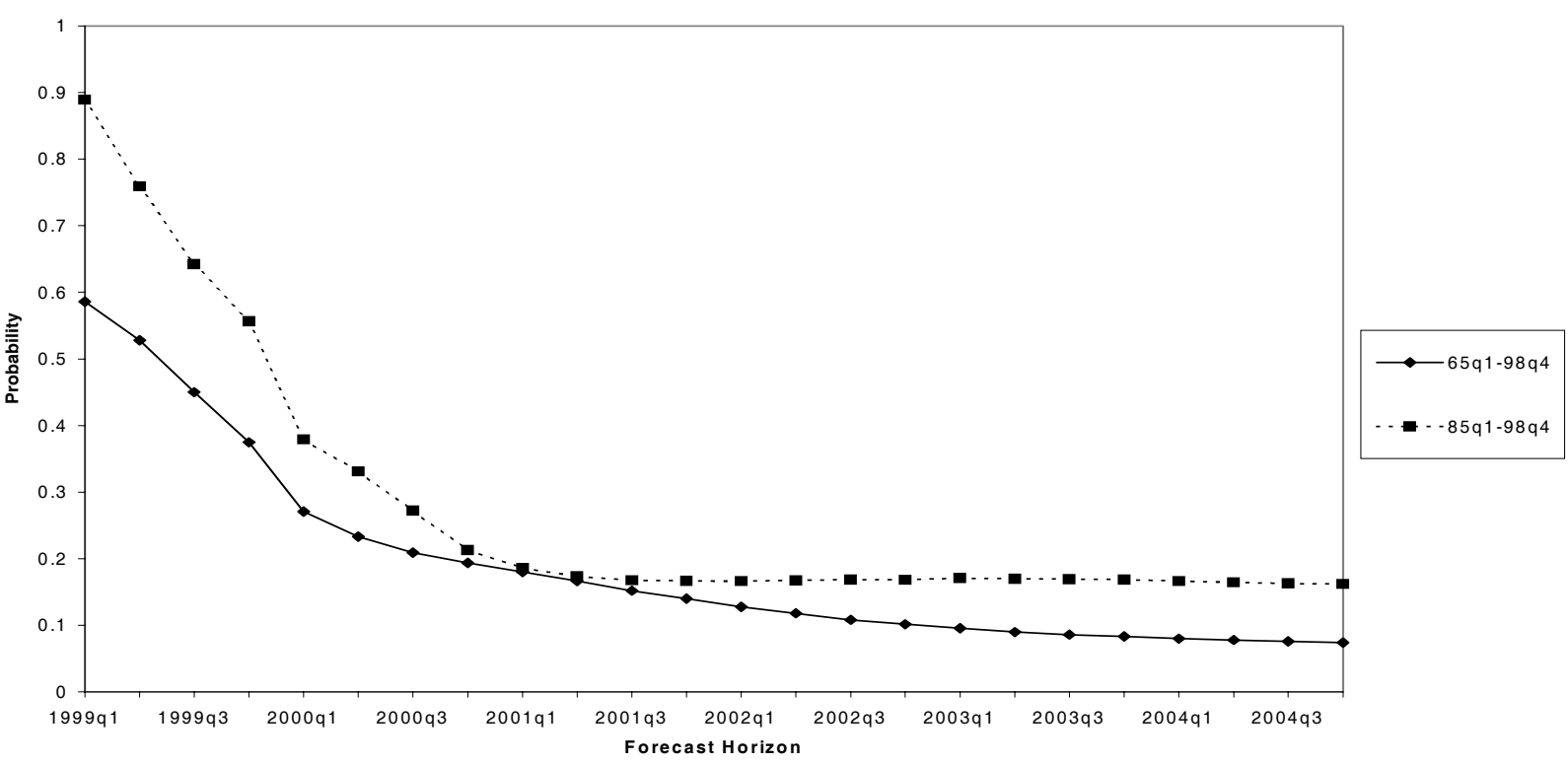

Figure 5d. The BPD-based Neutrality Index, $\frac{\operatorname{Pr}(\Delta \ln (G D P)>0 \%) . \operatorname{Pr}(1.5 \%<\Delta p<3.5 \%)}{\operatorname{Pr}(\Delta \ln (G D P)>0 \%, 1.5 \%<\Delta p<3.5 \%)}$

(Unrestricted Models Estimated Over 65q1-98q4 and 85q1-98q4 )

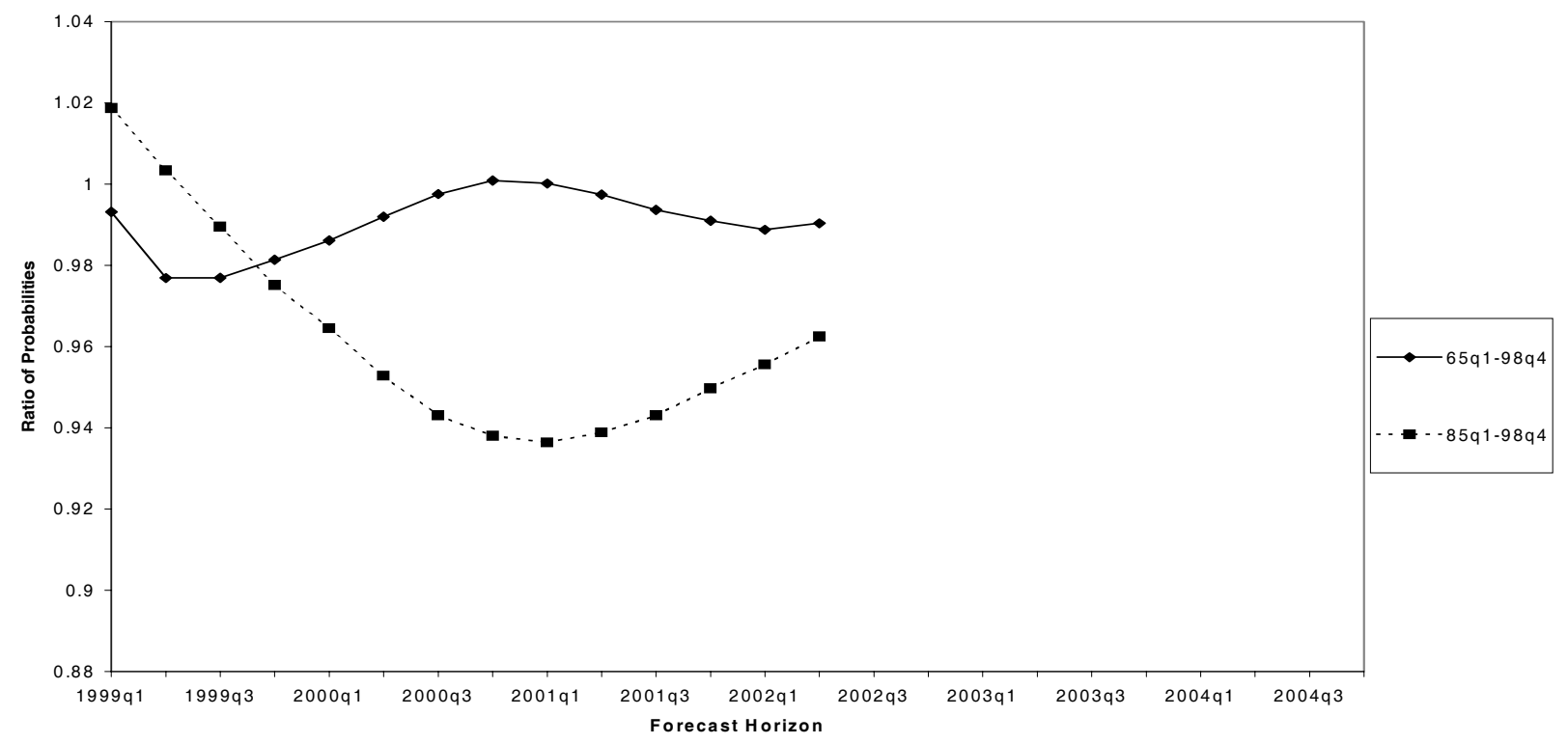


Figure 6a. Probability Estimates of Inflation Falling between $1.5 \%$ and $3.5 \%$ and Output Growth being Positive

(Unrestricted Model over 65q1-98q4, High Oil Price Scenario)

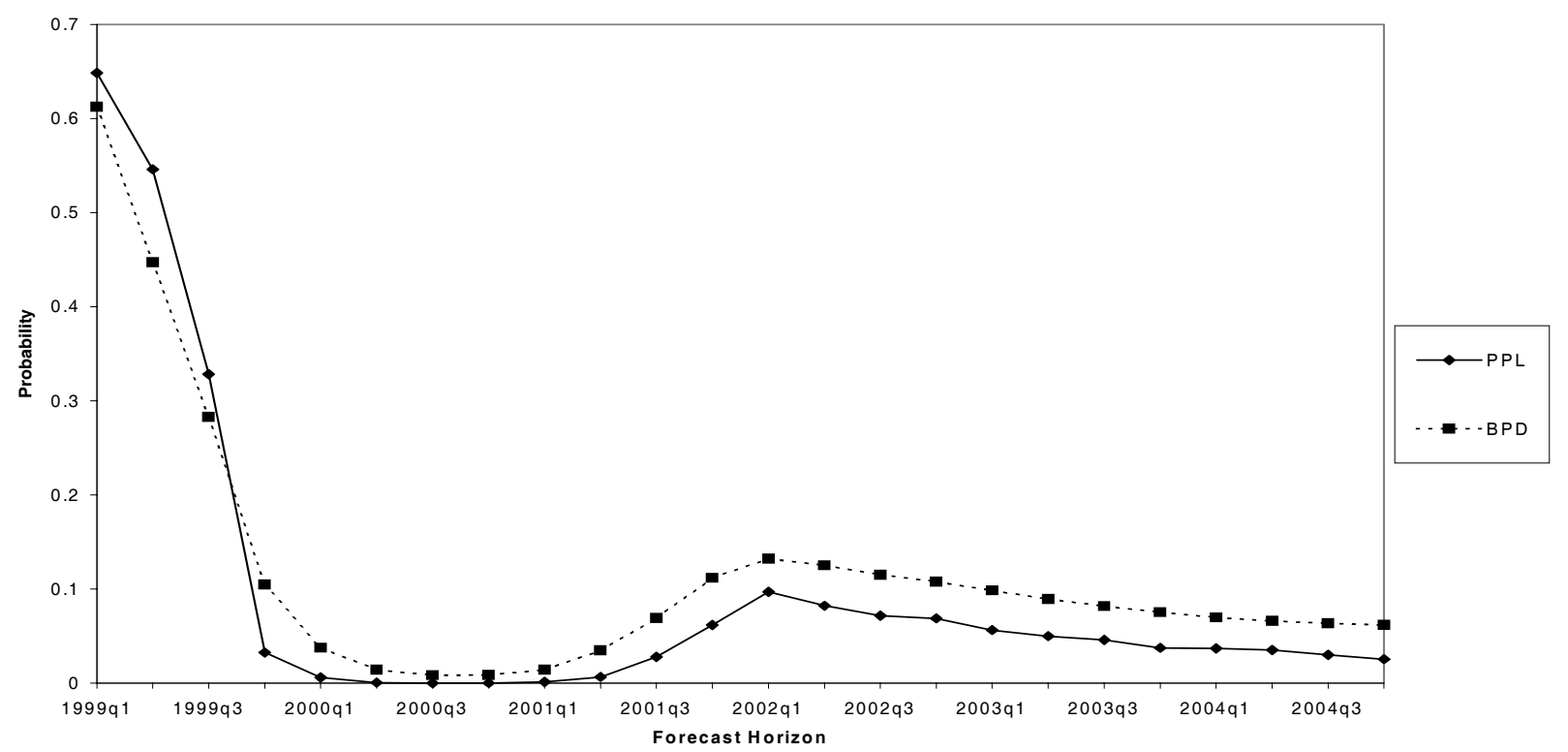

Figure 6b. Probability Estimates of Inflation Falling between $1.5 \%$ and $3.5 \%$ and Output Growth being Positive

(Unrestricted Model over 85q1-98q4, High Oil Price Scenario)

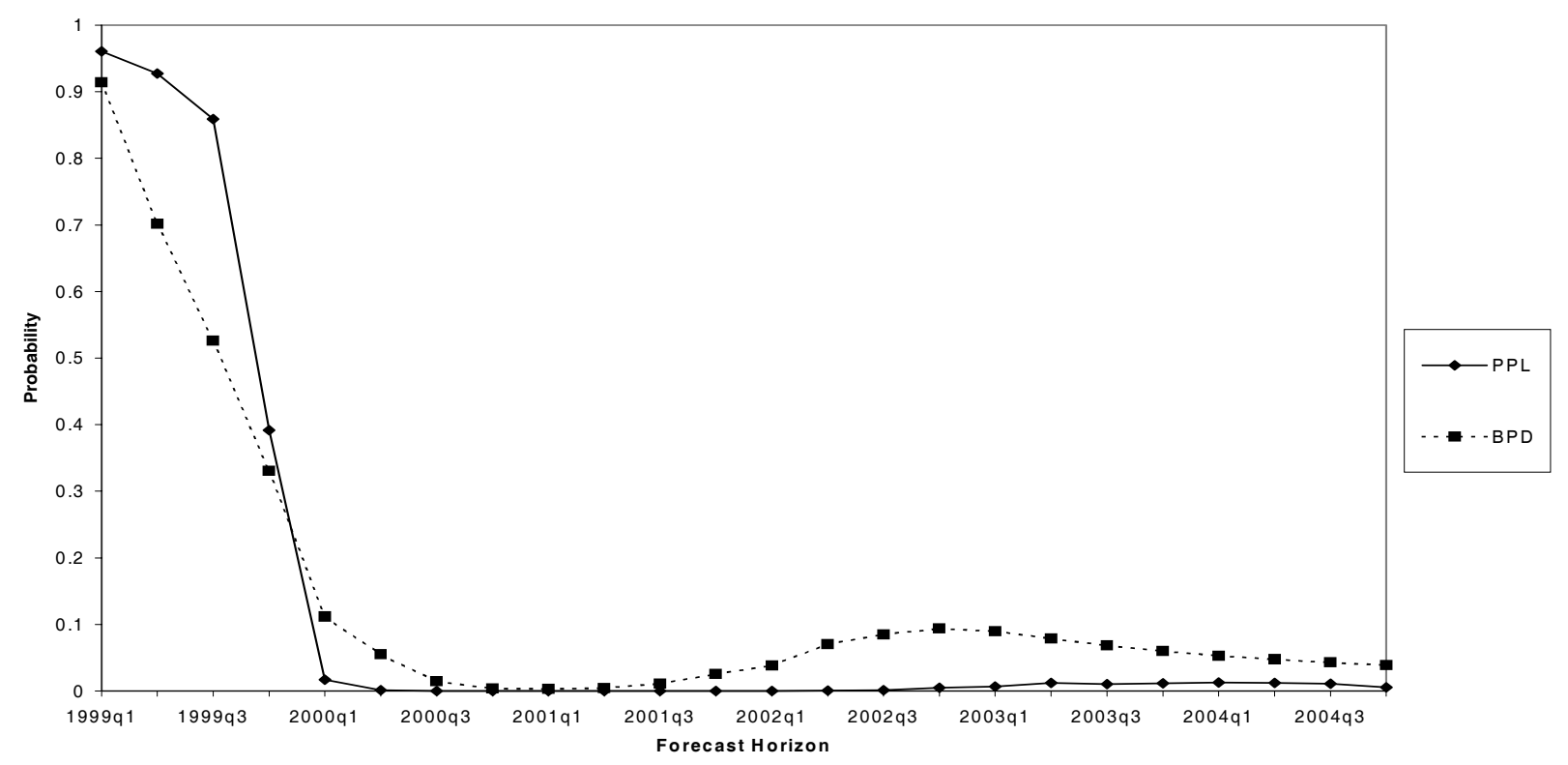

$[\mathrm{G} 10]$ 


\section{References}

[1] Berkowitz, J. (1999), "Evaluating the Forecasts of Risk Models," Federal Reserve Bank Finance and Economic Discussion Paper Series No. 1999-11.

[2] Blake, A.P. (1996), "Forecast Error Bounds By Stochastic Simulation," National Institute Economic Review, 72-79.

[3] Bjфrnstad (1990), "Predictive Likelihood: A Review," Statistical Science, 5, 242-265.

[4] Britton, E., P. Fisher and J. Whitley (1998), "The Inflation Report Projections: Understanding the Fan Chart," Bank of England Quarterly Bulletin, 38, 30-37.

[5] Chatfield, C. (1995), "Model Uncertainty, Data Mining and Statistical Inference," Journal of the Royal Statistical Society, 158, 419-444.

[6] Dawid, A. P. (1984), "Present Position and Potential Developments: Some Personal Views - Statistical Theory, The Prequential Approach," Journal of Royal Statistical Society Series A, 147, 278-292.

[7] Diebold, F.X., T.A. Gunther and A.S. Tay (1998), "Evaluating Density Forecasts, with Applications to Financial Risk Management," International Economic Review, $39,863-884$.

[8] Diebold, F.X., J. Hahn and A.S. Tay (1999), "Multivariate Density Forecast Evaluation and Calibration in Financial Risk Management: High Frequency Returns on Foreign Exchange," Review of Economics and Statistics, 81, 661-673.

[9] Draper, D. (1990), "Assessment and Propagation of Model Uncertainty," Journal of Royal Statistical Society Series B, 58, 45-97.

[10] Fair, R.C. (1980), "Estimating the Expected Predictive Accuracy of Econometric Models," International Economic Review, 21, 355-378.

[11] Fair, R.C. (1993), "Estimating Event Probabilities form Macroeconometric Models Using Stochastic Simulations," Chapter 3 in Business Cycles, Indicators, and Forecasting, eds. by J.H. Stock and M.W. Watson. National Bureau of Economic Research, Studies in Business Cycles Volume 28. Chicago: University of Chicago Press.

[12] Garratt, A., K. Lee, M.H. Pesaran, and Y. Shin (1999), "A Long Run Structural Macroeconometric Model of the UK," Revised version of University of Cambridge, DAE Working Paper No. 9812.

[13] Garratt, A., K. Lee, M.H. Pesaran, and Y. Shin (2000a), "A Structural Cointegrating VAR Approach to Macroeconometric Modelling," forthcoming in S. Holly and M. Weale (eds), Econometric Modelling: Techniques and Applications, Cambridge: Cambridge University Press. 
[14] Garratt, A., K. Lee, M.H. Pesaran, and Y. Shin (2000b), A Structural Cointegrating Macroeconomic Model of the UK (a monograph under preparation).

[15] Granger, C.W.J. and M.H. Pesaran (1999), "A Decision Theoretic Approach to Forecast Evaluation," forthcoming in W.S. Chan, W.K. Li and H. Tong (eds), Statistics and Finance: An Interface, Imperial College Press.

[16] Granger, C.W.J. and M.H. Pesaran (2000), "Economic and Statistical Measures of Forecast Accuracy," forthcoming in Journal of Forecasting.

[17] Hall, P. (1992), The Bootstrap and Edgeworth Expansion. New York: Springer-Verlag.

[18] Harding, D. and A. Pagan (2000), "Dissecting The Cycle: A Methodological Investigation," mimeo.

[19] Harris, I.R. (1989), "Predictive Fit for Natural Exponential Functions," Biometrika, $76,675-684$.

[20] Jansen, N. (1996), "Can We Explain the Shift in M0 Velocity? Some Time-Series and Cross Section Evidence," Bank of England Quarterly Bulletin, 36, 39-48.

[21] Koop, G., M.H. Pesaran and S.M. Potter (1996), "Impulse Response Analysis in Nonlinear Multivariate Models," Journal of Econometrics, 74, 119-47.

[22] Levy, M.S. and S.K. Perng (1986), "An Optimal Prediction Function for the Normal Linear Model," Journal of the American Statistical Association, 81, 196-98

[23] Peel, D.A., and R.A. Nobay (1998), "Optimal Monetary Policy in A Model of Asymmetric Central Bank Preferences," mimeo.

[24] Pesaran, M.H. and B. Pesaran (1997), Working with Microfit 4.0: An Interactive Introduction to Econometrics. Oxford: Oxford University Press.

[25] Pesaran, M.H. and Y. Shin (1999), "Long-Run Structural Modelling," Downloadable at http://www.econ.cam.ac.uk/faculty/pesaran/lrs.pdf. Revised version of University of Cambridge DAE Working Paper No. 9419

[26] Pesaran, M.H., Y. Shin and R.J. Smith (2000), "Structural Analysis of Vector Error Correction Models with Exogenous I(1) Variables," forthcoming in Journal of Econometrics.

[27] Poulizac, D., M. Weale and G. Young (1996), "The Performance of National Institute Economic Forecasts," National Institute Economic Review, 55-62.

[28] Rosenblatt, M. (1952), "Remarks on a Multivariate Transformation," Annals of Mathematical Statistics, 23, 470-472.

[29] Wallis, K.F. (1999), "Asymmetric Density Forecasts of Inflation and the Bank of England's Fan Chart," National Institute Economic Review, 106-112. 
[30] West, K.D. (1996), "Asymptotic Inference About Predictive Ability," Econometrica, 64, 1067-1084.

[31] Yates, A., (1995), "On the Design of Inflation Targets," in Targeting Inflation, ed. by A.G. Haldane. Bank of England, 135-169. 